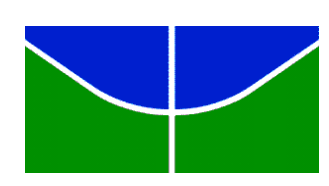

Universidade de Brasília - UnB

Instituto de Ciências Biológicas - IB

Programa de Pós-Graduação em Biologia Molecular

\title{
O papel da lisofosfatidilcolina na ativação do inflamassoma NLRP3 e sua relação com a formação de células gordurosas
}

\author{
Rafael Corrêa
}

Orientadora:

Prof ${ }^{a}$. Dra. Kelly Grace Magalhães

Brasília

Fevereiro, 2016 


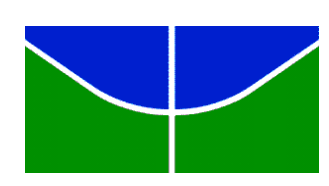

Universidade de Brasília - UnB

Instituto de Ciências Biológicas - IB

Programa de Pós-Graduação em Biologia Molecular

\author{
Rafael Corrêa
}

\title{
O papel da lisofosfatidilcolina na ativação do inflamassoma NLRP3 e sua relação com a formação de células gordurosas
}

Dissertação apresentada ao Programa de Pós-graduação em Biologia Molecular, para a obtenção do título de Mestre em Biologia Molecular.

\section{Orientadora:}

Prof a Dra. Kelly Grace Magalhães

\section{Brasília}

Fevereiro, 2016 


\section{Rafael Corrêa}

\section{O papel da lisofosfatidilcolina na ativação do inflamassoma NLRP3 e sua relação com a formação de células gordurosas}

Data: 19 de Fevereiro de 2016

\section{Banca Examinadora}

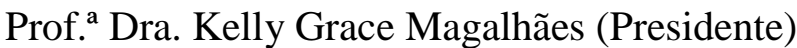

Programa de Pós-graduação de Biologia Molecular- Universidade de Brasília

Prof. Dr. Marcelo de Macedo Brígido (Membro)

Programa de Pós-graduação em Biologia Molecular - Universidade de Brasília

Prof. a Dra. Patrícia Torres Bozza (Membro)

Instituto Oswaldo Cruz - Rio de Janeiro

Prof. Dr. José Raimundo Correa (Membro suplente)

Programa de Pós-graduação em Biologia Molecular - Universidade de Brasília 


\section{Agradecimentos}

A Deus pelo dom da vida, ciência e sabedoria. Por todo o suporte emocional, físico e material, além de sempre estar presente na minha vida me abençoando e protegendo.

A minha orientadora Dra. Kelly Grace Magalhães por ter me acolhido, ensinado e direcionado durante toda a minha carreira acadêmica, e por todas as vezes que ela foi, amiga, psicóloga, confidente e principalmente Mãe. Agradeço por ter enxergado em mim, um potencial que nem eu mesmo sabia que possuía, por acreditar e confiar em mim desde sempre, sem você este trabalho certamente não existiria.

A minha amiga, irmã e co-autora Raquel das Neves Almeida por ter caminhado junto comigo desde do primeiro dia da graduação até hoje, por me ajudar nos momentos em que quis desistir, por ser companheira das madrugadas na escrita ou no lab. Por sempre acreditar e confiar em mim, e por todas as vezes que eu precisava de uma palavra amiga, um abraço ou até mesmo um chocolate e você estava sempre ao meu lado.

Aos meus co-autores Dalila e Luís Felipe, por todo apoio experimental e psicológico além da companhia maravilhosa de vocês dois todos os dias no lab. sem vocês esse trabalho não teria ficado tão bom. Aos meus colegas, ex-colegas e amigos do Laboratório de Imunologia e Inflamação (LIMI): Adrielle, Beatriz, Cecília, Érika, Gabriel, Larissa, Lívia, Luís Henrique, Nayara e Tiago. E aos agregados do LIMI: Ivy, Michelle e Pedro por toda a paciência em conviver comigo e por tudo o que fizeram por mim.

A todos estes listados que me ajudaram de alguma forma quando precisei: ao Lab. De Radicais Livres (GPRO): Daniel, Ting, Luana, Igor, Hylane e Prof. Marcelo. Lab. De Imunologia Aplicada (LIA): Raffael, Márcio, Karina, Angelina, Pedro, Isaque, Gabriela, Dawane, Prof. Aldo e Prof. Anamelia; (Ana Camila, Tássia e Luíza). Ao Lab. De Interação Parasito-Hospedeiro (LIPH): Raquel, Clênia, Camila, Milene, Natália, Grazi, Yanna, Carol, Marta e a Prof. Izabela, (Jhonata); Ao Lab. de Microscopia: Lorena, José, Núbia, Daniella e ao Prof. Corrêa. Ao Lab. de Virologia: Miguel, Débora, Daniel e o Prof. Fernando. Ao Lab. de Análises Moleculares de Patógenos (LAMP): Nayara, Erick, Prof. Tatiana e o Prof. Vicente. A Prof. Cecilia, Prof. Beatriz, Sara, Jivago e Adriana do Biotério. A Amanda, João Paulo e todos os colegas do corredor da Biofísica em especial ao Chiquinho por todo suporte e ajuda que me foi concedida. 
Aos meus bioamigos, Agnelo, Miguel e Mara, Raffael Castro e Raquel Almeida por serem os melhores amigos que a biologia poderia me conceder, obrigado por estarem junto comigo realizando este sonho. Que nossa amizade seja eterna.

As minhas melhores amigas Gleice Borges e Thaís Amanda por todo o apoio psicológico, emocional e por todas as vezes que me ajudaram no lab. Etiquetando meus tubinhos ou lavando minhas placas de ELISA, é uma honra ter amigas como vocês.

As minhas meninas, Carol, Jussara, Rayane, Deyse, Bia, Veronica, Isadora e Camila. Pela amizade, fidelidade, paciência e compreensão. Aos meus amigos da Igreja, Claiton, Ruan, Matheus Lothar, Matheus Rezende, Marcus Vinicius. Aos meus amigos de ensino médio, Weslen e Melissa, Geisiane, Diogo, Fabíula, Yuri e Nayara, Paulo, Davson, Vanya, Éirka e a todos que me apoiaram e me incentivaram durante todos esses anos.

Aos meus Vizinhos e amigos Jari e Evanor, por me ajudarem financeiramente, me dando apoio e incentivo em todos os momentos. Aos meus afilhados Carol, Pablynne e Paulo Henrique, Deus me deu vocês de presente pra cuidar e amar.

A minha família, minha mãe Lucineide e meu pai Marcos por me gerarem e criarem com tanto amor, carinho e cuidado. A minha irmã e melhor amiga Isabela por todas as vezes que cuidou de mim, me amou e foi pro lab. etiquetar meus tubinhos. A meus animais de estimação Amy e Uli por me mostrarem o amor da forma mais sincera e leal possível. Vocês são o bem mais precioso e valioso que eu possuo a melhor coisa que eu nunca tive e apesar das dificuldades defeitos, é a melhor família que eu poderia ter. A todos os meus Tios, Tias, primos e primas, em especial aos meus padrinhos Hildete e Minoro por serem os melhores padrinhos que eu poderia ter.

Essa dissertação eu dedico em especial a memoria das minhas duas avós, Maria Moraes Correa e Josefa Romana de Jesus, por todo o amor, carinho, palavras de sabedoria e incentivo. Esse título é pra vocês muito obrigado por tudo que fizeram por mim e por meus pais. Saibam que meu amor e gratidão por vocês serão infinitos.

Por fim, agradeço a Universidade de Brasília por ser minha segunda casa desde 2010, ao programa de pós-graduação em Biologia Molecular, e as agencias de fomento FAPDF e CNPq. 


\section{Sumário}

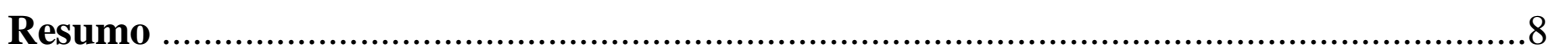

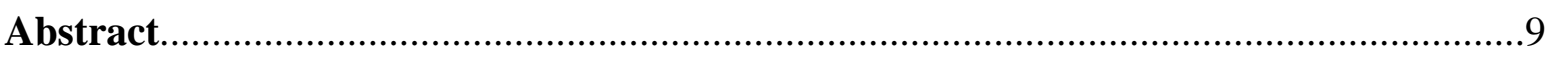

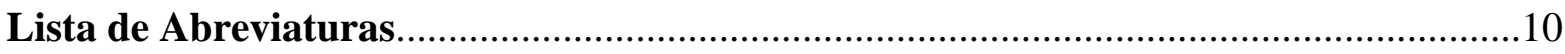

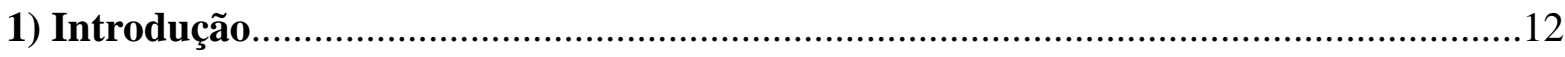

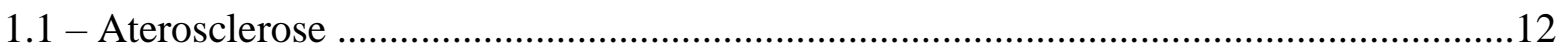

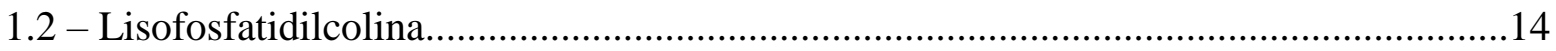

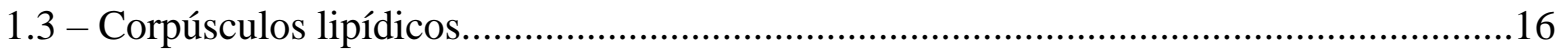

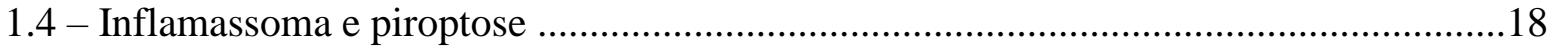

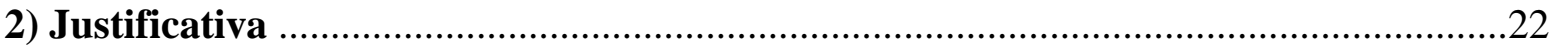

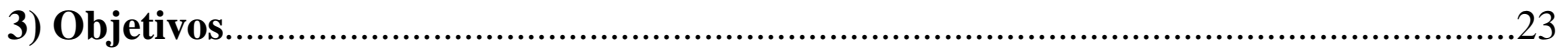

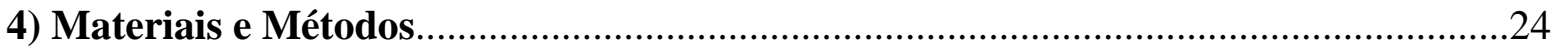

4.1 - Camundongos, tratamentos in vivo e considerações éticas..........................................24

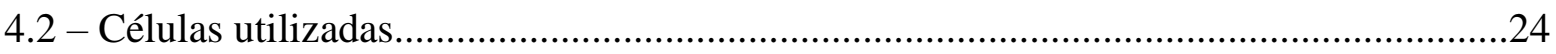

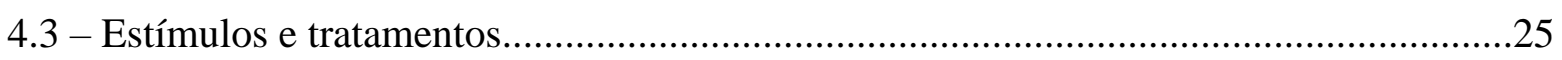

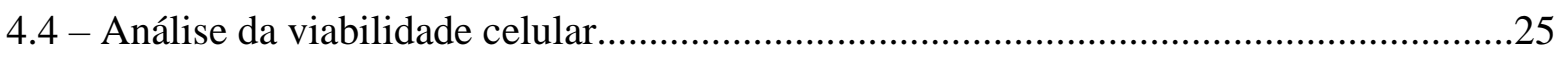

4.5 - Análise da ativação de caspase-1 .....................................................................26

4.6 - Análise da produção de espécies reativas de oxigênio...............................................26

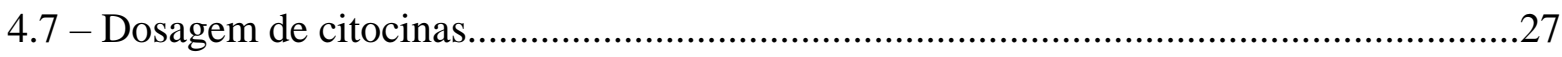

4.8 - Análise da biogênese de corpúsculos lipídicos por citometria de fluxo e microscopia de

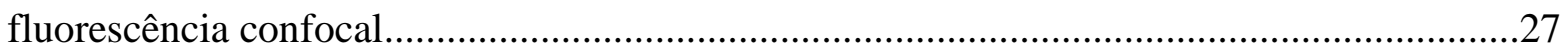

4.9 - Análise de HMGB1 por imunofluorescência.......................................................28

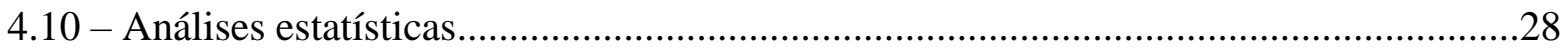

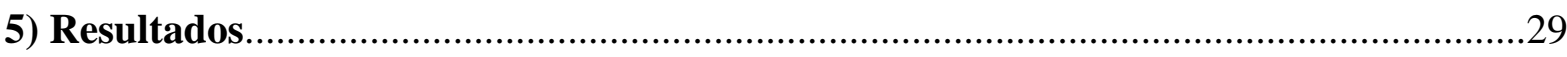

5.1 - A LPC possui um efeito citotóxico e diminui a viabilidade celular de monócitos e

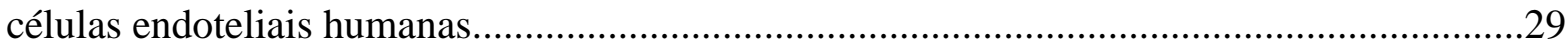

5.2 - LPC induz a ativação de Caspase-1 em macrófagos murinos........................................30

5.3 - LPC induz a produção de ROS in vitro e in vivo........................................................... 31 
5.4 - LPC induz a secreção de IL-1 $\beta$ em monócitos humanos.

5.5 - Mecanismos de secreção de IL-1 $\beta$ induzida por LPC

5.6 - A secreção de IL-1 $\beta$ em camundongos estimulados com LPC.

5.7 - LPC induz a translocação do HMGB1 para o citoplasma em monócitos e células endoteliais

5.8 - LPC induz a biogênese de corpúsculos lipídicos em monócitos humanos.

5.9 - Mecanismos envolvidos na biogênese de CL em monócitos mediados por LPC.

5.10 - LPC induz a biogênese de corpúsculos lipídicos em células endoteliais.

5.11 - Mecanismos envolvidos na biogênese de CL em células endoteliais mediados por LPC

5.12 - LPC induz a biogênese de CL in vivo, independente de Caspase-1/11 e NLRP3.

5.13 - LPC induz a liberação de fatores pela célula endoteliais que medeiam a ativação de monócitos humanos.

5.14 - LPC induz a secreção de citocinas pró-inflamatórias por monócitos e células endoteliais.

6) Discussão .53

7) Conclusões. .60

7.1 - Modelo Proposto. .61

8) Referências .62 
O papel da lisofosfatidilcolina na ativação do inflamassoma NLRP3 e sua relação com a formação de células gordurosas.

\section{Resumo}

\section{Dissertacão de mestrado}

\section{Rafael Corrêa}

A Lisofosfatidilcolina (LPC) é um lisofosfolipídio que constitui a membrana plasmática e possui um papel importante na sinalização celular, pois está diretamente associada à albumina e a lipopoliproteínas. A LPC tem um amplo espectro de atividades pró-inflamatórias e exerce um papel fundamental durante a aterosclerose, pois ela é o principal componente fosfolipídio de lipoproteínas de baixa densidade oxidada (oxLDL). Ela também é capaz de induzir a formação de células gordurosas, as quais são componentes celulares fundamentais para o estabelecimento da aterosclerose e recrutamento leucocitário para o sítio desta patologia, induzindo a progressão da doença. No entanto, o papel de LPC na ativação do inflamassoma e na modulação da biogênese de corpúsculos lipídicos (CLs) neste processo ainda é mal compreendido. Este estudo tem por objetivo investigar se LPC é capaz de ativar o inflamassoma NLRP3 e induzir a secreção de IL-1 $\beta$ relacionando com os mecanismos de formação de células gordurosas por meio da análise da biogênese de CLs. Nossos resultados mostraram que a LPC induz um efeito citotóxico em altas concentrações em monócitos e células endoteliais, além de induzir a produção de espécies reativas de oxigênio (ROS) e a ativação de caspase-1. A LPC induz a ativação do inflamassoma NLRP3 através da indução da secreção de IL-1 $\beta$ dependente de efluxo de potássio, dano lisossomal, reconhecimento via TLR-2, ativação de PPAR $\gamma$ e estabilização das jangadas lipídicas em monócitos humanos e dependentes das caspases-1/11 e do inflamassoma NLRP3 em macrófagos peritoneais de camundongos. Além disso, a LPC induz a translocação do HMGB-1 do núcleo para o citoplasma tanto em células endoteliais quanto em monócitos. Outro resultado importante foi à indução da formação de células gordurosas, via LPC, em monócitos e células endoteliais in vitro, através do aumento da biogênese de CLs de maneira independente do inflamassoma NLRP3 e das caspases-1/11 in vivo. Além disso, as células endoteliais estimuladas com LPC ativam monócitos a se transformarem em células gordurosas, através da indução da biogênese de CL, por mecanismo ainda desconhecido. Portanto, o presente trabalho caracterizou diferentes mecanismos celulares e moleculares envolvidos na formação de células gordurosas, correlacionando-os com as vias de ativação dos inflamassomas e do metabolismo lipídico celular, e que corroboraram para a criação de um microambiente propício ao estabelecimento e manutenção da formação de placas ateroscleróticas. 
The role of lysophosphatidylcholine in the activation of the NLRP3 inflammasome and its relation to the formation of foam cells

\section{Abstract \\ $\underline{\text { Dissertacão de mestrado }}$ \\ Rafael Corrêa}

Lysophosphatidylcholine (LPC) is a major lipid component of plasmatic membrane and has an important role in cell signaling because it is directly associated with albumin and lipoproteins. The LPC has a broad spectrum of pro-inflammatory activity and plays a key role in atherosclerosis, since it is a major phospholipid component of oxidized low density lipoprotein (oxLDL). Furthermore, LPC is also able to induce the formation of foam macrophages, which are the key cell component for the establishment of atherosclerosis and leukocyte recruitment on the site of the pathology. However, the role of LPC in modulating inflammasome activation and lipid droplet biogenesis in this process is poorly understood. This study is aimed to investigate if LPC is capable of inducing inflammasome activation and IL-1 $\beta$ secretion, verify the foam cell formation by analyzing lipid droplet biogenesis and characterize the signaling pathway involved in this process. Our results showed that LPC induces a cytotoxic effect in high concentrations in monocytes and endothelial cells, generation of reactive oxygen species (ROS) and activation of caspase-1. LPC induces activation of the inflammasome NLRP3 by induction of IL-1 $\beta$ secretion dependent of potassium efflux, and lysosomal damage via TLR-2 recognition, PPAR gamma activation and stabilization of lipid rafts in vitro, and caspase-1/11 and NLRP3 inflammasome in vivo assays. Furthermore, LPC induced translocation of HMGB1 from the nucleus towards the cytoplasm in endothelial cells and monocytes. Another important result was the induction of the formation of foam cells by LPC both in monocytes and endothelial cell in vitro assays, by increasing the biogenesis of lipid droplets in a manner independent of the NLRP3 inflammasome and caspase-1/11 in vivo. Additionally, endothelial cells stimulated with LPC activated monocytes to transform into foam cells through induction of lipid droplets biogenesis by unknown mechanism. Therefore, the present study characterized different cellular and molecular mechanisms involved in the formation of foam cells, correlating them with the activation pathways of inflammasomes and cellular lipid metabolism, and corroborated to create a favorable microenvironment for the establishment and maintenance of formation atherosclerotic plaques. 


\section{Lista de abreviaturas, acrônimos, siglas e símbolos}

AA Ácido araquidônico

ADRP Proteína relacionada à diferenciação de adipócitos

AIM-2 Ausente no melanoma 2

ASC Proteína particular associada à apoptose contendo domínio de recrutamento de caspase

ATP Adenosina Trifosfato

BIR Domínio inibidor de baculovírus

CARD Domínio para recrutamento de caspase (CARD)

CL Corpúsculo lipídico e ou CLs Corpúsculos lipídicos

$\mathrm{CO}_{2} \quad$ Dióxido de carbono

DAMPs Padrões moleculares associados a perigo

DAPI 4',6-diamidino-2-phenylindole

DFC-DA 2',7'Diclorodihidrofluoresceina-diacetato

DMSO Dimetilsulfóxido

DNA Ácido desoxirribonucleico

DP Desvio padrão

ELISA Ensaio imunoenzimático

Fig. $\quad$ Figura

GM-CFS Fator de crescimento de colônias para granulócitos/monócitos

GPCR Receptor acoplado à proteína $\mathrm{G}$

h Hora

HDL Lipoproteína de alta densidade

HMGB-1 Proteína do grupo de alta mobilidade B1

HMGCoa 3-hidroxi-3-methyl-glutaril-CoA redutase

HUVEC Células endoteliais derivadas de veia umbilical humana

ICAM-1 Molécula de adesão intercelular 1

INF Interferon

IL Inteleucina

LCAT Lecitina-colesterol aciltransferase

LDL Lipoproteína de baixa densidade

LE Lipase endotelial

LH Lipase hepática

LPC Lisofosfatidilcolina

LPL Lisofosfolipídios

LPS Lipopolissacarídeo

MPCD Metil- $\beta$-ciclodextrina

MCP-1 Proteína quimioatraente de monócitos/macrófagos

M-CSF Fator estimulante de colónia de macrófagos

MFI Média de intensidade de fluorescência

mL - $\quad$ Mililitro

mM- Milimolar

NAC N-Acetil-L-Cisteina

NE Não estimuladas

NFкB Fator nuclear $\kappa \mathrm{B}$ 
NLRC Receptor do tipo NOD que contém domínio CARD

NLRP Receptor do tipo NOD que contém domínio pirina

NOD Domínio de oligomerização de nucleotídeos

NK Células Natural Killer

OxLDL Lipoproteínas de baixa densidade oxidadas

PAMPS Padrões moleculares associados a patógenos

PARP Poli-[ADP-ribose]-polimerase

PAT Família composta por perilipina, ADRP e TIP47

PBS Tampão Salino Fosfato

PC Fosfolipídios

pg Picograma

PLA2 Fosfolipase A2

PPAR Receptor ativado por proliferadores de peroxissomos

PRR Receptor de reconhecimento padrão

PYD Pirina

ROS Espécies Reativas de Oxigênio

RPMI Meio Roswell Park Memorial Institute

SFB Soro Fetal Bovino

THP-1 Linhagem de monócitos humanos

TGF- $\beta \quad$ Fator de transformação do crescimento - $\beta$

TLR Receptores do tipo Toll

TCD4+ Linfócitos T CD4 + (T helper )

TNF- $\alpha \quad$ Fator de necrose tumoral $-\alpha$

TIP-47 Proteína de interação da porção terminal de 47 quilodaltons

V-CAM-1 Molécula de adesão celular vascular-1

WT - Tipo selvagem

$\mu \mathrm{g}$ - $\quad$ Micrograma

$\boldsymbol{\mu} \mathbf{M}-\quad$ Micromolar 


\section{Introdução}

\subsection{Aterosclerose}

As doenças cardiovasculares estão entre as principais causas de morte no mundo, onde a doença isquêmica do coração e o acidente vascular cerebral são responsáveis por uma em cada quatro mortes no mundo, e a aterosclerose é a causa subjacente na maioria dos casos (Lozano et al. 2012). A aterosclerose é uma doença inflamatória crônica que se estabelece pelo acúmulo de lipídios na camada íntima arterial, resultando na formação de lesões vasculares, ou placas, que são caracterizadas por inflamação, morte celular e fibrose. A aterosclerose geralmente permanece assintomática ao longo de várias décadas, até que ocorra uma ruptura da placa, provocando a formação de trombos que obstruem o vaso, causando severos danos teciduais e até mesmo um ataque cardíaco fulminante (Lundberg \& Hansson 2010).

Os tradicionais fatores de risco incluem a idade, hipercolesterolemia, hipertensão arterial, tabagismo, sexo, diabetes mellitus e histórico familiar, além de dietas ricas em gorduras, colesterol e triglicerídeos, obesidade e sedentarismo (Hopkins \& Williams 1981). Na última década, foi identificado um grande número de compostos biológicos como novos fatores de risco de aterosclerose. Estes compostos incluem fatores para a coagulação anormal e reduzida (fibrinólise), remodelação cardiovascular, inflamação, adesão celular e infecção (Frishman 1998). A partir dessa identificação muitos estudos se mostram importantes para o melhor entendimento dessa patologia (Hacman \& Anand 2003).

Após a descoberta de células imunes em placas ateroscleróticas utilizando anticorpos monoclonais (Jonasson et al. 1986), um grande foco foi colocado sobre a inflamação na investigação das doenças cardiovasculares e isto levou a grandes descobertas a respeito da patogênese da aterosclerose. Estudos in vitro demonstraram que a lipoproteína de baixa densidade oxidada (oxLDL) promove a ativação imunológica inata de macrófagos. Em lesões ateroscleróticas, macrófagos do infiltrado inflamatório têm o fator de transcrição nuclear NFkB translocado para o núcleo, indicando sua ativação e regulação de genes relacionados a imunidade inata (Edfeldt et al. 2002). Macrófagos presentes em placas ateroscleróticas expressam também vários receptores do tipo Toll (Toll-like receptors - TLRs), e a LDL modificada e seus produtos derivados podem ser ligantes endógenos de TLR2 e TLR4 (West et al. 2010; Miller et al. 2003). 
Dentre as células imunológicas inatas, neutrófilos, mastócitos, células matadoras profissionais (natural killer - NK) e células T matadoras naturais (NKT) desempenham papéis importantes durante a aterogênese, porém apresentam-se em menor número nos sítios ateroscleróticos em comparação com os macrófagos e células TCD4+ (Hansson \& Hermansson 2011). Experimentos usando camundongos hipercolesterolêmicos mostraram que neutrófilos são recrutados durante o inicio da aterosclerose, mas não estão presentes em fases posteriores (Drechsler et al. 2010). Já os mastócitos podem desempenhar um importante papel na estabilidade das placas, através de suas enzimas que degradam a matriz extracelular (Bot et al. 2014). As células NK e NKT agravam a aterosclerose, possivelmente devido a liberação de Interferon gama (IFN- $\gamma$ ) (Whitman 2004; Tupin 2004). As células NKT que produzem IL-10, por outro lado, podem limitar o desenvolvimento da doença (van Puijvelde et al. 2009). Tomados em conjunto, as diversas células imunológicas inatas desempenham papéis importantes em diferentes fases do desenvolvimento da doença, mas a principal célula efetora da resposta imune inata, e também a mais abundante nas placas ateroscleróticas, são os macrófagos.

Nos macrófagos gordurosos a formação de cristais de colesterol pode ativar o inflamassoma NLRP3, levando a secreção da citocina pró-inflamatória IL-1 $\beta$ (Duewell et al. 2010; Rajamäki et al. 2010). Isto proporciona uma ligação clara entre o metabolismo do colesterol e ativação imunológica inata. A inibição da IL-1 $\beta$ para prevenir eventos cardiovasculares, está atualmente sob avaliação em ensaios clínicos (Ridker et al. 2011). A IL-1 $\beta$ secretada atua sobre as células musculares lisas para a produção de IL-6 (Loppnow \& Libby 1990), esta por sua vez induz a produção de proteína C reativa (PCR) pelo fígado.

Uma artéria normal é constituída por três camadas: i) a camada íntima com células endoteliais e células do músculo liso; ii) a camada média com células de músculo liso e lamelas elásticas; iii) e uma camada adventícia circundante com tecido conjuntivo frouxo (Hansson 2005). O acúmulo de LDL ocorre na camada íntima, e promove o desenvolvimento da aterosclerose. Modificações oxidativas através de mieloperoxidases, lipoxigenases, e espécies reativas de oxigênio (ROS) levam à formação de oxLDL, que desencadeia uma resposta inflamatória inata (Hansson \& Hermansson 2011). Em resposta às oxLDLs, células endoteliais começam a aumentar a expressão de moléculas de adesão, tais como VCAM-1, ICAM-1, e P-selectinas, além de promover a quimiotaxia através da secreção de proteína quimiotática de monócitos-1 (MCP-1) (Nakashima et al. 1998). Sendo assim, monócitos circulantes e outros leucócitos são recrutados para estes locais. Os monócitos diferenciam-se em macrófagos, que se infiltram na camada íntima em resposta ao M-CSF e GM-CSF 
produzido pelas células endoteliais (Rajavashisth et al. 1990). Os macrófagos derivados de monócitos são os mais abundantes em placas ateroscleróticas e podem proliferar localmente (Robbins et al. 2013). Eles expressam receptores scavenger, dos quais o receptor Scavenger classe A e CD36 foram identificados como os mais importantes para a absorção de oxLDL (Kunjathoor 2002). Os receptores Scavenger são regulados positivamente em resposta à acumulação intracelular de colesterol. E a imersão contínua de lipídios leva à formação de células gordurosas a partir de macrófagos que fagocitam as oxLDLs (Park 2014).

O fosfolipídio Lisofosfatidilcolina e ácidos graxos oxidados não esterificados são gerados durante a oxidação da LDL, por lipoproteínas associadas à fosfolipase A2, que também ativam o sistema imune inato (Hurt-Camejo et al. 2001). Todos estes eventos são susceptíveis a serem fatores importantes que iniciam e contribuem para a manutenção da inflamação na formação de lesões ateroscleróticas.

\subsection{Lisofosfatidilcolina}

Por muitos anos os lisofosfolipídios (LPL) foram associados apenas com sua função estrutural e de armazenamento energético. Entretanto, com base em vários estudos realizados durante as últimas décadas, esta se tornando cada vez mais evidente a ação dos LPLs como hormônios, moléculas de sinalização e mediadores lipídicos intracelulares. Estas moléculas também possuem a capacidade de ativar receptores de membrana específicos e/ou receptores nucleares que regulam diversos processos fisiológicos e fisiopatológicos. Entre os LPLs, a lisofosfatidilcolina (LPC) vem se tornando um modelo cada vez mais utilizado e estudado (Drzazga et al. 2014) devido a sua importância, não só fisiológica, mas também patológica, em diferentes modelos.

A LPC é um lisofosfolipídio constituinte de membranas plasmáticas e possui um papel importante na sinalização celular por estar presente em alta quantidade na circulação sanguínea humana, a maior parte da LPC circulante esta associada à moléculas como a albumina e às oxLDLs (Schmitz \& Ruebsaamen 2010). Devido a essa associação, a LPC exerce um papel fundamental durante a aterosclerose, pois ela é o principal componente fosfolipídio de oxLDL e desta forma, está diretamente implicada como um fator crítico na atividade aterogênica da oxLDL. Ela também é capaz de induzir a formação de células gordurosas, as quais são componentes celulares fundamentais para o estabelecimento da aterosclerose e recrutamento leucocitário para o sítio desta patologia, induzindo a progressão 
da doença (Matsumoto et al. 2007). Devido a esta relação direta com a aterosclerose, a LPC tornou-se um interessante modelo pra estudos relacionados a essa patologia.

Várias isoformas de LPC, com diversas cadeias acil, já foram identificadas, como os ácidos palmítico (16: 0), esteárico (18: 0), oleico (18: 1), linoleico (18: 2), araquidônico (20: 4) e docosahexaenóico (22: 6), e encontradas no plasma humano (Riederer et al. 2010). Todas elas podem ser geradas por vários processos biológicos, incluindo: i) a clivagem da membrana plasmática de lipoproteínas de fosfatidilcolina (PC) pela fosfolipase A2 (PLA2) (Sato et al. 2008) ii) a atividade da enzima lecitina colesterol aciltransferase (LCAT) em lipoproteínas de alta densidade (HDL) (Rousset et al. 2009), e iii) a oxidação de lipoproteínas de baixa densidade (LDL) (Parthasarathy et al. 1985). Fontes adicionais de LPC são oriundas de lipases endoteliais (LE) e lipases hepáticas (LH) que por clivagem de HDL-PC, geram LPC saturada (16:0) e quantidades substanciais de LPC insaturadas (18:1; 18:2; 20:4) (Gauster et al. 2005; Santamarina-Fojo 2004).

Alguns receptores já foram descritos para a LPC, tais como receptores acoplados a proteína G (GPCRs), G2A, GPR4 e GPR119 (Murakami et al. 2004), TLR2 (Magalhães et al. 2010) e TLR4 (Carneiro et al. 2013). Tais receptores podem ativar diversas vias a partir de diferentes proteínas cinases (Schmitz \& Ruebsaamen 2010) e a via do fator de transcrição nuclear NFkB induzindo a sua translocação para o núcleo (Magalhães et al. 2010).

A LPC tem um amplo espectro de atividades pró-inflamatórias, que incluem a promoção do crescimento celular (Nakano et al. 1994), a indução da migração celular (Kohno et al. 1998) e a regulação positiva de moléculas de adesão, como a ICAM-1, VCAM-1, e Pselectinas (Zou et al. 2007), além de promover a quimiotaxia através da indução de proteína quimiotática de monócitos-1 (MCP-1) (Takahara et al. 1996; Quinn et al. 1988). Outra função conhecida da LPC é aumentar a atividade bactericida de neutrófilos via NADPH oxidase que estimula a produção de espécies reativas de oxigênio (ROS) (Hong et al. 2014; Lin et al. 2005). Também já foi descrito que a LPC ativa caspase-1 e a geração de ROS dependente das lipid rafts em micróglia (Schilling \& Eder 2010). Além disso, a LPC promove um aumento da permeabilidade celular, que pode levar a apoptose (Takahashi et al. 2002), e possui um efeito citotóxico em células musculares lisas vasculares, pois promove um influxo de cálcio e um aumento na síntese de DNA (Chen et al. 1995).

A LPC induz a produção e secreção de diversas citocinas, tais como a interleucina-1 $\beta$ (IL-1 $\beta$ )(Stock et al. 2006; Liu-Wu et al. 1998), o fator de necrose tumoral - $\alpha$ (TNF- $\alpha$ ) (Huang et al. 1999), a interleucina 6 (IL-6)(David \& Bryan 1996), o Interferon $\gamma$ (IFN $\gamma$ ) (Sheikh et al. 2001) e o fator transformador de crescimento $\beta 1$ (TGF- $\beta 1$ )(Hasegawa et al. 2011). 
LPC também está envolvido na produção de prostaglandina I2 (PGI2 também conhecido como prostaciclina) in vitro em células endoteliais aórticas humanas primárias e in vivo em modelo murino. O produto da degradação estável de PGI2, 6-ceto-prostaglandina F1a (PGF1 $\alpha$ ) também foi induzida por LPC (Riederer et al. 2010). Em células endoteliais a LPC promove a liberação de Ácido araquidônico (AA), graças a ação das fosfolipases (Wong et al. 1998)e induz a ação da ciclooxigenase-2, sendo assim, a LPC uma importante precursora da síntese de mediadores lipídicos (Zembowicz et al. 1995).

Em parasitos, como o Trypanossoma cruzi, a LPC tem demonstrado papel fundamental na modulação da transmissão do parasito, agindo como um potente fator quimiotático de células inflamatórias ao local da picada do vetor (Silva-Neto et al. 2012). Em Schistosoma mansoni, a LPC exerce papel importante na patologia causada por este helminto ao induzir intensa eosinofilia e liberação das citocinas IL-5 e IL-13 (Magalhães et al. 2010). Além disso, a LPC também tem sido utilizada como adjuvante de vacinas (Perrin-Cocon et al. 2006).

Em tumores, a LPC é hidrolisada em ácidos graxos para a nutrição do tumor, onde pacientes com cânceres metastáticos apresentam um menor nível de LPC no plasma. Outro ponto importante é que a LPC, tanto saturada quanto monoinsaturada, tendem a atenuar a atividade metastática do tumor, revelando uma importante ação da LPC na progressão do câncer (Raynor et al. 2015).

Outra importante função da LPC é a indução da biogênese de corpúsculos lipídicos, que são marcadores de ativação celular e importantes sítios de síntese e armazenamento de mediadores lipídicos celulares (Magalhães et al. 2010).

\subsection{Corpúsculos Lipídicos}

Corpúsculos lipídicos (CLs) são organelas distribuídas no citoplasma da maioria das células eucarióticas, possuem uma região central composta de lipídeos neutros e é envolto por uma monocamada de fosfolipídios associados a proteínas designadas PAT, que compreendem as perilipinas, as proteínas relacionadas com a diferenciação de adipócitos (ADRP) e a TIP47, o que difere os CLs das demais organelas celulares convencionais (Melo et al. 2006; U et al. 1999).

No passado, acreditava-se que a presença de CLs nas células serviria simplesmente para o armazenamento e transporte de lipídios, entretanto, atualmente já se sabe que CLs são organelas altamente reguladas que estão envolvidas em vários aspectos de ativação e metabolismo celular e inclusive no processo inflamatório (Bozza et al. 2009). CLs são especializados em armazenar lipídios neutros, triacilglicerol, colesterol-éster e fosfolipídios, 
associados a uma variada composição proteica. O armazenamento de lipídios celulares é variável, e reflete o balanço entre a chegada dos lipídios nas células e o seu consumo por elas; um acúmulo excessivo de CLs também ocorre em diversas doenças como a obesidade, esteatose, diabetes, miopatia e aterosclerose (Greenberg et al. 2011).

Em leucócitos em estado de repouso, existe apenas um número basal de CLs, entretanto, estas organelas se tornam abundantes quando as células se tornam ativadas e envolvidas em processos inflamatórios (Bozza et al. 2009). A biogênese dos CLs ocorre em decorrência à um estímulo inflamatório e está relacionado à diversas patologias (Melo et al. 2011). Sendo assim os CLs são formados sob duas condições ambientais diferentes: I) na primeira condição as células acumulam CLs em resposta a disponibilidade exógena de lipídios e sabe-se que os ácidos graxos armazenados nos CLs são utilizados como substrato para o metabolismo energético, síntese de membranas celulares e produção de moléculas derivadas de lipídios tais como lipoproteínas, sais biliares, hormônios e mediadores lipídicos do sistema imune (Pol et al. 2014); II) na segunda condição, as células recebem estímulos ou sofrem estresses, como a própria inflamação, o estresse oxidativo e patógenos que podem induzir a biogênese de CLs, refletindo assim o papel dos CLs em processos não diretamente relacionados com o metabolismo lipídico, tais como na degradação de proteínas ou na imunidade. (Melo et al. 2011; Walther \& Farese 2012). Dessa forma, os corpúsculos lipídicos atuam como importantes marcadores de ativação celular uma vez que sua biogênese é desencadeada imediatamente após a ativação de leucócitos (Bozza et al. 2009).

Os CLs possuem enzimas chaves envolvidos no metabolismo de colesterol e na síntese de ácidos graxos, pois são sítios ativos do metabolismo do ácido araquidônico e ambos os passos anabólicos e catabólicos do metabolismo lipídico estão presentes nessa organela. Todas as enzimas necessárias para síntese de eicosanoides, como fosfolipase A2 (PLA 2 , ciclooxigenases $(\mathrm{COX})$, prostaglandina E2 e D2 ( $\mathrm{PGE}_{2}$ e $\left.\mathrm{PGD}_{2}\right)$ sintase, 5- e 15-lipoxigenases (5-LO e 15-LO) e leucotrieno C4 ( $\left.\mathrm{LTC}_{4}\right)$ sintase, foram localizadas dentro de CLs em células ativadas (Melo et al. 2011; Haeggstrom \& Funk 2011). Outras enzimas envolvidas na liberação de ácido araquidônico como MAPK e PI3K, p38, ERK1/2 também estão colocalizadas em CLs (Yu et al. 1998). Desta forma, os CLs são organelas multifuncionais e sítios de eventos regulatórios, bem como potenciais fontes de produção de mediadores inflamatórios como os eicosanoides e as prostaglandinas (Bozza \& Viola 2010; Haeggstrom \& Funk 2011). Sendo assim, estas organelas atuam na inflamação como marcadores da ativação de leucócitos, constituindo assim um possível alvo anti-inflamatório (Bozza et al. 2009). 
Os CLs além de serem sítios de eicosanóides podem estar associados com o armazenamento de citocinas pró-inflamatórias, como TNF- $\alpha$, MIF e RANTES (Beil et al. 1995; Pacheco et al. 2002; Bandeira-Melo et al. 2001), além de fatores de crescimento (Dvorak et al. 2001). A relação entre os CLs e a citocina pró-inflamatória IL-1 $1 \beta$, a qual é processada e maturada pelo complexo dos inflamassomas, ainda é escasso e controverso.

\subsection{Inflamassoma e Piroptose}

Os inflamassomas são complexos multiproteicos intracelulares responsáveis pela clivagem e ativação da enzima pro-caspase-1 em caspase-1, que exerce um papel fundamental no processamento e maturação das citocinas pró-inflamatórias IL-1 $\beta$ e IL-18 e numa forma de morte pró-inflamatória rápida chamada de piroptose (Schroder \& Tschopp 2010; Miao et al. 2011).

Existem duas vias descritas pelas quais os inflamassomas são gerados. A via canônica na qual ele é formado por receptores de reconhecimento padrão (PRRs), uma caspase inflamatória e, se necessário, a proteína adaptadora ASC (Keyel 2014). E a via não canônica, na qual a caspase murina 11 ou a sua homóloga humana, a caspase-4, se liga diretamente ao estímulo microbiano (Shi et al. 2014). A ativação dos receptores ou ligação das caspases com o estímulo, leva ao recrutamento das proteínas do inflamassoma e à oligomerização da prócaspase-1, que promove sua autoproteólise e consequente ativação leva a clivagem e a secreção de IL-1 $\beta$ e IL-18 ou a piroptose (Guo et al. 2015).

Para que ocorra o processo completo, dois sinais são necessários para a eficiente maturação de IL-1 $\beta$ e IL-18: o primeiro sendo a sinalização por PRRs que induzam à ativação

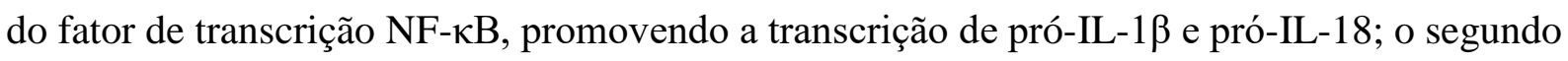
sinal, consiste no processamento proteolítico desses precursores em suas formas biologicamente ativa via caspase-1, a qual é ativada pelo inflamassoma (Strowig et al. 2012).

O inflamassoma é composto por PRRs intracelulares do tipo NLRs (Node-like receptors), que em humanos é codificado por 22 genes e possui a divisão em três subfamílias: NOD, NLRP e IPAF (NLRC). Esses são constituídos por três regiões funcionais, uma região NOD de regulação localizada na posição central, uma região N-terminal efetora envolvida na sinalização, nesse domínio pode conter um domínio pirina (PYD), um domínio para recrutamento de caspase (CARD), ou um domínio inibidor de baculovírus (BIR); e a região C-terminal que é composta por repetições ricas em leucina (LRRs) (Schroder \& Tschopp 
2010). A montagem desse complexo ocorre de forma que o NLR recruta uma proteína adaptadora, a ASC, que interage com a caspase-1 ou caspase-11 levando a sua ativação, para essa promover a maturação das citocinas pró-inflamatórias (Bauernfeind et al. 2011). Vários NLRs capazes de formar o complexo do inflamassoma já foram descritos, dentre eles: NLRP1, NLRP3 (NALP3), NLRP6, NLRC4 (IPAF) e AIM2 (Strowig et al. 2012).

Cada um destes receptores parece ser responsável por responder a estímulos distintos e específicos. Por exemplo, NLRP1 participa no reconhecimento da toxina letal de Bacillus anthracis, Toxoplasma gondii, e contribui para a depleção de ATP intracelular (Ewald et al. 2014; Liao \& Mogridge 2013; Boyden \& Dietrich 2006). Já o NLRP6 está relacionado com a manutenção e regulação da microbiota intestinal, previne contra inflamações intestinais, protege contra o câncer de cólon e regula a imunidade inata antiviral intestinais (Jackson et al. 2015; Chen 2014; Anand \& Kanneganti 2013). O inflamassoma AIM2 participa no reconhecimento de DNA citosólico proveniente de vírus e bactérias (Fernandes-Alnemri et al. 2009; Warren et al. 2010). Já o inflamassoma NLRC4 é responsável pelo reconhecimento de flagelina e componentes do sistema de secreção do tipo III de bactérias além de patógenos bacterianos diferentes, incluindo Legionella pneumophila, Pseudomonas aeruginosa, Salmonella typhimurium, Shigella flexneri (Miao et al. 2010; Miao et al. 2006; Cerqueira et al. 2015; Sutterwala et al. 2007; Franchi et al. 2006).

Dentre todos os inflamassomas até hoje descritos, o mais estudado e caracterizado é o NLRP3, que diferentemente dos receptores citados anteriormente, é responsável por reconhecer uma vasta gama de agentes infecciosos, incluindo diversas bactérias como Staphylococcus aureus, Vibrio cholerae, Escherichia coli, Neisseria gonorrhoeae, Chlamydia pneumoniae e Citrobacter rodentium (He et al. 2010; Shimada et al. 2011; Duncan et al. 2009; Harder et al. 2009; Toma et al. 2010); Alguns fungos patogênicos A. fumigatus, C. albicans , C.neoformans e P.brasiliensis (Gross et al. 2009; Hise et al. 2009; Tavares et al. 2013; Saïd-Sadier et al. 2010; Guo et al. 2014); E também vírus, como o influenza A (Allen et al. 2009); e os parasitas Schistosoma mansoni e T.cruzi (Ritter et al. 2010; Gonçalves et al. 2013).

A via e os mecanismos de ativação do Inflamassoma NLRP3 são muito bem caracterizados. Os principais mecanismos que desencadeiam a ativação do NLRP3 consistem, no primeiro sinal comum aos outros inflamassomas, na qual PAMPs ou DAMPs via PPRs como TLRs, receptores de IL-1 ou TNF desencadeiam uma cascata de sinalização ativando o fator de transcrição $\mathrm{NF \kappa B}$, que transcreve a pró IL-1 $\beta$, pró IL-18 e pró-caspase-1 e regula positivamente a expressão do NLRP3 (Schroder \& Tschopp 2010; Hornung \& Latz 2010). E 
o segundo sinal a partir do qual diversos mecanismos induzem a formação e ativação do complexo NLRP3, como a produção de espécies reativas de oxigênio (ROS)(Tschopp \& Schroder 2010); o efluxo de potássio e ATP (Pétrilli et al. 2007) e o dano lissosomal devido à liberação da protease catepsina B para o citoplasma. Estes eventos são iniciados a partir de diversos ativadores, como partículas de sílica, alum, proteína fibrilar amilóide- $\beta$ ou cristais de ácido úrico (Cassel et al. 2009). Estudos recentes demonstram que a ativação exacerbada do inflammasoma NLRP3 está associada com a patogênese de várias doenças auto-imune, crônicas, inflamatórias e doenças metabólicas, como alzheimer, aterosclerose, diabetes tipo 2, gota e doenças inflamatórias intestinais (DII) (Ozaki et al. 2015). Além disso, a ativação do inflamassoma NLRP3 também pode levar a piroptose da célula hospedeira (Wree et al. 2014).

A piroptose é um tipo de morte celular caracterizada pela lise celular resultante da formação de poros da membrana plasmática, aumento do volume celular, fragmentação nuclear e condensação da cromatina que ocorrem dependente da atividade da caspase-1 ou 11, e independentemente da secreção de IL-1 $\beta$ e IL-18 (Cookson \& Brennan 2001; Monack et al. 2001; Fink \& Cookson 2006; Silveira \& Zamboni 2010).

A piroptose possui algumas semelhanças com a apoptose, como a condensação da cromatina e a fragmentação do DNA. Entretanto, os efeitos entre estes dois tipos de morte celular são diferentes. A piroptose é considerada pró-inflamatório por apresentar rompimento da membrana celular e liberação dos componentes intracelulares, enquanto que a apoptose é descrita como não inflamatória por manter a integridade da membrana (Bergsbaken et al. 2009; Fernandes-Alnemri et al. 2007). Outra diferença diz respeito à Poli-[ADP-ribose]polimerase (PARP), a clivagem de PARP é determinante para a apoptose, mas não ocorre na piroptose. (Jorgensen \& Miao 2015).

As caspases são produzidas em sua pró-forma inativa e são clivadas e ativadas através do inflamassoma ou piroptossoma (Guo et al. 2015; Fernandes-Alnemri et al. 2007). Além de clivar e ativar as citocinas pró-inflamatórias IL-1 $\beta$ e IL-18, a caspase-1 também leva à secreção da proteína de alta mobilidade de grupo caixa-1 (HMGB1)(Keller et al. 2008). A proteína nuclear HMGB1 possui a função de determinar a estrutura da cromatina e regular a transcrição. Entretanto, ela pode ser secretada da célula por processo de morte celular ou ativação do inflamassoma (Lamkanfi et al. 2010). Contudo, por qual mecanismo a caspase-1 induz a morte por piroptose ainda é desconhecido, devido a isso, o interesse na piroptose e ativação de caspases permanece crescente (Tait et al. 2014). 
A relação entre CLs e os inflamassomas, bem como o papel dos CLs na maturação e secreção de IL-1 $\beta$, ainda é pouco descrita na literatura e os poucos trabalhos publicados apresentam dados controversos. Itoh e colaboradores (2014) mostraram que macrófagos deficientes para os componentes do inflamassoma NLRP3 apresentaram um aumento da biogênese de corpúsculos lipídicos em modelo de infecção por Chlamydia pneumoniae. Por outro lado, McRae e colaboradores (2015) demonstraram que quando se inibe farmacologicamente ou através de RNA de interferência as proteínas NLRP3, ASC e Caspase-1, ocorre uma diminuição da biogênese de corpúsculos lipídicos no modelo de infecção pelo vírus da dengue. Apesar de alguns estudos mostrarem que a LPC induz a secreção de IL-1 $\beta$ e a ativação de caspase-1, ainda não está descrito por qual inflamassoma e por quais mecanismos este lipídio atua na ativação deste complexo, nem qual a relação entre CLs e o inflamassoma no modelo de estimulação celular com LPC. 


\section{Justificativa}

O interesse pela lisofosfatidilcolina têm-se intensificado cada vez mais na comunidade científica. Tal relevância é devida a sua relação com a aterosclerose, e sua capacidade imunomoduladora. Como já é conhecido a LPC induz a secreção de IL-1 $\beta$ em monócitos humanos (Liu-Wu et al., 1998) e em macrófagos murinos (Magalhaes et al, 2010). Entretanto, ainda não foi descrito qual inflamassoma é ativado por este lipídeo imunomodulador, por quais mecanismos a LPC induz a maturação e secreção da citocina IL-1 $\beta$ e se este lipídio é capaz de induzir a piroptose em monócitos e células endoteliais, portanto uma de nossas hipóteses é de que a LPC está ativando o inflamassoma NLRP3 e induzindo a secreção de IL$1 \beta$ dependente dessa via.

Além disso, outro fator interessante a ser investigado é a relação entre a formação de células gordurosas, através da biogênese de CL, com a ativação dos inflamassomas e a secreção de IL-1 $\beta$. Nossa hipótese é de que a LPC induz a formação de células gordurosas dependente das vias de ativação do inflamassoma NLRP3. Com isso, esse projeto visa preencher lacunas existentes no entendimento dos mecanismos celulares e moleculares envolvidos na ativação inicial da resposta inflamatória desencadeada pela LPC, e desta maneira poder utilizar os complexos dos inflamassomas como alvos farmacológicos de intervenção contra a aterosclerose e outras patogenias relacionadas a este lipídio. 


\section{Objetivos}

\subsection{Objetivo geral:}

Caracterizar os mecanismos celulares e moleculares envolvidos na ativação do inflamassoma NLRP3 e sua relação com a formação de células gordurosas por biogênese de corpúsculos lipídicos pela Lisofosfatidilcolina (LPC).

\subsection{Objetivos específicos:}

a) Investigar o papel da LPC na ativação de caspase-1 e produção de ROS;

b) Caracterizar os mecanismos intracelulares envolvidos na secreção de IL-1 $\beta$ induzida por LPC;

c) Caracterizar os mecanismos intracelulares envolvidos na biogênese de Corpúsculos lipídicos induzida pela LPC e sua relação com a via do inflamassoma NLRP3;

d) Investigar o papel da LPC na formação de células gordurosas, analisando a, biogênese de Corpúsculos Lipídicos em monócitos e células endoteliais;

e) Analisar se a LPC induz piroptose em monócitos e células endoteliais humanas. 


\section{Materiais e Métodos}

\subsection{Camundongos, tratamentos in vivo e considerações éticas.}

Utilizamos camundongos da linhagem C57/BL6, NLRP3-/-, Caspase1/11-/- e selvagens, os quais foram mantidos no biotério do Instituto de Ciências Biológicas da Universidade de Brasília com água e alimento ad libitum. Todos os procedimentos experimentais envolvendo animais foram aprovados pela Comissão de Ética e uso de Animais da UnB. Os camundongos foram estimulados com LPC $100 \mu \mathrm{g} / \mathrm{mL}$ diluída em PBS e administrada intraperitonealmente ou intravenosa. Após $24 \mathrm{~h}$ os camundongos foram anestesiados com $30 \mu \mathrm{l}$ de quetamina e xilasina em proporções iguais, administrados intramuscularmente. O sangue foi coletado, para extração do soro e posteriormente, esses animais foram sacrificados em câmara de $\mathrm{CO}$, para a retirada das células do lavado peritoneal.

\subsection{Células utilizadas}

- THP-1: É uma linhagem imortalizada de monócitos humanos não aderentes. Essas células foram cultivadas em meio RPMI-1640 adquirido da Sigma-Aldrich e suplementado com bicarbonato de sódio, $10 \%$ de Soro Fetal Bovino (SFB), $50 \mu \mathrm{M}$ de 2-mercaptoethanol, $40 \mu \mathrm{g} / \mathrm{mL}$ de Gentamicina em estufa úmida a $37^{\circ} \mathrm{C}$ a $5 \% \mathrm{CO} 2$.

- HUVEC: É uma linhagem de células derivadas de endotélio vascular umbilical humano aderente com morfologia estrelada. Foram cultivadas com meio F12 adquirido da Sigma-Aldrich e suplementado com bicarbonato de sódio, $10 \%$ de SFB, $0.1 \mathrm{mg} / \mathrm{ml}$ heparina; $0.03 \mathrm{mg} / \mathrm{ml}$ de suplemento de crescimento de células endoteliais (ECGS), $40 \mu \mathrm{g} / \mathrm{mL}$ de Gentamicina e $10 \mu \mathrm{g} / \mathrm{mL}$ de Cloranfenicol em estufa úmida a $37^{\circ} \mathrm{C}$ a $5 \% \mathrm{CO} 2$.

- Macrófagos Peritoneais: Os macrófagos peritoneais foram obtidos através de lavagem peritoneal de camundongos previamente estimulados com tioglicolato. Brevemente, os animais receberam injeção intraperitoneal de tioglicolato a $4 \%$ e após $72 \mathrm{~h}$ eles foram sacrificados e a lavagem peritoneal foi realizada injetando $5 \mathrm{~mL}$ de RPMI refrigerado dentro do peritônio. O meio foi recolhido, centrifugado a $300 \mathrm{~g}$ por $5 \mathrm{~min}$. a $4^{\circ} \mathrm{C}$. As células então foram ressuspendidas, contadas e plaqueadas em placas 
de cultura. Após $24 \mathrm{~h}$ em estufa úmida a $37^{\circ} \mathrm{C}$ a $5 \% \mathrm{CO} 2$, o sobrenadante foi descartado e as células fortemente aderidas consideradas macrófagos.

\subsection{Estímulos e tratamentos}

Durante todo o projeto foi utilizado o lisofosfolipídio 1-palmitoil-2-hidroxi-sn-glicero3- fosfocolina (16:0 LysoPC), mais conhecido como lisofosfatidilcolina (LPC), da Avanti Polar Lipids. O estoque de LPC foi diluído em etanol e mantido a $-20^{\circ} \mathrm{C}$ em tubos de vidro. Em todos os experimentos a quantidade de LPC total era retirada do estoque, secada em gás nitrogênio em outro tudo cônico de vidro. Em seguida a LPC era ressuspendida em meio de cultura, sonicada durante $10 \mathrm{~min}$, vortexada por $30 \mathrm{seg}$, e imediatamente pipetada a quantidade desejada nos poços, a fim de estimular as células. Como controles positivos foram utilizados lipopolisacarídeo (LPS) (500ng/mL; Sigma-Aldrich), adenosina-tri-fosfato (ATP) (1mM; Sigma-Aldrich) e Menadiona (100 $\mu \mathrm{M}$; Sigma-Aldrich).

Para a caracterização de vias e mecanismos envolvidos no desenvolvimento do trabalho, as células foram pré-tratadas de $45 \mathrm{~min}$ a $1 \mathrm{~h}$ com alguns inibidores farmacológicos. As drogas utilizadas foram: inibidor de espécies reativas de oxigênio (ROS) [N-Acetil-LCisteina (NAC) 5mM; Sigma-Aldrich] e [Rotenona 10 $\mu \mathrm{M}$; Sigma-Aldrich]; inibidor de catepsina B (CA074-Me 50 $\mu \mathrm{M}$; Sigma-Aldrich); Inibidor de caspase-1 (Ac-YVAD-cho $20 \mu \mathrm{M}$; Enzo Life Sciences,); Inibidor de canais de potássio sensíveis a ATP (Glibenclamida ou Gliburídeo, $150 \mu \mathrm{M}$; Sigma-Aldrich); Inibidor de HMG-CoA redutase (Atorvastatina

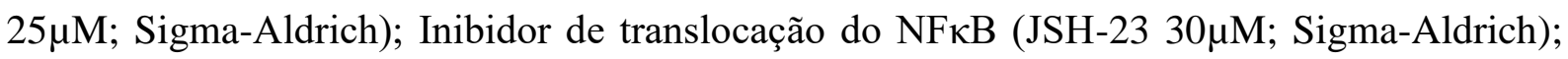
Antagonista de PPAR- $\gamma$ (GW9662 1 $\mu \mathrm{M}$; Sigma-Aldrich); Desestabilizador de lipids rafts (Metil- $\beta$-ciclodextrina $10 \mu \mathrm{M}$; Sigma-Aldrich) e um anticorpo neutralizante de TLR-2 (PAbhTLR2 $10 \mu \mathrm{g} / \mathrm{mL}$; InvivoGen).

\subsection{Análise da viabilidade celular}

O reagente MTT (3-(4,5-Dimetiltiazol-2-yl)-2,5-difeniltetrazolio brometo), foi utilizado para análise de viabilidade celular. Para esse experimento as células THP-1 e HUVEC foram plaqueadas em placas de cultura de 96 poços, tratadas por 24 horas com LPC em diferentes concentrações, 0.1, 1, 10, 20, 50 e $100 \mu \mathrm{g} / \mathrm{mL}$. Após o tempo de estímulo, o sobrenadante foi substituído por uma solução de $10 \%$ MTT, $5 \mathrm{mg} / \mathrm{mL}$ (Sigma-Aldrich, USA) diluído no próprio meio de cultura celular. Em seguida, a placa foi incubada por $4 \mathrm{~h}$ protegida 
da luz na estufa de cultivo. O sobrenadante foi descartado e os cristais de formazan formados foram diluídos em $100 \mu \mathrm{L}$ de DMSO. A absorbância foi lida a $570 \mathrm{~nm}$ no espectrofotômetro SpectraMax M3 (Molecular Devices, USA). Para o cálculo da viabilidade, as células não estimuladas foram consideradas como $100 \%$ viáveis e os demais estímulos foram calculadas proporcionalmente.

\subsection{Análise da ativação de caspase-1}

A detecção de caspase-1 ativa foi obtido através da utilização de um kit específico e manipulado de acordo com as instruções do fabricante: FLICA FAM-YVAD-FMK (Immunochemistry). Este kit é composto por uma sonda fluorescente que se liga de forma irreversível à uma subunidade específica de caspase-1 clivada. Macrófagos peritoneais estimulados com LPC $1 \mu \mathrm{g} / \mathrm{ml}$ por 1,3 , e $6 \mathrm{~h}$ foram submetidos à marcação com FLICA, e posteriormente analisados por citometria de fluxo (FACS VERSE, BD Biosciences). O gate foi plotado na população de células viáveis, excluindo-se os debris celulares da análise. Os histogramas e médias de intensidade de fluorescência (MFI) foram feitos no software FlowJo V10 (Tree Star Inc).

\subsection{Análise da geração de espécies reativas de Oxigênio (ROS)}

Para análise da formação de espécies reativas de oxigênio (ROS) foi utilizada a sonda 2',7' Diclorodihidrofluoresceína-diacetato (DFC-DA) a qual é permeável à membrana celular e não é fluorescente. Na presença de ROS, este composto é oxidado no interior da célula e produz um composto fluorescente, a 2',7' - diclorofluoresceína (DFC), que permanece no interior da célula. Tanto THP-1 quanto HUVECs foram estimuladas com LPC $1 \mu \mathrm{g} / \mathrm{mL}$ por diferentes tempos 1, 3, 6 e 24h. Completado o tempo dos estímulos as culturas de células foram incubadas a $37^{\circ} \mathrm{C}$, protegidas da luz por 30 minutos com a sonda DFC-DA dissolvida em meio de cultura na concentração final de $20 \mu \mathrm{M}$. Após esse período as células foram lavadas com PBS1x 3 vezes, resuspendidas em $500 \mu \mathrm{L}$ de PBS1x gelado e mantidas a $4^{\circ} \mathrm{C}$. A leitura foi realizada imediatamente por citometria de fluxo (FACS verse ou FACS Calibur), O gate foi plotado na população de células viáveis, excluindo-se os debris celulares da análise. Os histogramas e médias de intensidade de fluorescência (MFI) foram feitos no software FlowJo V10 (Tree Star Inc). 


\subsection{Dosagens de Citocinas}

As citocinas provenientes do sobrenadante das culturas foram analisadas pelo método de ELISA, utilizando-se kits comerciais (eBioscience e R\&D System). O ensaio foi realizado seguindo-se as instruções do fabricante e os níveis de citocinas foram demonstrados em valores absolutos $(\mathrm{pg} / \mathrm{mL})$.

\subsection{Análise da biogênese de corpúsculos lipídicos por citometria de fluxo e microscopia de fluorescência confocal}

Para analisar e quantificar a biogênese de corpúsculos lipídicos (CLs) foi utilizado uma sonda fluorescente lipofílica, BODIPY 493/503 (Life technologies), usado para a identificação de lipídios neutros intracelulares (triglicerídeos e ésteres de colesterol) presentes em grandes quantidades em CLs. Para a quantificação de CL por citometria de fluxo, THP-1 e HUVECs pré-tratadas ou não com inibidores foram estimuladas com LPC $1 \mu \mathrm{g} / \mathrm{mL}$ por $24 \mathrm{~h}$. Após o estimulo as células foram incubadas com uma solução de bodipy/PBS na concentração de $1 / 5000$ por 30 minutos a $4{ }^{\circ} \mathrm{C}$ protegido da luz. Após esse período as mesmas foram lavadas com PBS1x 3 vezes, resuspendidas em $500 \mu \mathrm{L}$ de paraformaldeído $1 \%$ e mantidas a $4^{\circ} \mathrm{C}$ até leitura por citometria de fluxo (FACS Calibur). O gate foi plotado na população de células viáveis, excluindo-se os debris celulares da análise. Os histogramas e médias de intensidade de fluorescência (MFI) foram feitos no software FlowJo V10 (Tree Star Inc).

Para analise de CL por microscopia de fluorescência confocal, as células pré-tratadas ou não com inibidores e estimuladas com LPC $1 \mu \mathrm{g} / \mathrm{mL}$ por $24 \mathrm{~h}$ foram fixadas com paraformaldeído a $4 \%$ por 10 minutos em temperatura ambiente. Em seguida foram lavadas por três vezes com PBS e incubadas com uma solução de Bodipy/PBS na concentração de 1/300 por 30 minutos a $4^{\circ} \mathrm{C}$ protegido da luz. Após esse período as mesmas foram lavadas com PBS 3 vezes e incubadas com uma solução de 4',6-diamidino-2-phenylindole (DAPI) que é um corante fluorescente que se liga a DNA amplamente utilizado na microscopia de fluorescência para demarcar o núcleo da célula. Essa solução de DAPI foi diluída na concentração de 1/5000 de DAPI em PBS, as células foram incubadas por 5 minutos e em seguida lavadas 3 vezes com PBS. As lâminas foram montadas em meio anti-fadding Prolong (Life technologies). As imagens foram obtidas no microscópio Leica TCS SP5 (Leica Microsystems, DEU). 


\subsection{Análise de HMGB1 por imunofluorescência}

Para verificar a localização da proteína HMGB1 nas células tratadas com LPC, foi feita imunomarcação intracelular e análise por microscopia de fluorescência confocal. Após o tempo de estímulo, as células foram fixadas com paraformaldeído a $4 \%$ por 10 minutos em temperatura ambiente. Em seguida foram lavadas por três vezes com PBS e permeabilizadas em Triton a $0,2 \%$ por 20 minutos em temperatura ambiente. Após novas lavagens, foi adicionada solução de bloqueio ( $2 \%$ de BSA, 5\% de SFB e PBS) por 20 minutos à temperatura ambiente. O anticorpo primário foi diluído em solução de bloqueio na concentração de 1:400 e incubado overnight a $4^{\circ} \mathrm{C}$. Após esse período, as células foram lavadas e incubadas com o anticorpo secundário conjugado a Alexa Fluor 546 (1:2000 em PBS) por 1 hora à temperatura ambiente. Foram feitas novas lavagens e, em seguida, incubação com o DAPI (1:5000 em PBS) por 5 minutos à temperatura ambiente. As lâminas foram montadas em meio anti-fadding Prolong (Life technologies). As imagens foram obtidas no microscópio Leica TCS SP5 (Leica Microsystems, DEU).

\subsection{Análises Estatísticas}

Os resultados foram analisados estatisticamente utilizando programa GraphPad Prism 6.0, GraphPad Software, Inc. Os testes utilizados foram one-way ou two-way ANOVA para comparação de médias, seguido do pós-teste de Turkey ou test t de student não pareado. A significância estatística foi assumida com valor de $p \leq 0,05$. 


\section{Resultados}

\subsection{A LPC possui um efeito citotóxico e diminui a viabilidade celular de monócitos e células endoteliais humanas.}

A fim de verificar se a LPC possui um efeito citotóxico, monócitos (A), e células endoteliais (B), foram plaqueadas e estimuladas durante $24 \mathrm{~h}$ por diferentes concentrações de LPC, após o período de incubação o teste de MTT foi realizado e os dados analisados. Os dados demonstraram que a LPC diminui a viabilidade celular a partir de $10 \mu \mathrm{g} / \mathrm{mL}$ em monócitos humanos de forma dose dependente (Figura 1A). Já em células endoteliais a LPC diminuiu a viabilidade celular a partir da concentração de $20 \mu \mathrm{g} / \mathrm{mL}$ (Figura 1B). Desta forma, estes resultados comprovam que em altas concentrações a LPC possui um efeito citotóxico, diminuindo a viabilidade de diferentes tipos celulares. A partir destes resultados, a concentração de $1 \mu \mathrm{g} / \mathrm{mL}$ de LPC foi escolhida como concentração ideal de trabalho para grande parte dos ensaios.

A)

THP-1

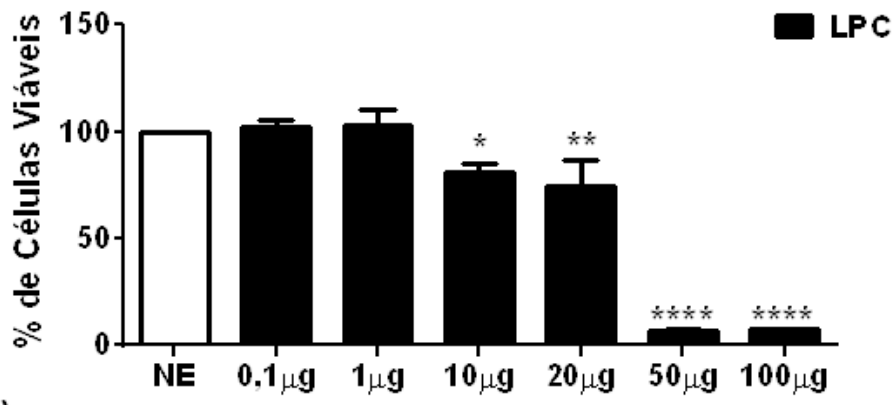

B)

HUVEC

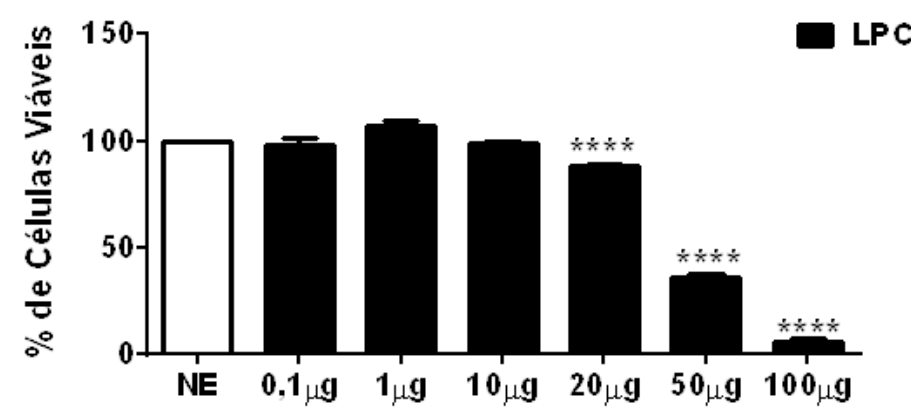

Figura 1: LPC diminui a viabilidade celular em monócitos e células endoteliais humanas. THP-1 (A) e HUVEC (B) foram plaqueadas e estimuladas com LPC nas concentrações de $0,1 \mu \mathrm{g} / \mathrm{mL}$, $1 \mu \mathrm{g} / \mathrm{mL}, 10 \mu \mathrm{g} / \mathrm{mL}, 20 \mu \mathrm{g} / \mathrm{mL}, 50 \mu \mathrm{g} / \mathrm{mL}$ e $100 \mu \mathrm{g} / \mathrm{mL}$ por $24 \mathrm{~h}$, Após os estímulos as células foram incubadas com MTT, a citotoxidade foi analisada pelas médias dos percentuais de células vivas em relação as células não estimuladas (NE) (consideradas $100 \%$ vivas). Cada barra representa a média do percentual \pm DP $(n=3)$ e * representa a diferença estatística significativa $(p<0,05)$ em relação ao NE. 


\subsection{LPC Induz a ativação de Caspase-1 em macrófagos murinos}

A atividade da enzima caspase-1 possui um importante papel no processamento e maturação da citocina IL-1 $\beta$ e na promoção da piroptose. Por este motivo, foi investigado se a LPC induziria a ativação de caspase-1. Macrófagos peritoneais foram estimulados com $1 \mu \mathrm{g} / \mathrm{mL}$ de LPC por diferentes tempos. Após o período de estimulação os macrófagos foram marcados com FLICA, e as células foram analisadas por citometria de fluxo. Os resultados demonstram que a LPC induziu a ativação da Caspase-1 a partir de 1h, com uma taxa de células positivas para FLICA de cerca de $45 \%$, em $3 \mathrm{~h}$ a porcentagem de células positivas para FLICA continua elevada com cerca de $40 \%$ e então a partir de $6 \mathrm{~h}$ e $24 \mathrm{~h}$ de estímulo observa-se um decréscimo da porcentagem de células positivas para FLICA, que corrobora para uma diminuição da ativação da caspase-1 em tempos mais tardios já descritos na literatura. Portanto, a LPC ativa caspase-1 de modo tempo dependente com picos de ativação em tempos iniciais de estimulação (Figura 2).

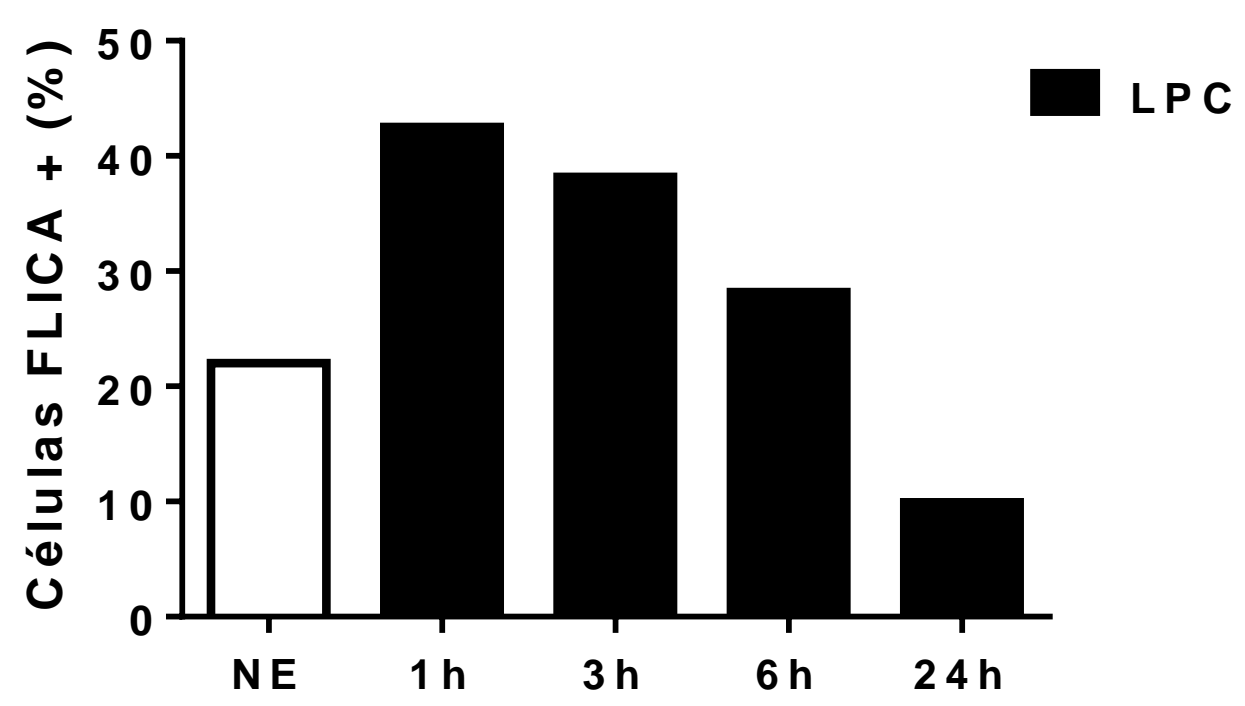

Fig. 2: LPC induz a ativação de Caspase-1 em macrófagos murinos de modo tempo dependente. Macrófagos peritoneais oriundos de camundongos C57/BL6 foram plaqueados e estimulados com $1 \mu \mathrm{g} / \mathrm{mL}$ de LPC por $1 \mathrm{~h}, 3 \mathrm{~h}, 6 \mathrm{~h}$ e $24 \mathrm{~h}$. Após os estímulos as células foram marcadas com FAMFLICA-Caspase-1, e em seguida as células foram analisadas por citometria de fluxo. As barras representam a porcentagem de células positivas para FLICA, e o gráfico representativo de três exprimentos independentes. Células não estimuladas (NE). 


\subsection{LPC induz a produção de ROS in vitro e in vivo}

Espécies reativas de oxigênio (ROS) são metabólitos de oxigênio que, devido à sua capacidade de ganhar e perder elétrons, são propensas a participar de reações de oxidaçãoredução. As células de mamíferos desenvolveram vários mecanismos para limitar a produção de ROS, entre elas desativá-los, e reparar os danos às células. No entanto, quando a taxa de produção de ROS aumenta dramaticamente e/ou as defesas antioxidantes são insuficientes ou falham, ocorre o estresse oxidativo. Esse estresse oxidativo é um importante sinal para a ativação do inflamassoma e desempenha um papel importante na patogênese da aterosclerose (Peluso et al. 2012; Yu \& Bennett 2014).

A fim de verificar se a LPC induz estresse oxidativo, via geração de ROS, células endoteliais e monócitos humanos foram estimulados com $1 \mu \mathrm{g} / \mathrm{mL}$ de LPC por diferentes tempos. Após o período de estimulo as células foram incubadas com a sonda DFC-DA e a geração de ROS analisada por citometria de fluxo. Nas células endoteliais a LPC induziu a geração de ROS a partir de 3h, e o pico de indução foi verificado com 6h,. Em 24 h houve um decréscimo da geração de ROS (Figura 3A). A partir destes resultados podemos concluir que a LPC induz a geração de ROS de modo tempo dependente em células endoteliais humanas. Já em monócitos humanos não houve geração de ROS via LPC em nenhum dos tempos verificados (Figura 3B).

Nos experimentos in vivo, camundongos C57/Black06 foram estimulados intraperitonealmente com $100 \mu \mathrm{g} / \mathrm{mL}$ de $\mathrm{LPC}$, por $24 \mathrm{~h}$, após o tempo de estimulo os camundongos foram sacrificados e as células do lavado peritoneal foram coletadas e marcadas com a sonda DFC-DA e a geração de ROS analisada por citometria de fluxo. Como já era esperado a LPC também induziu consideravelmente o estresse oxidativo, via produção de ROS in vivo (Figura 3C). 
A)

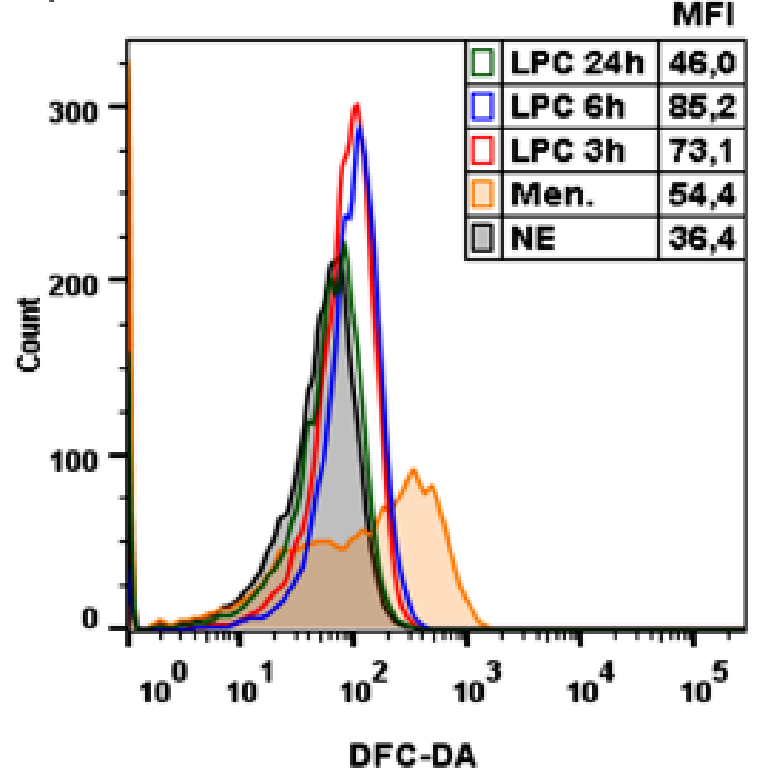

B)

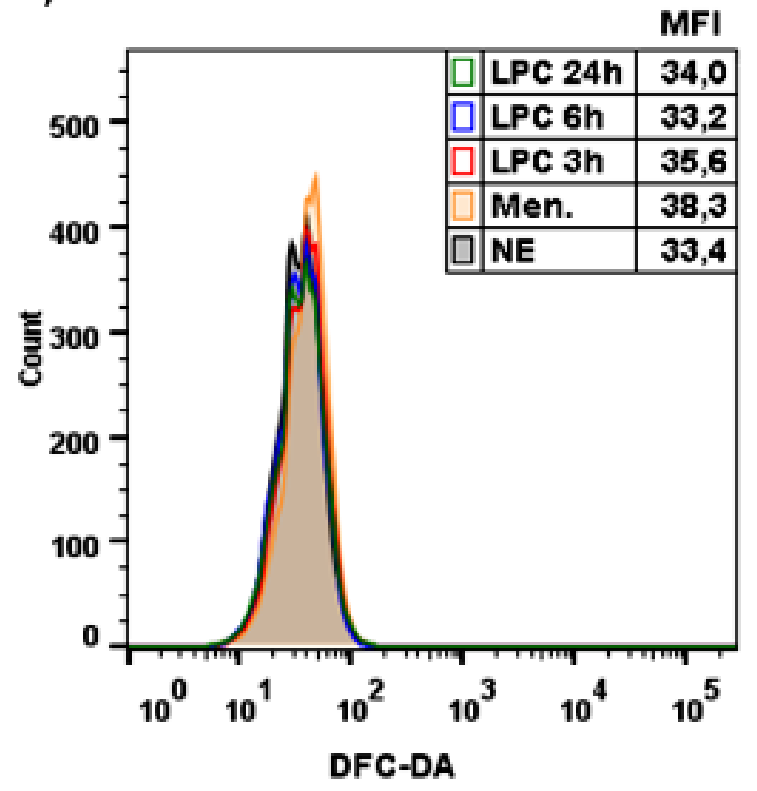

C)

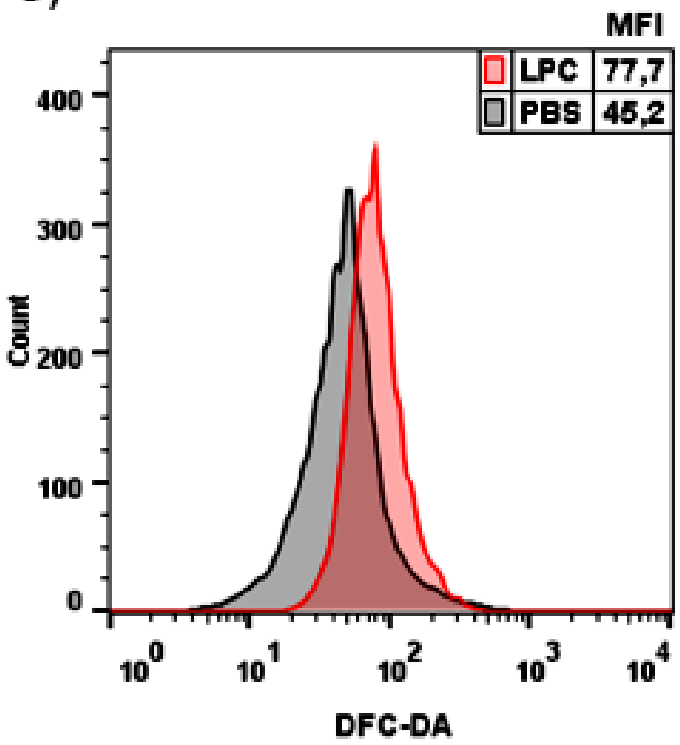

Fig.3: A indução da produção de ROS via LPC in vitro e in vivo. HUVEC (A) e THP-1(B) foram estimuladas com LPC $1 \mu \mathrm{g} / \mathrm{mL}$ por $3 \mathrm{~h}, 6 \mathrm{~h}$ e $24 \mathrm{~h}$, Após a estimulação as células foram marcadas com a sonda DFC-DA e a geração de ROS nas células foi analisada por citometria de fluxo. Como controle negativo foi usado células não estimuladas (NE) e para controle positivo células estimuladas com menadiona $100 \mu \mathrm{M}$ (Men.). (C) Macrófagos peritoneais coletados de camundongos C57/BL6 estimulados com $100 \mu \mathrm{g} / \mathrm{mL}$ de LPC, durante $24 \mathrm{~h}$, foram marcados com DFC-DA e a geração de ROS nas células também foi analisada por citometria de fluxo. Como controle negativo foi utilizado macrófagos peritoneais coletados de camundongos estimulados com PBS. Os histogramas são equivalentes à análise de células vivas. Os números são equivalentes à média de intensidade de fluorescência (MFI). Os histogramas (A) e (B) são representativos de dois experimentos distintos, enquanto o histograma (C) é representativo de um experimento com $\mathrm{N}=5$ animais. 


\subsection{LPC induz a secreção de IL-1ß em monócitos humanos}

A inflamação crônica da parede arterial é um elemento chave na patogênese da aterosclerose, dentre os fatores que desencadeiam a inflamação a ativação dos inflamassomas e a consequente secreção de IL-1 $\beta$ e IL-18 têm sido cada vez mais estudados devido a sua capacidade aterogênica (Liu et al. 2014). Sendo assim, fomos investigar se a LPC induz a ativação do inflamassoma e a secreção de IL-1 $\beta$ tanto em monócitos quanto em células endoteliais humanas. Para isso, monócitos THP-1 e células endoteliais HUVEC, foram tratadas e estimuladas da seguinte maneira: I) primadas com 500ng/mL de LPS por $4 \mathrm{~h}$, como primeiro sinal de ativação do inflamassoma, e estimuladas com $1 \mu \mathrm{g} / \mathrm{mL}$ de LPC, como segundo sinal de ativação do inflamassoma. II) Estimuladas apenas com a $1 \mu \mathrm{g} / \mathrm{mL}$ de LPC e III) Estimuladas com LPC como primeiro sinal da ativação do inflamassoma e depois tratadas com $1 \mathrm{mM}$ de ATP como segundo sinal.

Em monócitos, LPC induziu a secreção de IL-1 $\beta$ significativamente quando comparada aos monócitos não estimulados, entretanto podemos observar uma potencialização dessa secreção quando primamos os monócitos com LPS. Além disso, uma secreção semelhante a das células estimuladas somente com LPC foi observado em monócitos que receberam o ATP como segundo sinal (Figura 4A). Porém, em células endoteliais não observamos o mesmo fenômeno, nelas a LPC não induziu a secreção de IL-1 $\beta$ significativamente (Figura 4B). Também é importante notar que células endoteliais apresentaram níveis constitutíveis de IL$1 \beta$ nas células não estimuladas (Figura 4B). Portanto, nossos dados demonstram um papel importante da LPC na ativação do inflamassoma, onde este lipídeo foi capaz de ativar o inflamassoma tanto sozinha quanto atuando como primeiro e/ou segundo sinal para a secreção de IL-1 $\beta$. 


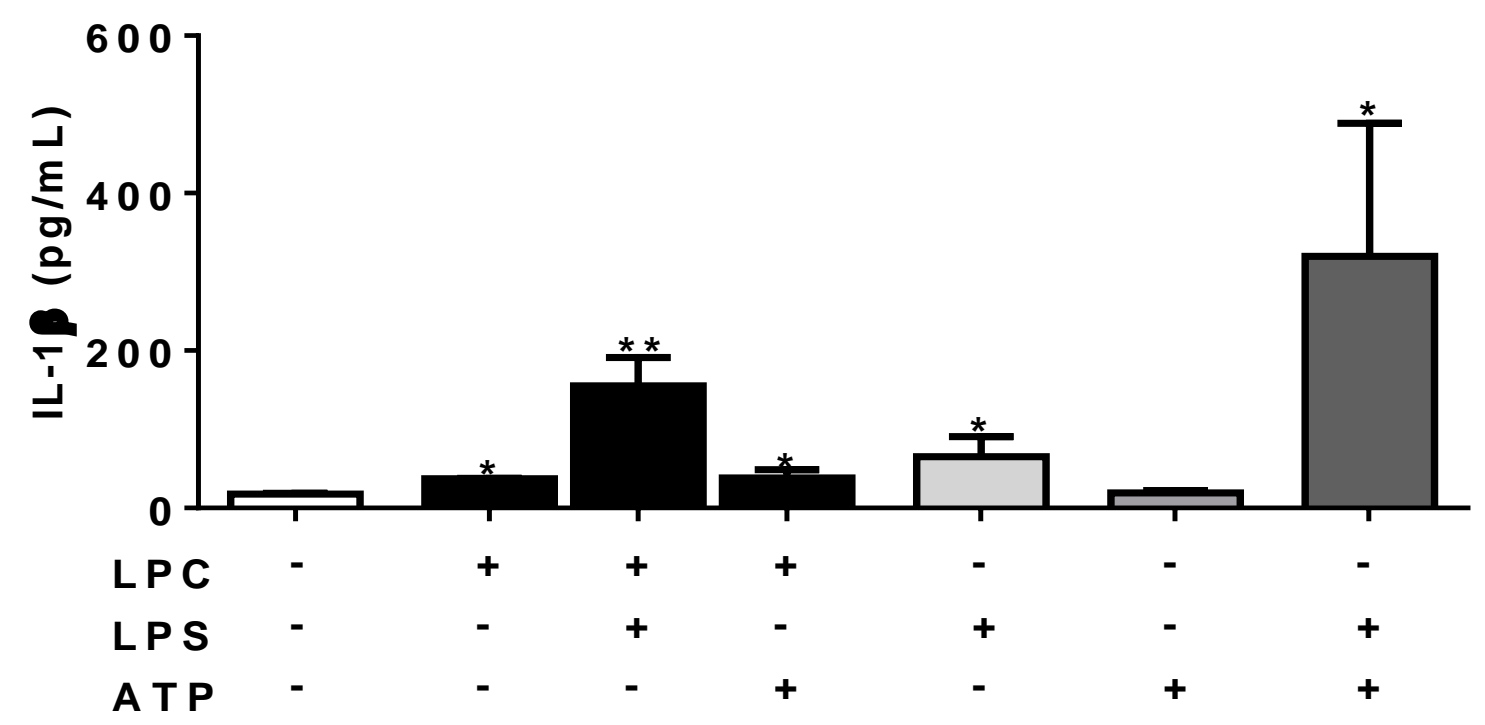

B )

HUVEC

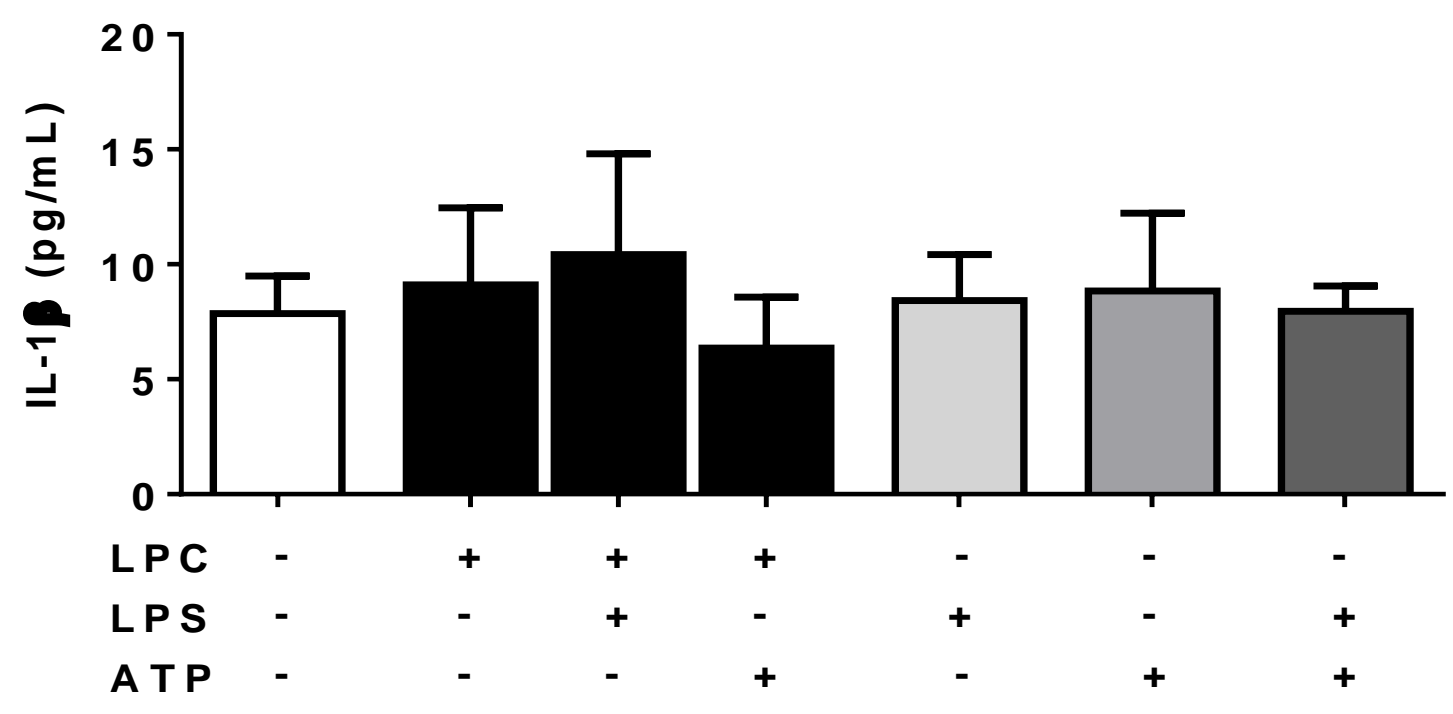

Fig.4: LPC induz a secreção de IL-1ß em monócitos humanos. Monócitos THP-1 (A) e células endoteliais HUVEC (B) foram plaqueadas e tratadas da seguinte maneira: um grupo foi primado com $500 \mathrm{ng} / \mathrm{mL}$ de LPS por $4 \mathrm{~h}$ antes do estímulo de LPC $1 \mu \mathrm{g} / \mathrm{mL}$, outro grupo foi estimulado somente com LPC $1 \mu \mathrm{g} / \mathrm{mL}$ e um ultimo grupo foi estimulado com $1 \mu \mathrm{g} / \mathrm{mL}$ de LPC e uma hora antes da coleta do sobrenadante tradas com $1 \mathrm{mM}$ de ATP. Como controles foram usados células sem tratamento e estímulos, tratadas somente com LPS, somente com ATP e células tratadas com ambos, controle positivo. O sobrenadante foi recolhido após aproximadamente $24 \mathrm{~h}$ de estimulação, e os níveis de IL$1 \beta$ foram dosados pela técnica de ELISA. Cada barra representa a média da concentração \pm DP. Os dados são de um experimento em triplicata. Diferenças estatísticas entre os grupos foram representados por asteriscos em comparação com as células sem tratamento $* \mathrm{p} \leq 0.05$ 


\subsection{Mecanismos de secreção de IL-1ß induzida por LPC}

Vários mecanismos estão associados à ativação do inflamassoma e a secreção de IL-1ß. O inflamassoma NLRP3 é o inflamassoma mais conhecido e bem estudado, entretanto como a LPC poderia estar ativando esse inflamassoma e seus mecanismos de ativação, ainda são desconhecidos. Sabe-se que a ativação do inflamassoma NLRP3 é caracterizada por um primeiro sinal que pode ser um DAMP ou PAMP que via receptores de membrana, como os da família dos TLRs, desencadeiam a ativação de fatores de transcrição como o NFkB a transcreverem os genes da pró-caspase-1, pró-IL1 $\beta$, ASC e NLRP3, entretanto um segundo sinal é necessário para a montagem desse complexo e sua ativação. Os segundos sinais conhecidos que exercem essa função, são as espécies reativas de oxigênio (ROS), o efluxo de potássio e dano lisossomal, o qual induz a liberação de enzimas lisossomais como a catepsinaB.

Para verificar se estes mecanismos estavam envolvidos na ativação do inflamassoma NLRP3 pela LPC, monócitos humanos foram pré-tratados durante uma hora com: A) Anticorpo neutralizante de TLR2; B) Inibidor de catepsina B; C) Inibidor de caspase-1; D) Inibidor de ROS; E) Inibidor de efluxo de potássio; F) Inibidor de NFкB; G) Desestabilizador de jangadas lipídicas (lipid rafts); e H) agonista de PPAR $\gamma$. Após os tratamentos os monócitos foram estimulados com $1 \mu \mathrm{g} / \mathrm{mL}$ de LPC, e aproximadamente $24 \mathrm{~h}$ depois da interação o sobrenadante foi coletado e os níveis de secreção de IL-1 $\beta$ foram dosados pela técnica de ELISA.

Os resultados mostraram que indução da secreção de IL-1 $\beta$ via LPC é dependente de reconhecimento via TLR2, uma vez que observou-se uma diminuição dos níveis de IL-1 $\beta$ nas células tratadas com anticorpo neutralizante de TLR2 quando comparadas com as células estimuladas com LPC (Figura 5A). Os resultados demonstraram também que a LPC induz a secreção de IL-1 $\beta$ independente de caspase-1, uma vez que os níveis de IL-1 $\beta$ gerados nas células tratadas com inibidor de caspase-1 e não tratadas foram similares (Figura 5C). A

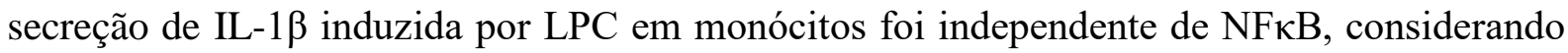

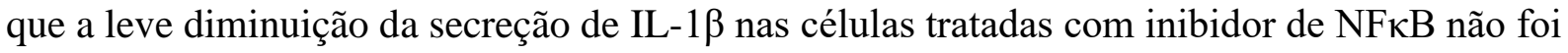
significativa quando comparadas as células estimuladas apenas com LPC (Figura 5F).

Com relação aos mecanismos envolvidos nos segundos sinais de ativação do inflamassoma, a secreção de IL-1 $\beta$ mediada por LPC foi independente da geração de espécies reativas de oxigênio, pois não houve diminuição da secreção de IL-1 $\beta$ nas células tratadas com o inibidor de ROS, NAC (Figura 5D), e Rotenona (Dados não mostrados), quando 
comparada com as células estimuladas apenas com LPC. Entretanto a secreção de IL-1 $\beta$ via LPC é dependente do efluxo de potássio (Figura 5E) e dano lisossomal (Figura 5B), pois houve uma redução significativa nos níveis de IL-1 $\beta$ nas células tratadas com os respectivos inibidores quando comparado com as células estimuladas apenas com LPC. O PPAR $\gamma$ e as jangadas lipídicas (lipid rafts) presentes na membrana plasmática, são fatores importantes no metabolismo lipídico. Nossos resultados mostraram que eles apresentam um papel importante na secreção de IL-1 $\beta$ mediada por LPC, uma vez que em células tratadas com os inibidores de PPAR $\gamma$ e lipid rafts houve uma diminuição significativa da secreção de IL-1 $\beta$ quando comparada com monócitos estimulados apenas por LPC (Figuras 5G e 5H). 
A)

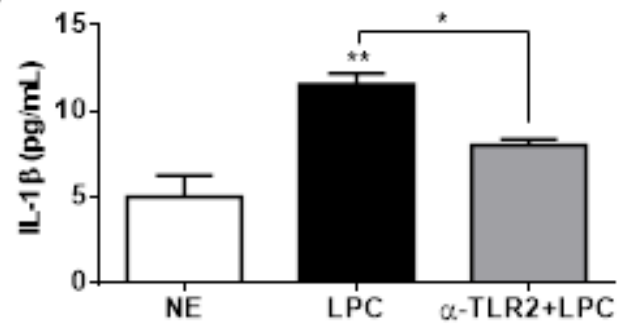

C)

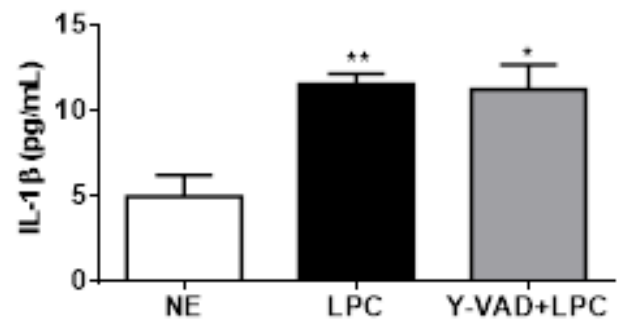

E)

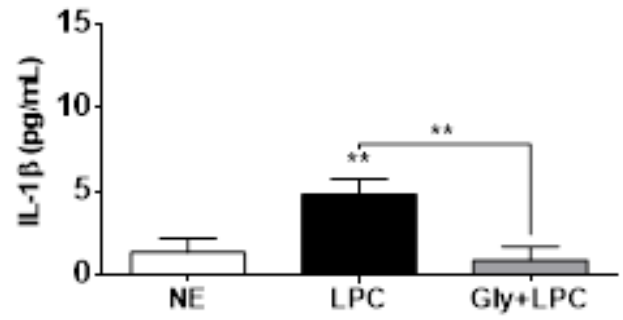

G)

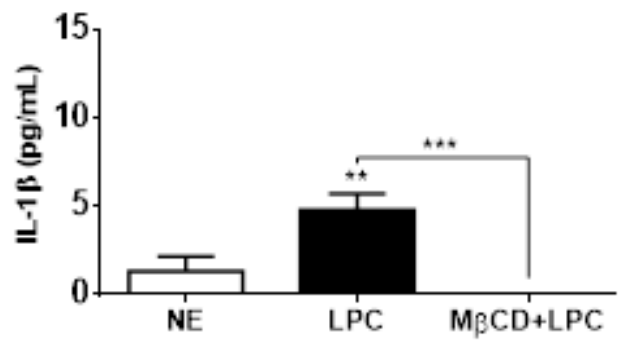

B)

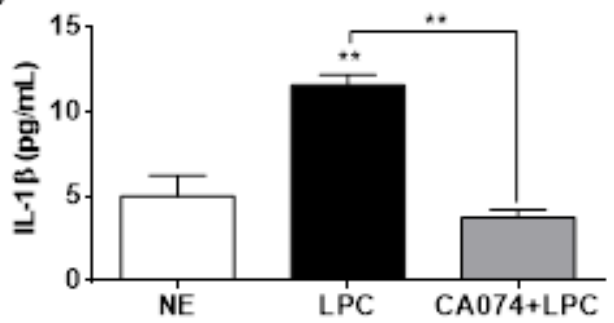

D)

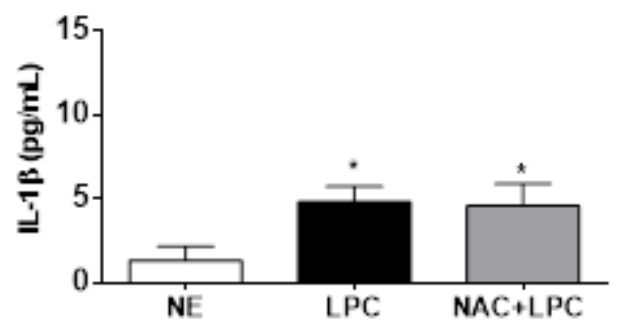

F)

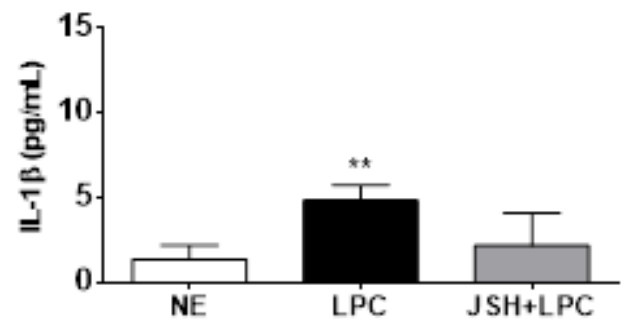

H)

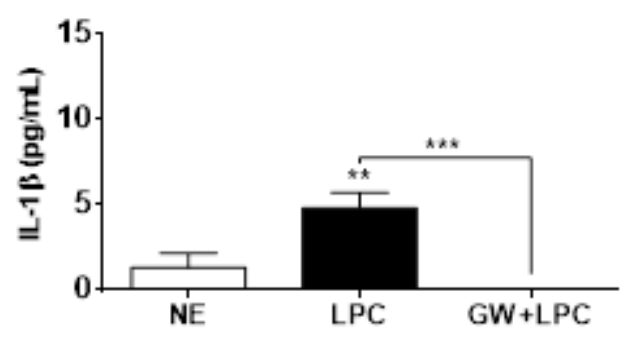

Fig.5: LPC induz a secreção de IL-1ß dependente de TLR-2, dano lisossomal, efluxo de potássio, estabilização de jangadas lipídicas, NFkB e PPAR $\gamma$. Monócitos THP-1 foram pré-tratados com (A) anticorpo bloqueador de TLR-2( $\alpha$-TLR2); (B) Inibidor de catepsina B , CA074-ME (CA074) ; (C) Inibidor de caspase-1, Ac-YVAD-cho (Y-VAD); (D) Inibidor de ROS, N-Acetil-L-Cisteina (NAC); (E) Inibidor de Efluxo de potássio, Glibenclamida (Gly); (F) Inibidor de NFkB, JSH-23 (JSH); (G) Desestabilizador de jangadas lipídicas , Metil- $\beta$-ciclodextrina (MBCD); (H) Antagonista de PPAR- $\gamma$, GW9662 (GW) por uma hora e em seguidas estimuladas com $1 \mu \mathrm{g} / \mathrm{mL}$ de LPC, após aproximadamente $24 \mathrm{~h}$ de interação o sobrenadante foi coletado e os níveis de secreção de IL-1 $\beta$ foram dosados pela técnica de ELISA. Os gráficos são representativos de três experimentos distintos e os dados são de um experimento em triplicata. Cada barra representa a média da concentração \pm DP. Diferenças estatísticas entre os grupos foram representados por asteriscos em comparação com as células sem tratamento e com as células estimuladas com LPC $* \mathrm{p} \leq 0.05$. 


\subsection{A secreção de IL-1ß em camundongos estimulados com LPC}

A fim de verificar se a LPC induz a secreção de IL-1 $\beta$ in vivo, e entender se essa secreção é dependente ou não de NLRP3 e Caspase-1/11 in vivo, camundongos C57/BL6 selvagens e nocautes para Caspase-1/11 e NLRP3 foram estimulados via intraperitoneal ou via intravenosa com $100 \mu \mathrm{g} / \mathrm{mL}$ de LPC, por $24 \mathrm{~h}$. Após o tempo de estimulo os camundongos foram sacrificados e seu sangue coletado para obtenção do soro, nos quais os níveis de secreção de IL-1 $\beta$ foram dosados pela técnica de ELISA. Nossos resultados demonstram que embora a LPC tenda a induzir um aumento na secreção de IL-1 $\beta$, tanto intraperitonealmente quanto via intravenosa em camundongos selvagens, esse aumento não foi estatisticamente significativo, assim como a tendência dessa secreção ser dependente de NLRP3 (Figura 6A) e Caspase-1/11 (Figura 6B). Desta forma, são necessários outros experimentos e novas repetições, testando outras concentrações de LPC e outros tempos de estimulação in vivo.

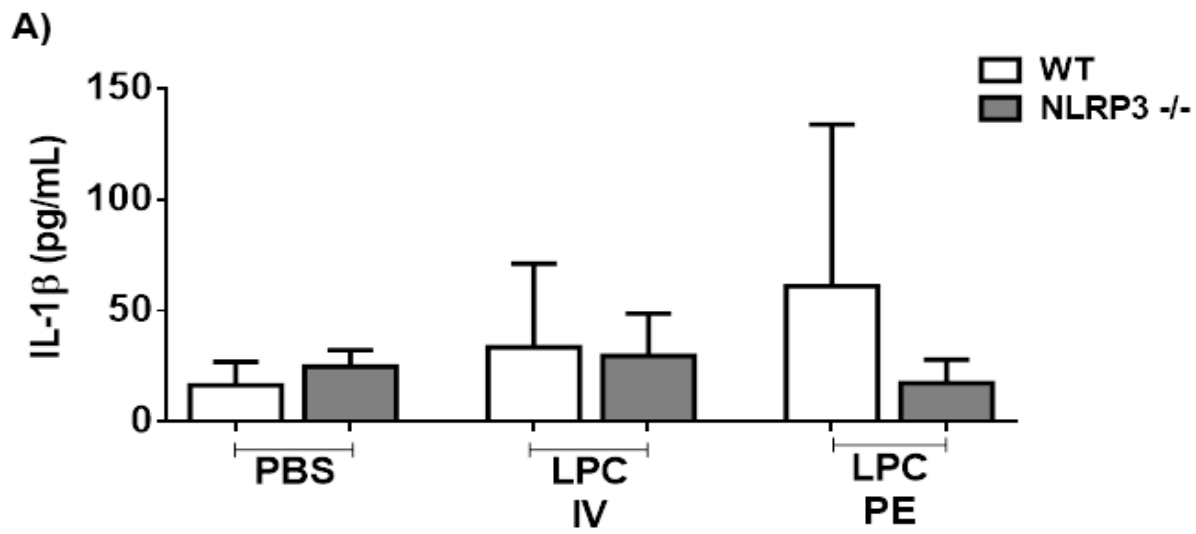

B)

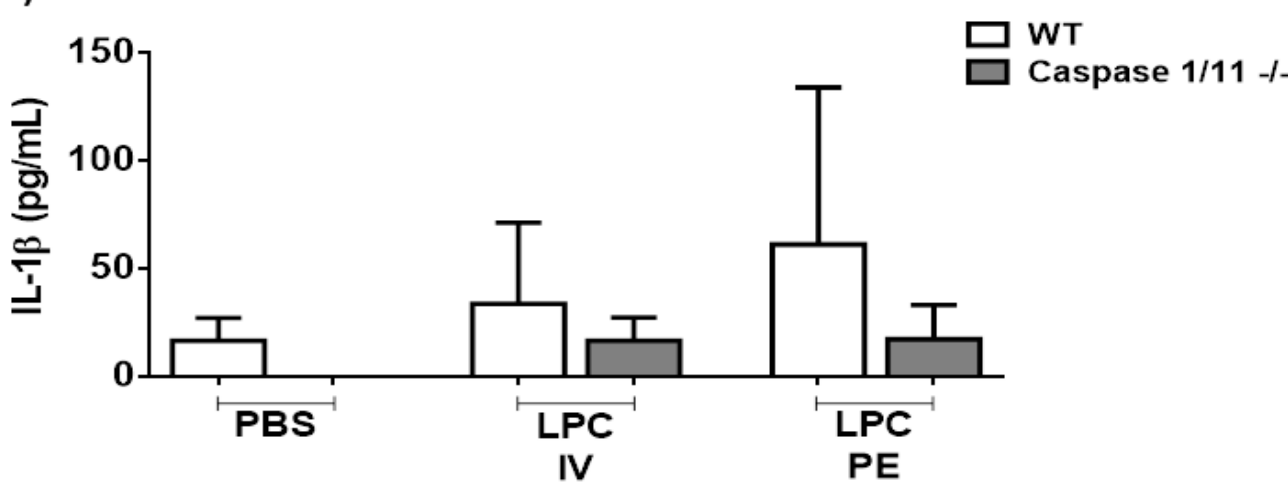

Fig.6: Secreção de IL-1ß induzida por LPC in vivo. Camundongos C57/BL6 Selvagens (WT) e Nocautes para o inflamassoma NLRP3 e Caspases-1/11 foram infectados com $100 \mu \mathrm{g} / \mathrm{mL}$ de LPC intraperitonealmente (PE) ou via intravenosa (IV) e com PBS como controle negativo. Após 24h o sangue dos camundongos foi coletado para obtenção de soro, neste foi dosado a quantidade de IL-1 $\beta$ secretada por ELISA. Os gráficos são representativos de um único experimento e os dados são de um $\mathrm{n}$ de 5 animais. Cada barra representa a média da concentração \pm DP. Não foram encontradas diferenças significativas entre os grupos. 


\subsection{LPC induz a translocação do HMGB1 para o citoplasma em monócitos e células endoteliais}

A HMGB1 é uma proteína de alta mobilidade, não histônica, com papel estrutural na arquitetura cromossômica que geralmente é encontrada no núcleo. Durante a inflamação, ativação celular e morte celular, estas proteínas translocam para o citoplasma. A translocação de HMGB1 para o citoplasma ocorre após a ativação da caspase-1 por diferentes inflamassomas, levando a sua consequente secreção. Após ser secretada por células do sistema imune, a HMGB1 funciona como um DAMP que desencadeia a resposta inflamatória em diversas células, podendo levar a morte por piroptose (Lamkanfi et al. 2010; Keyel 2014).

Para verificar se a LPC induz a translocação da HMGB-1 para o citoplasma, monócitos e células endoteliais foram estimuladas com $10 \mu \mathrm{g} / \mathrm{mL}$ de LPC durante $18 \mathrm{~h}$ e depois marcadas para microscopia confocal. Em monócitos (Figura 7A) e em células endoteliais (Figura 7B) a LPC induziu a translocação do HMGB1 para o citoplasma, quando comparadas com as células não tratadas. Indicando que a HMGB1 pode estar envolvida na indução da piroptose mediada por LPC. 


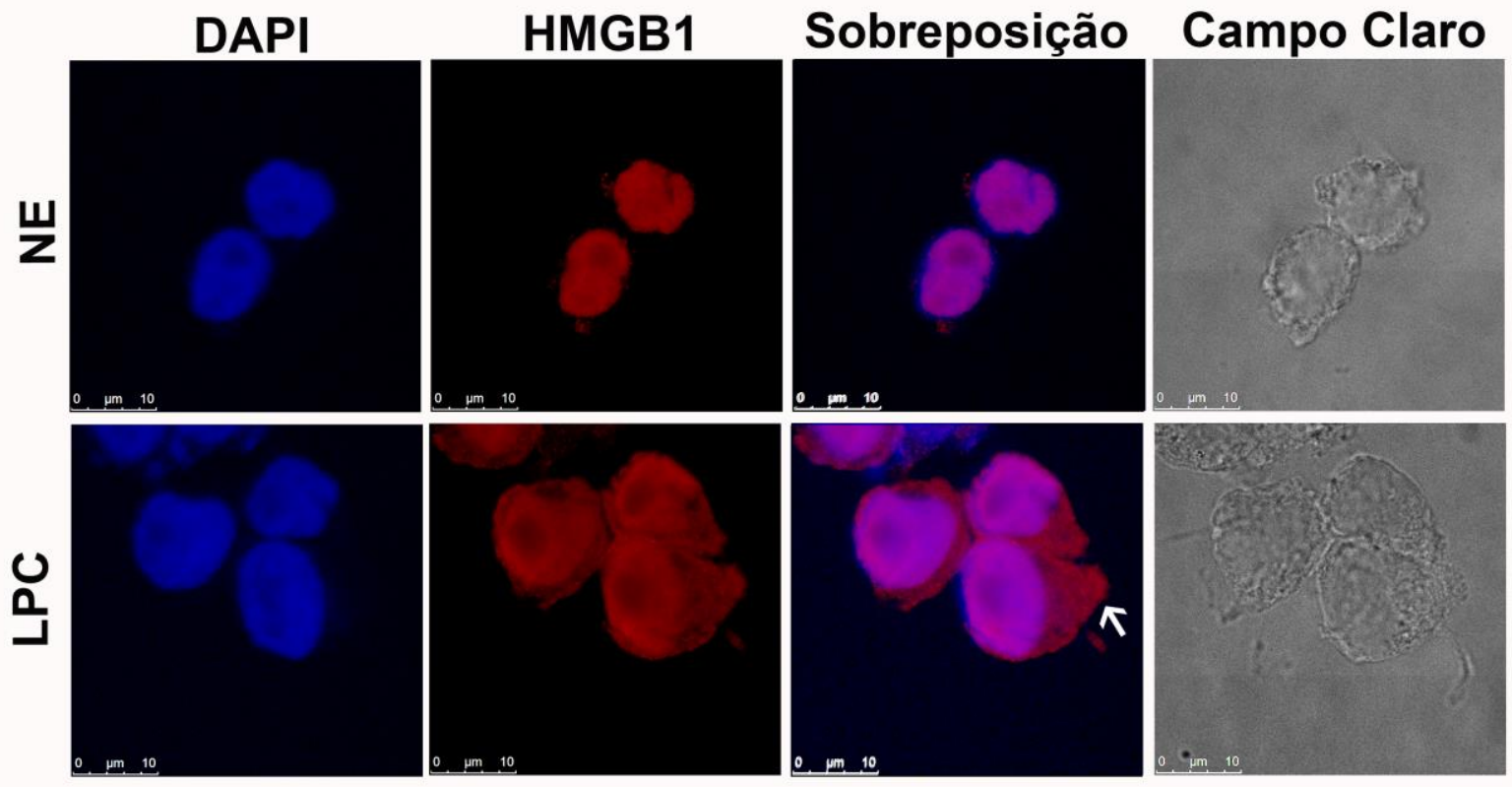

B)

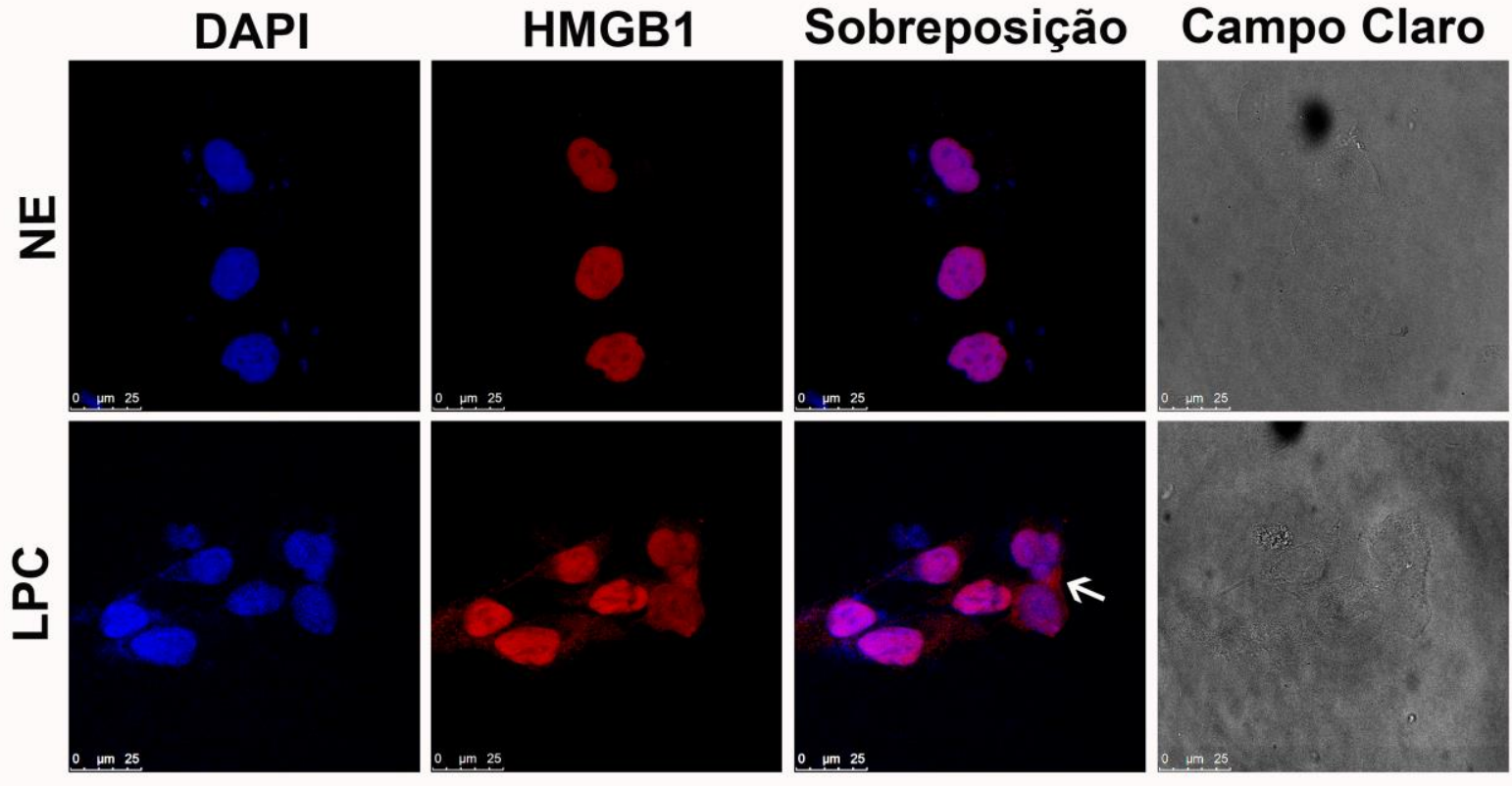

Fig.7: LPC induz a translocação da HMGB-1 para o citoplasma. THP-1 (A) e HUVEC(B) foram estimuladas com $10 \mu \mathrm{g} / \mathrm{mL}$ de LPC durante $18 \mathrm{~h}$, as células foram marcadas e as imagens obtidas por microscópio confocal Leica TCS SP5 com aumento de 63X e Zoom de 6 para THP-1 (A) e Zoom de 4 para HUVEC (B), as imagens são representativas de toda população das lâminas. O Núcleo das células foi corado com o DAPI que fluoresce em azul, a HMGB1 foi corada com anticorpo conjugado a fluoróforo Alexa 546 que fluoresce em vermelho, na figura nomeada sobreposição estão expostas as sobreposições das imagens do DAPI com o HMGB-1 para mostrar a localização da HMGB1 no citoplasma ou núcleo da célula e o Campo claro mostra as imagens das células sem marcadores fluorescentes para observação da morfologia celular. 


\subsection{LPC induz a biogênese de corpúsculos lipídicos em monócitos humanos}

Durante a aterosclerose, células gordurosas desempenham um papel importante no desenvolvimento dessa patologia, pois macrófagos fagocitam as oxLDLs e o colesterol presentes no local e armazenam este conteúdo em corpúsculos lipídicos (CL), o que é crítico para o estabelecimento e manutenção do estado inflamatório característico da aterosclerose. Nos macrófagos gordurosos a formação de cristais de colesterol pode ativar o inflamassoma NLRP3, levando a secreção de IL-1 $\beta$. Nossos dados já comprovaram que a LPC induz a ativação do inflamassoma e a secreção de IL-1 $\beta$, entretanto não estava claro se a LPC seria capaz de induzir a formação de células gordurosas através da biogênese de CL.

Para isso, monócitos foram estimulados com $1 \mu \mathrm{g} / \mathrm{mL}$ de LPC, durante $24 \mathrm{~h}$ e em seguida marcados com a sonda fluorescente bodipy, que marca lipídeos neutros presentes nos CL. A formação de CL foi analisada quantitativamente, por citometria de fluxo (Figura 8A) e morfologicamente, por microscopia de fluorescência confocal (Figura 8B). Como já era esperado a LPC induziu um aumento significativo na biogênese de CL em monócito humanos quando comparado com o controle não estimulado (NE), como pode ser visualizado no histograma e nas fotos de microscopia confocal. 


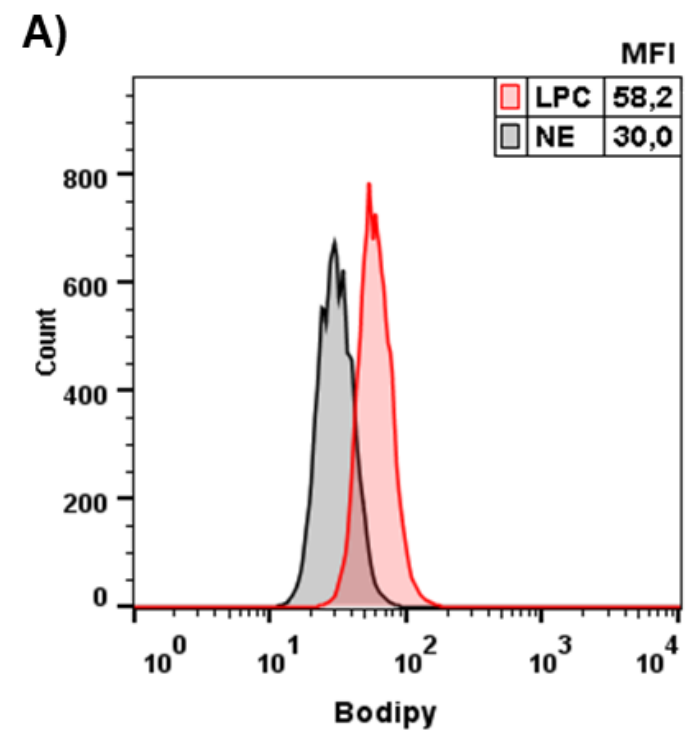

B)

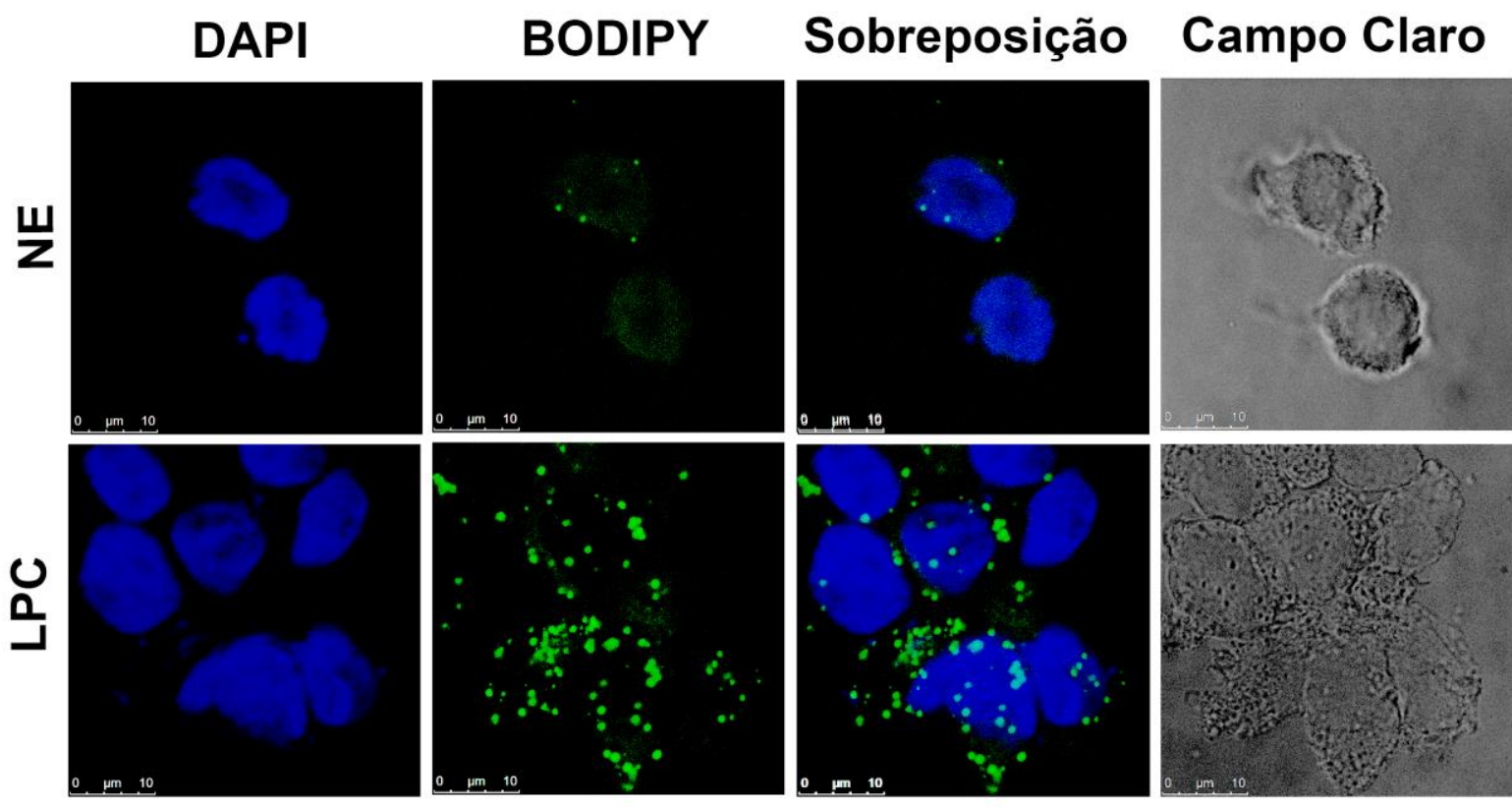

Fig.8: LPC induz o aumento da biogênese de corpúsculos lipídicos em monócitos humanos. Monócitos THP-1 foram estimulados com $1 \mu \mathrm{g} / \mathrm{mL}$ de LPC, e após $24 \mathrm{~h}$ de estimulação as células foram marcadas com a sonda fluorescente Bodipy e o aumento da biogênese de CL nas células foi analisada por citometria de fluxo e microscopia de fluorescência confocal. (A) O histograma é equivalente à análise de células vivas. Os números são equivalentes à média de intensidade de fluorescência (MFI). Esse histograma é representativo de 3 experimentos distintos. (B) mostra imagens obtidas por microscópio confocal Leica TCS SP5 com aumento de 63X e Zoom de 6, as imagens são representativas de toda população das lâminas de três experimentos realizados separadamente $(\mathrm{n}=3)$. O Núcleo das células foi corado em azul com o DAPI, os corpúsculos lipídicos foram corados em verde com Bodipy, na figura nomeada sobreposição estão expostas as sobreposições das imagens do DAPI com o bodipy para mostrar a localização dos corpúsculos no citoplasma da célula e o campo claro mostra as imagens das células sem marcadores fluorescentes para observação da morfologia da célula. Como controle foram usadas células não estimuladas (NE). 


\subsection{Mecanismos envolvidos na biogênese de CL em monócitos mediados por LPC}

Após verificarmos que a LPC induz um aumento significativo na biogênese de CL em monócitos, contribuindo para a formação de células gordurosas, fomos investigar por quais mecanismos a LPC induz esse fenômeno. Para isso usamos inibidores relacionados a via de ativação do inflamassoma e ao metabolismo lipídico, afim de compreender melhor a relação da formação de células de gordura com a ativação do inflamassoma e a secreção de IL-1 $\beta$.

Para essa investigação, monócitos humanos foram pré-tratados durante uma hora antes com: A) Inibidor de ROS; B) Inibidor de caspase-1; C) Inibidor de efluxo de potássio; D) Inibidor de catepsina B; E) Anticorpo neutralizante de TLR2; F) Inibidor de HMG-CoA redutase G) Inibidor de PPAR $\gamma$ e H) Desestabilizador de jangadas lipídicas. Após uma hora os monócitos foram estimulados com $1 \mu \mathrm{g} / \mathrm{mL}$ de LPC, e após aproximadamente $24 \mathrm{~h}$ de interação as células foram marcadas com a sonda fluorescente Bodipy, e a biogênese de CLs foi analisada quantitativamente, por citometria de fluxo.

Nossos resultados mostraram que a LPC induziu a biogênese de CL de maneira dependente do estresse oxidativo via produção de ROS, pois a fluorescência pra bodipy diminuiu em células tratadas com inibidores de ROS, Rotenona (Figura 9A) e NAC (Dados não mostrados), quando comparadas com as células não tratadas. Outro dado importante relacionado a via de ativação do inflamassoma é a dependência de caspase-1 para a produção de CL, induzida pela LPC (Figura 9B). Todavia, quando os monócitos foram tratados com inibidor de efluxo de potássio, não houve diminuição da produção de CL induzida pela LPC, mostrando que essa produção é independente de Efluxo de potássio (Figura 9C). Entretanto, como era esperado, quando inibimos a liberação de catepsina B, que é liberada quando temos dano lisossomal, diminuímos a produção de CL mediada por LPC (Figura 9D).

LPC como já era esperada, também induz a biogênese de CL dependente de reconhecimento via TLR2 (Figura 9E). Analisando fatores relacionados ao metabolismo lipídico, quando inibiu-se a enzima HMG-CoA redutase, importante na síntese de colesterol, observou-se uma diminuição expressiva na produção de CL mediada por LPC (Figura 9F). Outro resultado já esperado é a dependência de PPAR $\gamma$ (Figura 9G) e jangadas lipídicas (Figura 9H) para a formação de CL, induzida por LPC, pois são fatores importantes e que regulam a biogênese de CL. 
A)

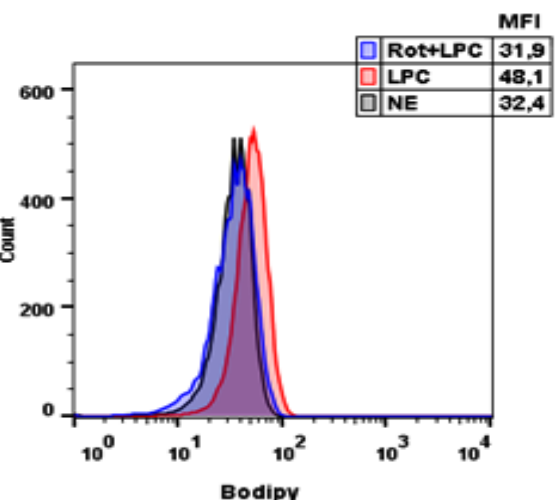

C)

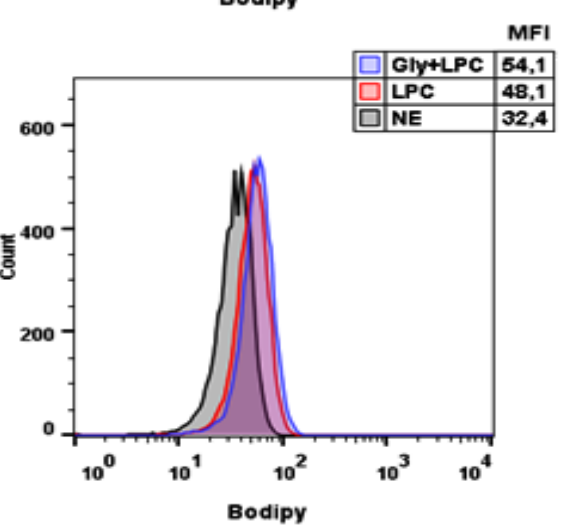

E)

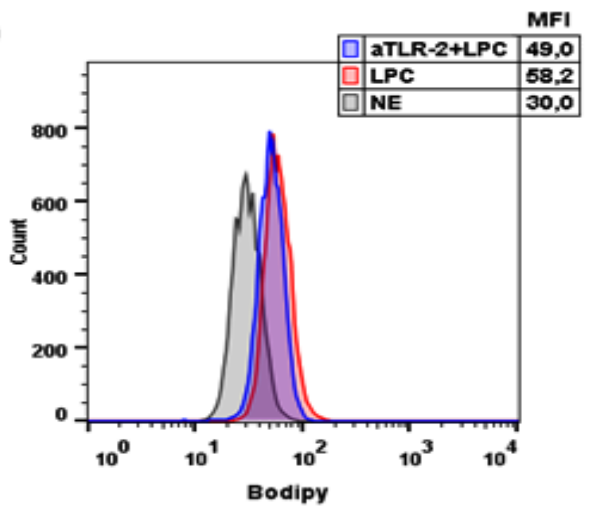

G)

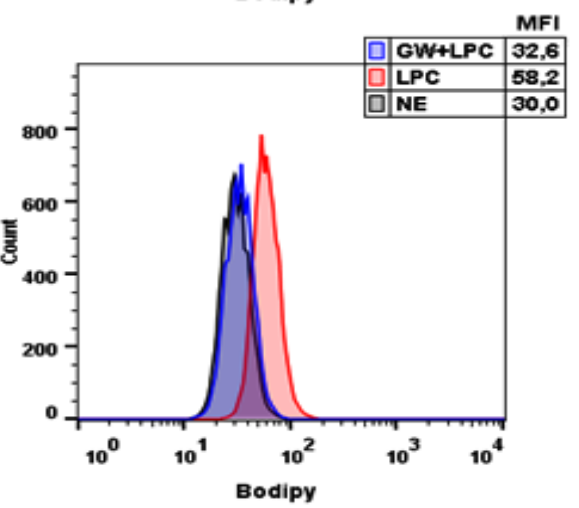

B)
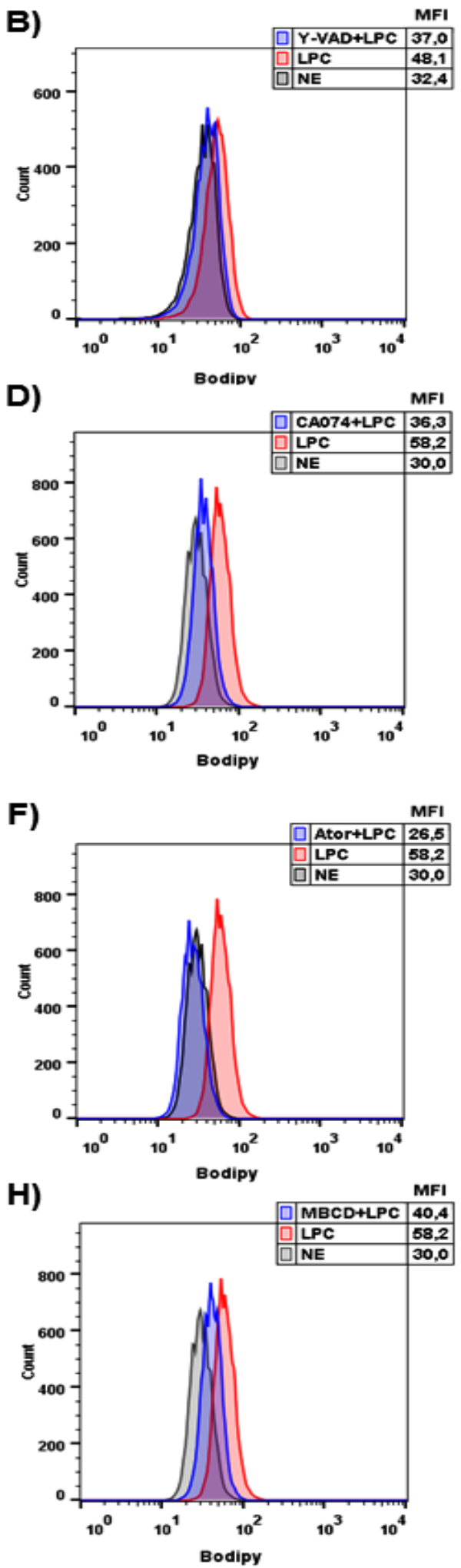

Fig.9: LPC induz a biogênese de corpúsculos lipídicos dependente de ROS, caspase-1, dano lisossomal, TLR-2, HMG-CoA redutase, PPAR $\gamma$ e estabilização de jangadas lipídicas em monócitos humanos. Monócitos THP-1 foram pré-tratados com: (A) Inibidor de ROS, Rotenona (Rot); (B) Inibidor de caspase-1, Ac-YVAD-cho (Y-VAD); (C) Inibidor de Efluxo de potássio, Glibenclamida (Gly); (D) Inibidor de catepsina B , CA074-ME (CA074); (E) anticorpo bloqueador de TLR-2( $\alpha$-TLR2) (F) Inibidor de HMG-CoA redutase, Atorvastatina (Ator); (G) Antagonista de PPAR- $\gamma$, GW9662 (GW) e (H) Desestabilizador de jangadas lipídicas, Metil- $\beta$-ciclodextrina (M $\beta C D)$; por uma hora e em seguidas estimuladas com $1 \mu \mathrm{g} / \mathrm{mL}$ de LPC, após aproximadamente $24 \mathrm{~h}$ de interação, as células foram marcadas com a sonda fluorescente Bodipy e o aumento da biogênese de CL nas células foi analisada por citometria de fluxo. Os histogramas são equivalentes à análise de células vivas. Os números são equivalentes à média de intensidade de fluorescência (MFI). Esses histogramas são representativos de três experimentos distintos. 


\subsection{LPC induz a biogênese de corpúsculos lipídicos em células endoteliais.}

Durante a aterosclerose, as células endoteliais desempenham um papel importante no desenvolvimento dessa patologia, pois secretam quimiocinas e fatores que atraem os monócitos circulantes para o sítio de formação da placa aterosclerótica, além de super expressarem moléculas de adesão que facilitam a diapedese dos leucócitos do vaso para o tecido. Entretanto, ainda não foi descrito na literatura se LPC seria capaz de induzir a biogênese de CL em células endoteliais. Como nossos resultados mostram que a LPC induz a biogênese de CL em monócitos humanos, fomos investigar se a LPC também poderia induzir o aumento da biogênese de CL e a sua diferenciação de células endotelial para célula gordurosa.

Para isso, células endoteliais foram estimuladas com $1 \mu \mathrm{g} / \mathrm{mL}$ de LPC, durante $24 \mathrm{~h}$ e em seguida marcadas com a sonda fluorescente Bodipy, a qual marca lipídeos neutros presentes nos CL. A formação de CL foi analisada quantitativamente, por citometria de fluxo (Figura 10A) e morfologicamente, por microscopia de fluorescência confocal (Figura 10B). Para nossa surpresa a LPC induziu um aumento significativo na biogênese de CL em células endoteliais quando comparado com o controle não estimulado (NE), o qual já possui uma grande quantidade de CL basais, como pode ser visualizado no histograma e nas fotos de microscopia confocal. 
B)

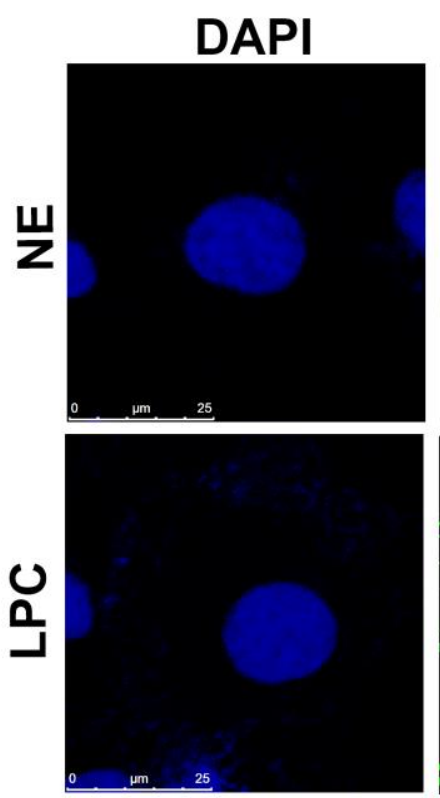

A)

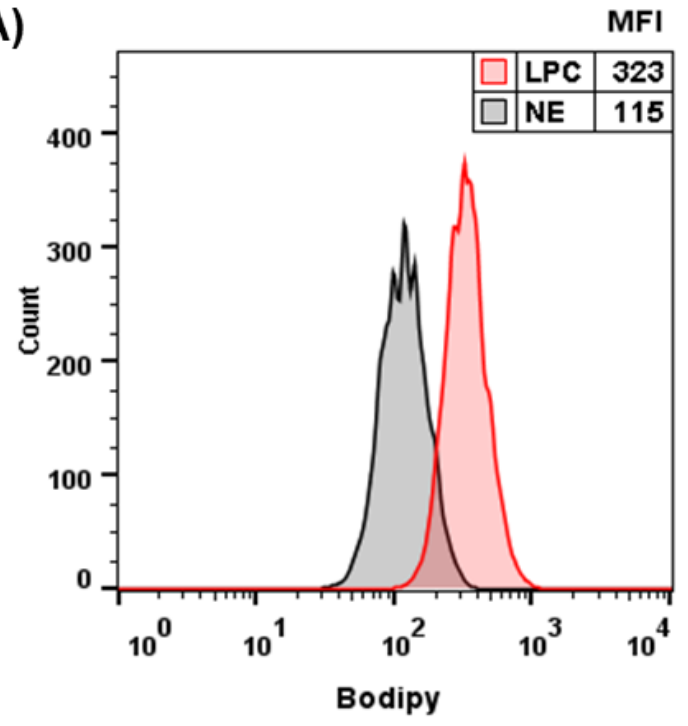

Fig.10: LPC induz o aumento da biogênese de corpúsculos lipídicos em células endoteliais. Células endoteliais HUVEC, foram estimuladas com $1 \mu \mathrm{g} / \mathrm{mL}$ de LPC, e após $24 \mathrm{~h}$ de estimulação as células foram marcadas com a sonda fluorescente Bodipy e o aumento da biogênese de CL nas células foi analisada por citometria de fluxo e microscopia de fluorescência confocal. (A) O histograma é equivalente à análise de células vivas. Os números são equivalentes à média de intensidade de fluorescência (MFI). Esse histograma é representativo de 3 experimentos distintos. (B) mostra imagens obtidas por microscópio confocal Leica TCS SP5 com aumento de 63X e Zoom de 4, as imagens são representativas de toda população das lâminas de três experimentos realizados separadamente $(\mathrm{n}=3)$. O Núcleo das células foi corado em azul com o DAPI, os corpúsculos lipídicos foram corados em verde com bodipy, na figura Sobreposição estão expostas as sobreposições das imagens do DAPI com o bodipy para mostrar a localização dos corpúsculos lipídicos no citoplasma da célula e o Campo claro mostra as imagens das células sem marcadores fluorescentes para observação da morfologia da célula. Como controle foram usadas células não estimuladas (NE). 


\subsection{Mecanismos envolvidos na biogênese de CL em células endoteliais mediados por LPC}

Após verificarmos que a LPC induz um aumento significativo na biogênese de CL em células endoteliais, fomos investigar por quais mecanismos a LPC induz esse fenômeno. Para isso, assim como nos monócitos, usamos inibidores relacionados a via de ativação do inflamassoma e ao metabolismo lipídico, afim de compreender melhor a relação da formação de células de gordura com a ativação do inflamassoma e a secreção de IL-1 $\beta$. Para essa investigação, células endoteliais foram pré-tratados durante uma hora antes com: A) Inibidor de ROS; B) Inibidor de caspase-1; C) Inibidor de efluxo de potássio; D) Inibidor de catepsina B; E) Anticorpo neutralizante de TLR-2; F) Inibidor de HMG-CoA redutase G) Antagonista de PPAR $\gamma$ e H) Desestabilizador de jangadas lipídicas. Posteriormente ao tratamento os monócitos foram estimulados com $1 \mu \mathrm{g} / \mathrm{mL}$ de LPC, e após aproximadamente $24 \mathrm{~h}$ de interação as células foram marcados com a sonda fluorescente Bodipy, e a formação de CL foi analisada quantitativamente, por citometria de fluxo.

Nossos resultados mostraram que a LPC induziu a biogênese de CL de maneira dependente do estresse oxidativo via geração de ROS, pois a fluorescência pra bodipy diminuiu significativamente em células tratadas com inibidor de ROS (Figura 11A), quando comparadas com as células não tratadas e estimuladas com LPC. Outro dado importante relacionado a via de ativação do inflamassoma é que LPC induziu a biogênese de CL em células endoteliais de maneira dependente de caspase-1 (Figura 11B). Ao contrário dos monócitos, quando as células endoteliais foram tratadas com inibidor de efluxo de potássio estimuladas com LPC, houve diminuição significativa da produção de CL, comparada com as células estimuladas apenas com LPC, mostrando que a biogênese de CL em células endoteliais é dependente de efluxo de potássio (Figura 11C). De forma semelhante, quando inibimos a liberação de catepsina B, que é liberada quando ocorre dano lisossomal, observou-se uma diminuição significativa da biogênese de CL induzida por LPC (Figura 11D). A indução da biogênese de CL por LPC em células endoteliais também dependente de reconhecimento via TLR2 (Figura 11E). Analisando fatores relacionados ao metabolismo lipídico, igualmente ao que ocorreu em monócitos, quando inibiu-se a enzima HMG-CoA redutase, importante na síntese de colesterol, observou-se uma diminuição significativa na biogênese de de CL induzida por LPC (Figura 11F). Outro resultado relevante é a dependência de PPAR $\gamma$ (Figura 11G) e jangadas lipídicas (Figura 11H) para a formação de CL em células endoteliais induzida por LPC, por serem fatores importantes na regulação da biogênese de CL. 
A)

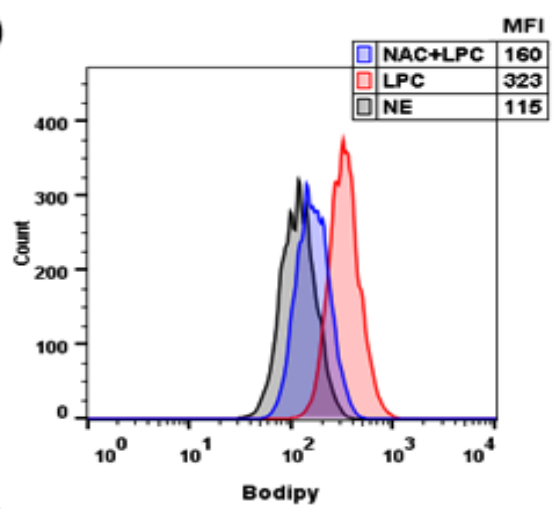

C)

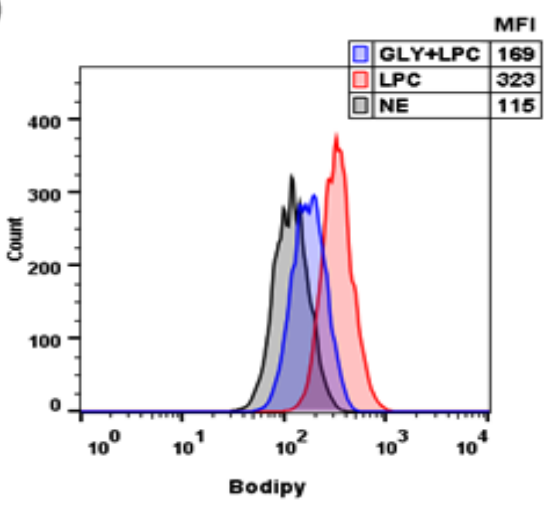

E)

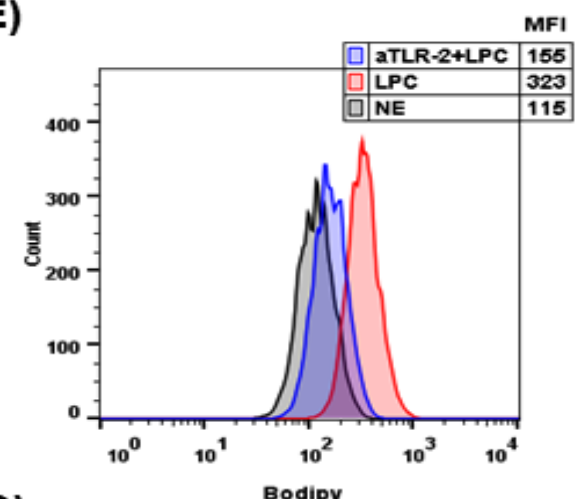

G)

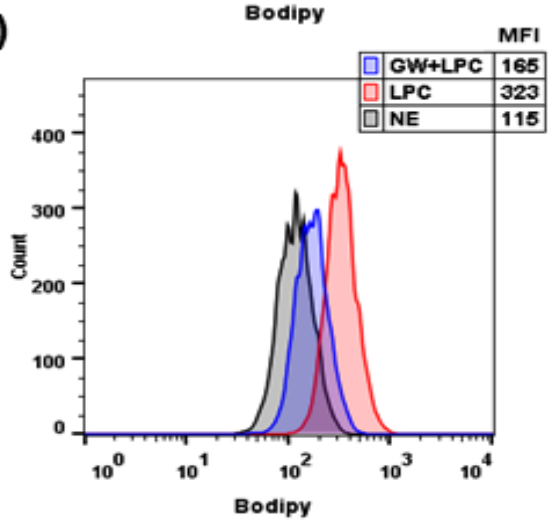

B)

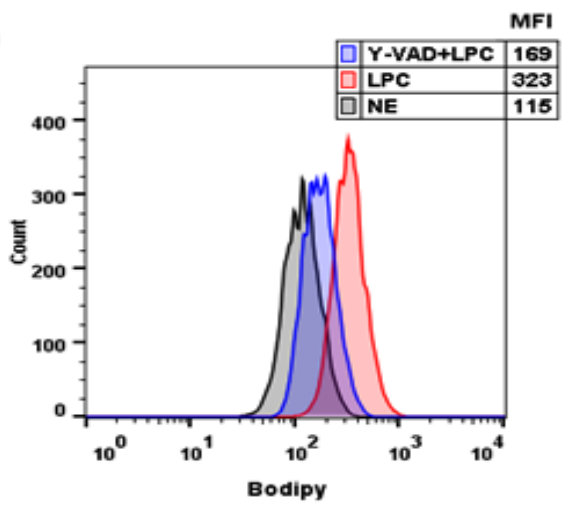

D)

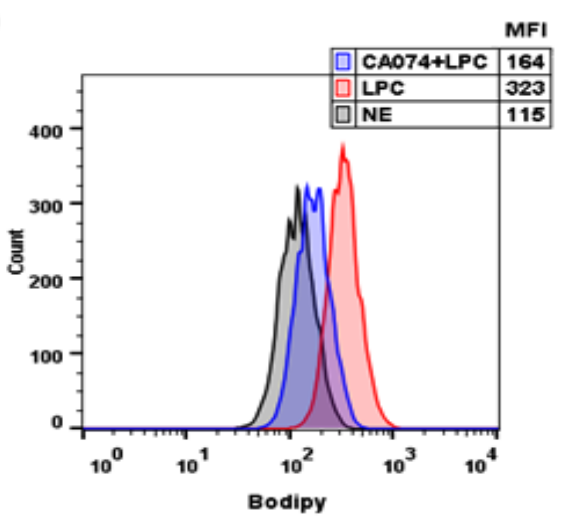

F)

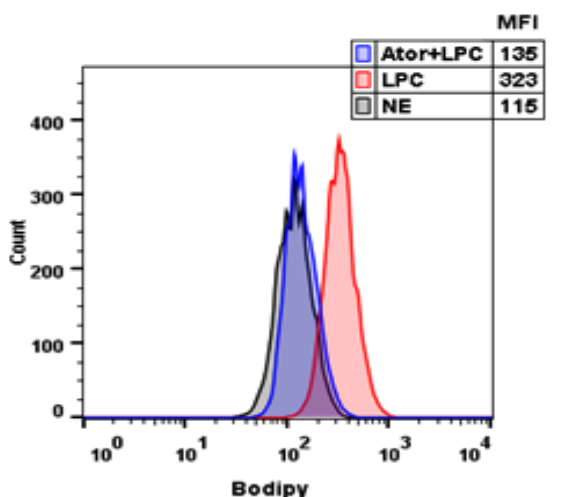

H)

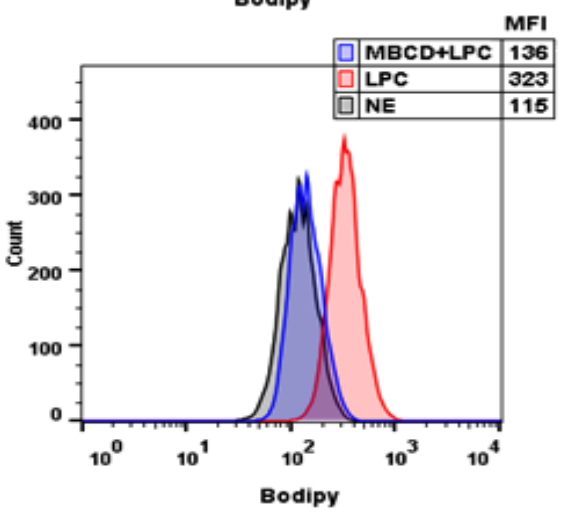

Fig.11: LPC induz a biogênese de corpúsculos lipídicos dependente de ROS, caspase-1, efluxo de potássio, dano lisossomal, TLR2, HMG-CoA redutase, PPAR $\gamma$ e estabilização de jangadas lipídicas em células endoteliais. HUVECs foram pré-tratados com: (A) Inibidor de ROS, N-Acetil-L-Cisteina (NAC); (B) Inibidor de caspase-1, Ac-YVAD-cho (Y-VAD); (C) Inibidor de Efluxo de potássio, Glibenclamida (Gly); (D) Inibidor de catepsina B , CA074-ME (CA074); (E) anticorpo neutralizante de TLR2( $\alpha$-TLR2) (F) Inibidor de HMG-CoA redutase, Atorvastatina (Ator); (G) Antagonista de PPAR- $\gamma$, GW9662 (GW) e (H) Desestabilizador de jangadas lipídicas , Metil- $\beta$ ciclodextrina $(\mathrm{M} \beta \mathrm{CD})$; por uma hora e em seguidas estimuladas com $1 \mu \mathrm{g} / \mathrm{mL}$ de LPC, após aproximadamente $24 \mathrm{~h}$ de interação, as células foram marcadas com a sonda fluorescente Bodipy e o aumento da biogênese de CL nas células foi analisada por citometria de fluxo. Os histogramas são equivalentes à análise de células vivas. Os números são equivalentes à média de intensidade de fluorescência (MFI). Histogramas representativos de dois experimentos distintos. 


\subsection{LPC induz a biogênese de CL in vivo, independente de Caspase-1/11 e NLRP3}

A fim de verificar se a LPC induz a biogênese de CL in vivo, e entender se essa produção é dependente ou não do inflamassoma NLRP3 e de Caspase-1/11 camundongos C57/BL6 selvagens e nocautes para Caspase-1/11 e NLRP3 foram estimulados intraperitonealmente com $100 \mu \mathrm{g} / \mathrm{mL}$ de $\mathrm{LPC}$, por $24 \mathrm{~h}$. Após o período de estímulo os camundongos foram sacrificados e as células do lavado peritoneal foram coletadas e marcadas com a sonda fluorescente Bodipy, e a biogênese de CL foi analisada quantitativamente, por citometria de fluxo.

Como já era esperado, a LPC também induz em camundongos, um aumento significativo da biogênese de CL em macrófagos peritoneais in vivo. Entretanto, nossos resultados demonstraram que a biogênese de CL induzida por LPC in vivo ocorreu de maneira independente de Caspase-1/11, e que na ausência dessas enzimas observa-se um aumento ainda mais significativo da biogênese de CL (Figura 12A). Além disso, a LPC induziu um aumento da biogênese de CL, em camundongos nocautes para o inflamassoma NLRP3, muito semelhante ao induzido em camundongos selvagens, confirmando assim que a biogênese de CL induzida por LPC ocorre de maneira independente da proteína NLRP3 (Figura 12B).
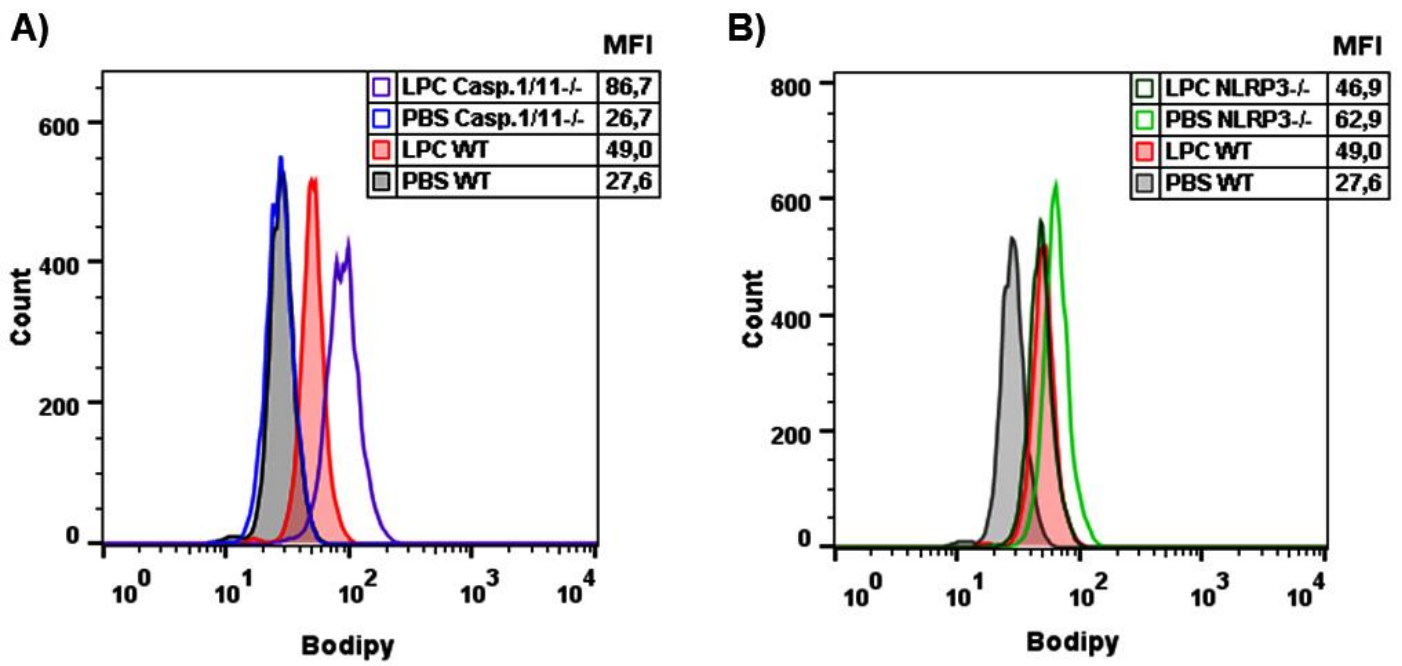

Fig.12: LPC induz um aumento na biogênese de $C L$ in vivo, independente do inflamassoma NLRP3 e das enzimas Caspase-1/11. Macrófagos peritoneais coletados de camundongos C57/Black06 selvagens (WT) e nocautes para o inflamassoma NLRP3 (NLP3-/-) e as caspases 1/11 (Casp.1/11 -/-) estimulados intraperitonealmente com $100 \mu \mathrm{g} / \mathrm{mL}$ de LPC, durante $24 \mathrm{~h}$, foram marcados com bodipy e o aumento da biogênese de CL nas células foi analisada por citometria de fluxo. Como controle negativo foi utilizado macrófagos peritoneais coletados de camundongos estimulados com PBS . Os histogramas são equivalentes à análise de células vivas. Os números são equivalentes à média de intensidade de fluorescência (MFI). Os histogramas (A) e (B) são representativos de um único experimento com $\mathrm{N}=5$ animais. 


\subsection{LPC induz a liberação de fatores pela célula endoteliais que medeiam a ativação de monócitos humanos}

Monócitos circulantes e células endoteliais são peças chave na formação das placas ateroscleróticas, tomados todos os dados desse trabalho em conjunto, percebemos que monócitos e células endoteliais respondem ao estimulo com LPC de maneira muito semelhante. Entretanto em um ambiente inflamatório essas células estão sempre em contato entre si trocando informações através da liberação de mediadores inflamatórios secretados ou expressão de moléculas de superfície. Baseado nesse contexto, nos perguntamos se monócitos estimulados pela LPC seriam capazes de ativar células endoteliais, e também o inverso, se células endoteliais estimuladas com LPC seriam capazes de ativar monócitos.

Sendo assim, fizemos um experimento de co-cultura, na qual estimulamos monócitos com LPC durante $24 \mathrm{~h}$ e transferimos o sobrenadante dessa interação para células endoteliais e deixamos em interação por mais $24 \mathrm{~h}$. O mesmo foi feito com células endoteliais, a qual estimulamos com LPC durante $24 \mathrm{~h}$ e transferimos o sobrenadante dessa interação para monócitos por mais $24 \mathrm{~h}$. Após o período de interação, avaliamos a ativação celular através da biogênese de CL por citometria de fluxo.

Nossos resultados mostraram que o sobrenadante de células endoteliais estimuladas com LPC induzem um aumento da biogênese de CL em monócitos, quando comparado com os monócitos tratados com o sobrenadante de células endoteliais sem estímulos, este aumento foi bem menor quando comparado com os monócitos estimulados diretamente com a LPC (Figura 13A).

Entretanto o mesmo fenômeno não foi observado em células endoteliais. Quando células endoteliais foram tratadas com o sobrenadante de monócitos estimulados com LPC, observou-se uma diminuição da biogênese de CL (Figura 13B). 
A)

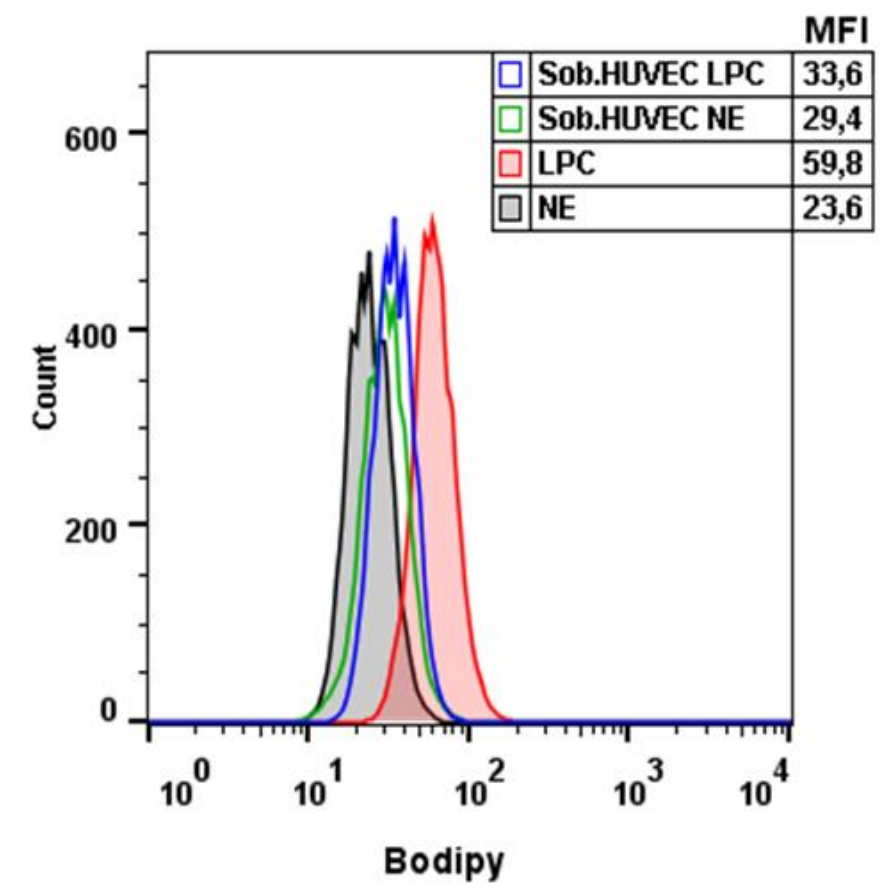

B)

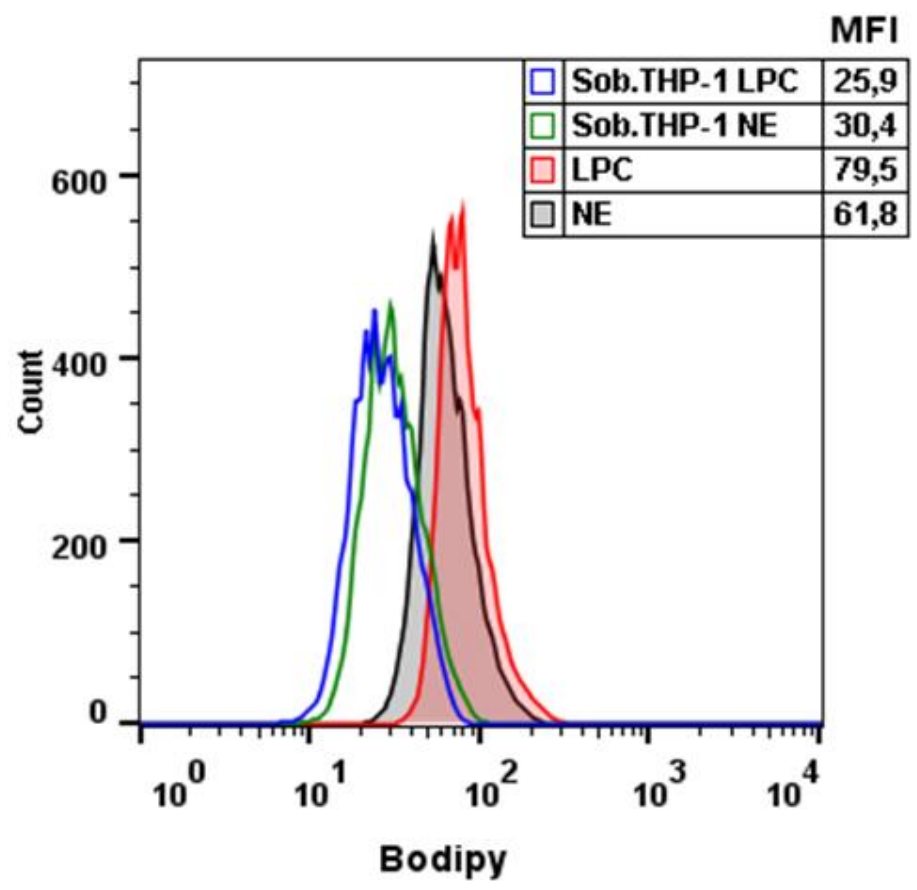

Fig.13: LPC induz a liberação de fatores pela célula endoteliais que medeiam a ativação de monócitos humanos. THP-1(A) estimuladas com $1 \mu \mathrm{g} / \mathrm{mL}$ de LPC e sobrenadante de HUVEC não estimulada e estimulada com LPC, durante $24 \mathrm{~h}$ foram marcadas com bodipy e analisadas por citometria de fluxo. HUVEC (B) estimuladas com $1 \mu \mathrm{g} / \mathrm{mL}$ de LPC e sobrenadante de THP-1 não estimuladas e estimuladas com LPC foram marcadas com bodipy e analisadas por citometria de fluxo. Os histogramas são equivalentes à análise de células vivas. Os números são equivalentes à média de intensidade de fluorescência (MFI). Os histogramas (A) e (B) são representativos de 4 experimentos distintos. 


\subsection{LPC induz a secreção de citocinas pró-inflamatórias por monócitos e células endoteliais.}

A fim de investigar a capacidade pró-inflamatória da LPC, fomos investigar se a LPC induz a secreção de outras citocinas pró-inflamatórias como a IL-6 e o TNF- $\alpha$ tanto em células endoteliais quanto em monócitos humanos. Para isso plaqueamos e estimulamos as células com $1 \mu \mathrm{g} / \mathrm{mL}$ de LPC e após $24 \mathrm{~h}$ coletamos o sobrenadante dessa interação e dosamos a quantidade de citocinas presentes neste sobrenadante pela técnica de ELISA.

Nossos dados comprovam que a LPC induz a secreção de TNF- $\alpha$ (Figura 14A) e IL-6 (Figura 14B) em quantidades significativas quando comparadas com o controle não estimulado (NE) em células endoteliais. Assim como em monócitos, a LPC possui o mesmo efeito pró-inflamatório induzindo também a secreção de TNF- $\alpha$ (Figura 14C) e IL-6 (Figura 14D) em níveis significativos quando comparadas com as células não estimuladas.

A)

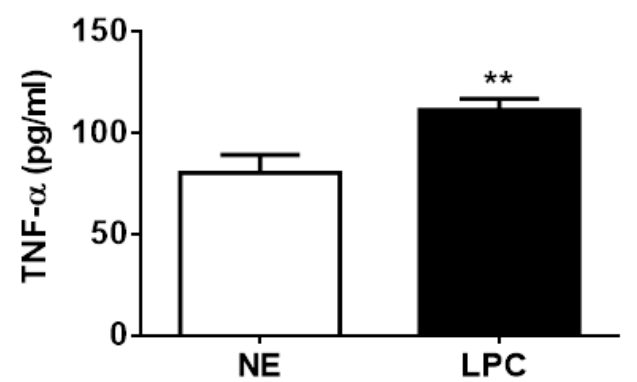

C)

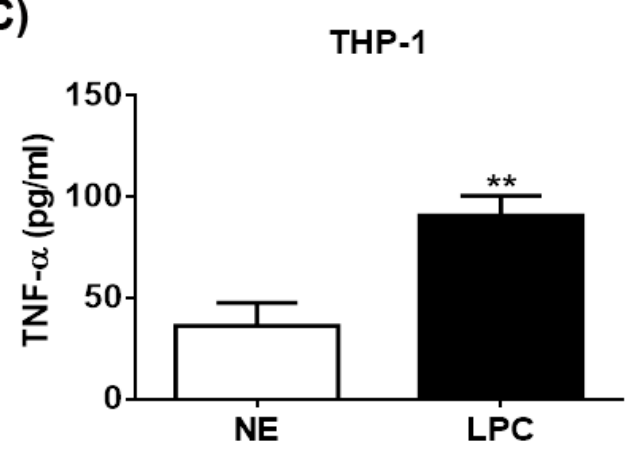

B)

HUVEC

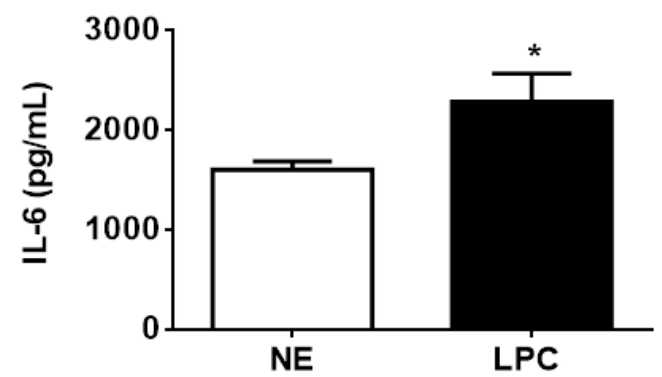

D)

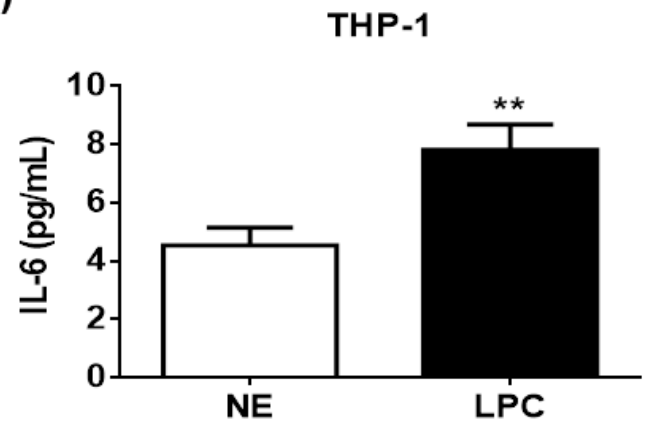

Fig.14: LPC induz a secreção de TNF- $\alpha$ e IL-6 por monócitos e células endoteliais humanas. THP-1 e HUVEC foram plaqueadas e estimuladas com $1 \mu \mathrm{g} / \mathrm{mL}$ de LPC durante $24 \mathrm{~h}$, após esse período o sobrenadante foi coletado e os níveis de secreção de TNF- $\alpha$ (A e C) e IL-6 (B eD)foram dosados pela técnica de ELISA. Os gráfico são representativos de 3 experimentos distintos e os dados são de um experimento em triplicata. Cada barra representa a média da concentração \pm DP. Diferenças estatísticas entre os grupos foram representados por asteriscos em comparação com as células não estimuladas $(\mathrm{NE}) * \mathrm{p} \leq 0.05$. 


\section{Discussão}

No presente trabalho, obtivemos resultados inéditos e outros que corroboram com o que já está descrito na literatura a respeito dos mecanismos de ativação do inflamassoma e secreção de IL-1 $\beta$, e a relação com a formação de células gordurosas, células endoteliais e seus mecanismos.

A principio fomos investigar a capacidade citotóxica da LPC, a fim de definirmos uma concentração de trabalho que não diminuísse a viabilidade das células a serem utilizadas durante o estudo. A partir dos resultados do ensaio de viabilidade celular, por MTT, vimos que em concentrações a partir de $10 \mu \mathrm{g} / \mathrm{ml}$ a LPC já começava a diminuir a viabilidade celular em monócitos. Já em células endoteliais a citotoxidade foi observada a partir de $20 \mu \mathrm{g} / \mathrm{ml}$. Desta maneira, comprovamos que em altas concentrações a LPC possui um efeito citotóxico que pode levar a morte celular. Resultados semelhantes também foram demonstrados por Takahashi e colaboradores (2002), que observaram que altas concentrações de LPC levaram células endoteliais à morte por apoptose, e que a partir de concentrações de $25 \mu \mathrm{M}$ de LPC, já ocorria à diminuição da viabilidade nessas células (Takahashi et al. 2002).

Definida a concentração de $1 \mu \mathrm{g} / \mathrm{ml}$ de uso de LPC para os ensaios in vitro, fomos investigar se a LPC induz a ativação de Caspase-1 em macrófagos murinos. As caspases consistem em uma família de proteases classicamente dividida em dois grupos de acordo com a sua função: as apoptóticas e as inflamatórias (Creagh 2014). As caspases são produzidas em sua forma inativa e ativadas através do inflamassoma ou piroptossoma (Guo et al. 2015; Fernandes-Alnemri et al. 2007). A ativação das caspases inflamatórias, em especial a caspase1, leva a clivagem e ativação das citocinas pró-inflamatórias IL-1 $\beta$ e IL-18 e à secreção destas, e também da proteína HMGB1 assim como de outras proteínas celulares (Keller et al. 2008; Lamkanfi et al. 2010). Nossos resultados mostraram que a LPC induz a ativação de caspase-1 durante as $6 \mathrm{~h}$ iniciais de estimulação, tempo suficiente para realizar suas atividades pró-inflamatórias. Estes dados são condizentes com os descobertos por Schiling e Eder (2010, 2011) que mostraram que a LPC induz a ativação de caspase-1 dependente de sódio e integridade das jangadas lipídicas em micróglias (Schilling \& Eder 2010; Schilling \& Eder 2011).

Outro importante mecanismo de ativação do inflamassoma e que está diretamente ligado à patogênese da aterosclerose é o estresse oxidativo, via produção de ROS. Sendo assim, fomos investigar a capacidade da LPC em induzir a produção de ROS in vitro e in vivo. Nossos resultados mostraram que a LPC induz a geração de ROS de modo tempo dependente 
em células endoteliais, corroborando os dados publicados por Kim e colaboradores (2009) que mostraram que LPC induz a produção de óxido nítrico e ROS levando a um estresse oxidativo e causando danos a células endoteliais (Kim et al. 2009). Um dado inédito, entretanto já esperado, foi o estresse oxidativo gerado em células peritoneais de camundongos estimulados com LPC in vivo, o qual ainda não está descrito na literatura.

Já é evidente que a LPC induz a secreção de IL-1 $\beta$ em monócitos humanos e em micróglias (Liu-Wu et al. 1998; Stock et al. 2006), entretanto por quais mecanismos a LPC induz a secreção de IL-1 $\beta$ ainda não estavam definidos. Nossos resultados demonstraram que a LPC induz a secreção de IL-1 $\beta$, funcionando tanto como o primeiro e/ou segundo sinal de ativação do inflamassoma em monócitos, esse resultado corrobora com o dado achado por Estruch e colaboradores (2015) que mostram que a LDL eletronegativa induz a secreção de IL-1 $\beta$ como primeiro e/ou segundo sinal de ativação do inflamassoma NLRP3 (Estruch et al. 2015). Entretanto não conseguimos ver a indução de secreção de IL-1 $\beta$ em células endoteliais via LPC, pois neste modelo celular ainda não se conhece fator que induza a ativação dos inflamassomas e a secreção de IL-1 $\beta$.

A ativação do inflamassoma NLRP3 por oxLDL leva ao acumulo de lipídeos por macrófagos resultando na formação de células gordurosas (Liu et al. 2014). Sabe-se que tanto a oxLDL quanto a LPC induzem a biogênese de CL (Silva et al. 2009; Magalhães et al. 2010). Nossos dados confirmaram que em monócitos a LPC é capaz de aumentar a biogênese de CL. Entretanto, um dado bem relevante que descrevemos no presente trabalho é que a LPC aumenta consideravelmente a quantidade de CL em células endoteliais, mostrando pela primeira vez que estas se transformam em células com um perfil semelhante ao de células gordurosas apresentando um perfil bem pró-inflamatório com abundante número de CLs.

Na busca por entendermos os mecanismos envolvidos na ativação do inflamassoma e na formação de células gordurosas induzidas pela LPC, fomos investigar o papel do receptor TLR2, o qual já se sabe que está envolvido no reconhecimento da LPC (Magalhães et al. 2010). Um dado inédito que nosso trabalho trouxe, foi que o reconhecimento da LPC por TLR2 é importante para a secreção de IL-1 $\beta$, bem como na biogênese de CL induzida pela LPC, tanto em monócitos quanto em células endoteliais humanas. Estes dados corroboram com os resultados anteriores do nosso grupo que já havia mostrado que a LPC depende do reconhecimento por TLR2 para induzir a biogênese de CL (Magalhães et al. 2010).

Schiling e Eder (2010) descobriram que a estabilidade das jangadas lipídicas são importantes pra LPC induzir a ativação de Caspase-1 e a geração de ROS em micróglias 
(Schilling \& Eder 2010). As jangadas lipídicas são microdomínios da membrana plasmática que possuem uma elevada concentração de colesterol e de esfingolípidos, agindo como plataformas para a organização e interação de proteínas envolvidas na sinalização celular e em várias funções celulares importantes, incluindo divisão, migração, fagocitose, e a liberação de diversas citocinas, quimiocinas entre outros. Baseados nessas informações, decidimos investigar o papel da estabilização das jangadas lipídicas na secreção de IL-1 $\beta$ e na formação de CL induzidos por LPC. Nossos resultados mostram um papel fundamental das jangadas lipídicas, tanto na secreção de IL-1 $\beta$ estimulados com LPC, quanto na formação de células gordurosas, pois a desestabilização das jangadas lipídicas diminui a biogênese de CL em monócitos e em células endoteliais.

Os receptores ativados por proliferador de peroxissomos, conhecidos como PPAR são um grupo de proteínas receptoras nucleares que funcionam como fatores de transcrição que regulam a expressão de genes e possuem diferentes isoformas. Os PPARs desempenham um papel essencial na regulação da diferenciação celular, desenvolvimento, e metabolismo lipídico (Berger \& Moller 2002). É sabido que a expressão de PPAR $\gamma$ em macrófagos está intimamente relacionada com a aterosclerose. Utilizando o modelo murino, Tontonoz e colaboradores (1998) evidenciaram que o PPAR $\gamma$ estava expresso em altos níveis no núcleo de células gordurosas isoladas de lesões ateroscleróticas (Tontonoz et al. 1998). Portanto fomos investigar o papel do PPAR $\gamma$ na secreção de IL-1 $\beta$ e na biogênese de CL induzidas por LPC. Nossos resultados mostraram que a inibição de PPAR $\gamma$ inibe a secreção de IL-1 $\beta$ induzido por LPC e ainda diminui a biogênese de CL, tanto em monócitos quanto em células endoteliais, sugerindo uma forte relação entre o metabolismo lipídico celular e a ativação do inflamassoma e consequente maturação e secreção de IL-1 $\beta$. Nossos dados estão de acordo com os descritos por Hou e colaboradores (2007) em que a LPC promove um efluxo de colesterol em células de gordura, dependente da via de ativação do PPAR $\gamma$ e LXF $\alpha$ associados com apoE (Hou et al. 2007).

$\mathrm{O}$ fator de transcrição nuclear $\mathrm{NF \kappa B}$ é um importante regulador gênico e pode ser encontrado em quase todos os tipos de células animais, o NFKB está envolvido na resposta celular a estímulos como o estresse, citocinas, radicais livres, radiação ultravioleta, oxidação de LDL e antígenos virais e bacterianos. Além de transcrever os genes responsáveis pelo complexo do inflamassoma em resposta ao PAMPs ou DAMPs (Bauernfeind et al. 2009). Sendo assim, fomos investigar se o NFאB estava sendo requerido para a secreção de IL-1 $\beta$ induzida por LPC, entretanto, nossos resultados mostram que quando o NFkB é inibido ocorre uma pequena diminuição dos níveis de IL-1 $\beta$ que não foram significativos, embora já se sabe 
que a LPC induz a translocação do NFאB e sua ativação dependente de reconhecimento e sinalização de TLR2 e TLR4 (Carneiro et al. 2013).

Durante a formação de células gordurosas, ocorre um grande efluxo de colesterol e oxLDL que são armazenadas nos CL, uma enzima localizada no tecido hepático, que produz mevalonato, uma pequena molécula usada na síntese de colesterol e outros derivados do mevalonato, a HMG-CoA redutase, é o alvo de fármacos da classe das estatinas usadas para abaixar os níveis de colesterol (Kureishi et al. 2000). Sabendo da importância do colesterol durante o estabelecimento e desenvolvimento da aterosclerose, decidimos investigar o papel dessa enzima na biogênese de CL induzida por LPC. Nossos dados mostram pela primeira vez na literatura que ao inibir a HMG-CoA redutase, diminui-se a produção de CL em monócitos e células endoteliais estimulados por LPC.

Já esta bem definido que a LPC induz o estresse oxidativo via geração de ROS, entretanto não se sabe se essa geração de ROS é importante para a secreção de IL-1 $1 \beta$ nem na biogênese de CL, mediada por LPC. Entretanto, para a nossa surpresa, a secreção de IL-1 $\beta$ induzida por LPC ocorreu de maneira independente da geração de ROS. Porém a formação de células gordurosas via biogênese de CL, tanto em monócitos quanto células endoteliais ocorreu de forma dependente da geração de ROS. Liu e colaboradores (2014) mostraram que a oxLDL induz a secreção de IL-1 $\beta$ e formação de células gordurosas via CD36, e geração de ROS para a ativação do inflamassoma NLRP3 (Liu et al. 2014). Portanto nossos dados corroboram o papel da geração de ROS na secreção na formação de células gordurosas induzida por LPC já descritas na literatura, demonstrando pela primeira vez esse mecanismo em células endoteliais.

Ao investigar os outros sinais de ativação do inflamassoma, vimos que a LPC induz a secreção de IL-1 $\beta$ dependente de efluxo de potássio e dano lisossomal. Estes resultados estão de acordo com os encontrados por Stock e colaboradores (2006), que ao inibirem canais de potássio, viram que a secreção de IL-1 $\beta$ induzida por LPC diminui significativamente em micróglias (Stock et al. 2006). De forma semelhante, nossos dados corroboram os já descritos por Liu e colaboradores (2014) os quais descreveram que o bloqueio da liberação de catepsina B diminui a secreção de IL-1 $\beta$ induzida por oxLDL em monócitos (Liu et al. 2014).

Um dado bastante relevante que descrevemos no presente trabalho, é que LPC é capaz de modular a ativação de células endoteliais, adquirindo características de células gordurosas e inflamatórias através da indução significativa da biogênese de CL, de maneira dependente da ativação de vias dos inflamassomas. Desta forma, LPC induz a biogênese de CL 
dependente de efluxo de potássio e dano lisossomal em células endoteliais. Em contrapartida, LPC induziu a biogênese de CL de forma independente de efluxo de potássio e dependente do dano lisossomal em monócitos. Portanto nossos dados demonstram que a biogênese de CL e a consequente formação de células gordurosas podem ser reguladas pelas vias de ativação do inflamassoma NLRP3. Dentro deste mesmo contexto, ao verificar que a LPC induz a ativação de caspase-1, fomos investigar qual seria o papel desta enzima na secreção de IL-1 $\beta$ e na formação de células gordurosas induzidas por LPC. Curiosamente, nossos dados mostraram que quando inibimos farmacologicamente a caspase-1, a secreção de IL-1 $\beta$ induzida pela LPC não é alterada em monócitos humanos. Nossos dados são diferentes daqueles publicados por Stock e colaboradores (2006), que mostraram que a secreção de IL-1 $\beta$ induzida por LPC é dependente da ativação de caspase-1 em micróglia (Stock et al. 2006), bem como dos dados descritos por Estruch e colaboradores (2015) que demonstram que a secreção de IL-1 $\beta$ induzida por LDL eletronegativa em monócitos é dependente da ativação de caspase-1 (Estruch et al. 2015). Entretanto nossos dados in vivo mostram certa dependência da ativação de caspase-1 e/ou caspase-11 na indução da secreção de IL-1 $\beta$ via estimulação com LPC, mas precisam ser repetidos e testados outras concentrações de LPC e novos tempos de estimulação.

Outro dado novo que nosso trabalho abordou, foi averiguar se a biogênese de CL é dependente ou não da ação da caspase-1. Sendo assim, nossos dados in vitro, tanto com monócitos quanto com células endoteliais, demonstram que quando a caspase-1 é inibida ocorre uma diminuição na formação de CL induzida por LPC. Em contrapartida nossos dados in vivo, mostram que camundongos nocautes para caspase-1/11 quando estimulados com LPC aumentam mais expressivamente ainda a quantidade de CL, demostrando assim que a formação de células gordurosas por LPC em camundongos murinos é independente da ação da caspase-1 e/ou caspase-11. Esses dados conflitantes in vitro e in vivo, podem ser devidos ao fato de que o composto Ac-YVAD-CHO, é um inibidor reversível tanto de caspase-1 quanto de caspase-4, e quanto aos resultados in vivo se deve ao fato dos camundongos serem duplo nocautes tanto para caspase-1 quanto para caspase-11, o que dificulta a analise especifica do papel da caspase-1 nos fenômenos estudados. Entretanto esses dados demonstram que não somente a Caspase-1, mas também a Caspase-4 (Humanos) e sua homóloga Caspase-11 (Camundongos) podem estar exercendo uma papel importante na secreção de IL-1 $\beta$ e na formação de células gordurosas.

Nossos dados mostram também certa tendência da LPC induzir a secreção de IL-1 $\beta$ in vivo dependente do inflamassoma NLRP3. Além disso, nossos resultados mostram que existe 
uma relação e certa dependência das vias de ativação do inflamassoma NLRP3 na biogênese de CL e na formação de células gordurosas, tanto com células endoteliais quanto monócitos humanos. Entretanto não se tem conhecimento se a biogênese de CL induzida por LPC é dependente do complexo do inflamassoma NLRP3. O que já esta descrito na literatura é que quando o inflamassoma NLRP3 está ativado e induzindo a secreção de IL-1 $\beta$ ocorre uma indução na formação de células gordurosas (Li et al. 2014). Entretanto nossos dados mostram que camundongos nocautes pra proteína NLRP3 quando estimulados com LPC induzem um aumento de CL semelhante aos camundongos selvagens. No presente trabalho, mostramos pela primeira vez que a biogênese de CL via LPC é independente da presença da proteína NLRP3, entretanto a sua ativação e seus produtos induzem um aumento no acumulo de colesterol e formação de células gordurosas através da biogênese de CL, como mostrado por Li e seus colaboradores.

A fim de analisarmos a capacidade da LPC em induzir a piroptose, fomos avaliar se a LPC induz a translocação da proteína HMGB-1 do núcleo para o citoplasma. Essa translocação e futura secreção da HMGB-1 são realizadas pela ação de caspase-1 e ativação dos inflamassomas, os quais já constatamos a ativação via LPC. Nossos dados demonstram ineditamente que tanto em monócitos, quanto em células endoteliais, a LPC induz a translocação da proteína HMGB-1 para o núcleo, embora não conseguimos ter analisado a secreção dessa proteína para o meio extracelular, esse resultado mostra que a LPC pode estar iniciando um processo de morte por piroptose tanto em célula endoteliais quanto em monócitos. Embora Lopez-Pastrana e seus colaboradores já terem comprovados que a LPC induz a piroptose em célula endoteliais dependente da ação da caspase- 1 em modelo de isquemia (Lopez-Pastrana et al. 2015), ele não estudou o papel da HMGB-1 nesse contexto, deixando assim nosso resultado inédito e importante no entendimento desse processo desencadeado pela LPC. Experimentos de análise da formação de poros na membrana de células endoteliais e monócitos humanos ainda estão em andamento a fim de se caracterizar melhor a ocorrência de piroptose nestas células induzida pela LPC.

Tomados todos esses resultados em conjunto, observamos que células endoteliais e monócitos respondem de maneira muito semelhante à LPC, entretanto no ambiente aterosclerótico e na formação das placas ateroscleróticas estas células exercem papeis e funções diferentes. Pensando assim fomos investigar se a célula endotelial estimulada com LPC seria capaz de induzir a ativação de monócitos através da biogênese de CL, da mesma forma o inverso, se os monócitos estimulados com LPC seriam capazes de induzir a ativação de células endoteliais. Nosso resultado in vitro mostrou que células endoteliais estimuladas 
com LPC, secretam fatores que podem induzir a ativação de monócitos localmente através da indução da biogênese de CL. Entretanto o mesmo fenômeno não ocorre com monócitos, uma vez que células endoteliais tratadas com secreção de monócitos estimulados com LPC, não foram ativadas através da indução da biogênese de CL. Experimentos utilizando alguns bloqueios farmacológicos estão em andamento, a fim de se identificar quais poderiam ser os fatores secretados pela célula endotelial responsáveis pela indução da ativação de monócitos.

Por fim, fomos investigar que outras citocinas pró-inflamatórias poderiam estar sendo secretadas por monócitos e células endoteliais durante a estimulação por LPC. Desta forma, analisamos a secreção das citocinas pró-inflamatórias IL-6 e TNF- $\alpha$. Observamos que a LPC induz a secreção significativa de IL-6 e TNF- $\alpha$ tanto em células endoteliais quanto em monócitos. Nossos dados foram condizentes com os já previamente encontrados por Huang e colaboradores (1999) que mostraram que a LPC induz a secreção de citocinas próinflamatórias, como INF- $\gamma$ e TNF- $\alpha$ (Huang et al. 1999).

Portanto, caracterizamos no presente trabalho diferentes mecanismos celulares e moleculares envolvidos na formação de células gordurosas, correlacionando-os com as vias de ativação dos inflamassomas e do metabolismo lipídico celular, e que potencialmente poderiam corroborar para a criação de um microambiente propício ao estabelecimento e manutenção da formação de placas ateroscleróticas. 


\section{Conclusões}

Tomados todos os resultados do presente trabalho em conjunto, concluímos que:

- A LPC induz a ativação de Caspase-1 e produção de ROS;

- A LPC induz a ativação do inflamassoma NLRP3 e a secreção de IL-1 $\beta$ dependes de efluxo de potássio, dano lisossomal, reconhecimento via TLR-2, ativação de PPAR- $\gamma$ e estabilização das jangadas lipídicas in vitro.

- $\quad$ A LPC induz a secreção de IL-1 $\beta$ dependente de NLRP3 e Caspase-1/11;

- A LPC induz a translocação de HMGB-1 do núcleo para o citoplasma em células endoteliais e monócitos humanos.

- A LPC induz a formação células gordurosas a partir de monócitos humanos, através da indução da biogênese de CL nestas células, bem como a formação de células endoteliais humanas com perfil semelhante ao de células gordurosas com alta biogênese de CL, de maneira dependente das vias de ativação do inflamassoma NLRP3.

- A LPC induz a formação de células gordurosas, através da biogênese de CL, de forma independente de Caspase-1/11 e do inflamassoma NLRP3 in vivo.

- As células endoteliais estimuladas com LPC podem ativar monócitos a se transformarem em células gordurosas, através da indução da biogênese de CL, por mecanismo ainda desconhecido.

- A LPC induz a secreção de citocinas de perfil pró-inflamatório em monócitos e células endoteliais, favorecendo o estabelecimento e manutenção de um microambiente próinflamatório. 


\subsection{Modelo proposto}

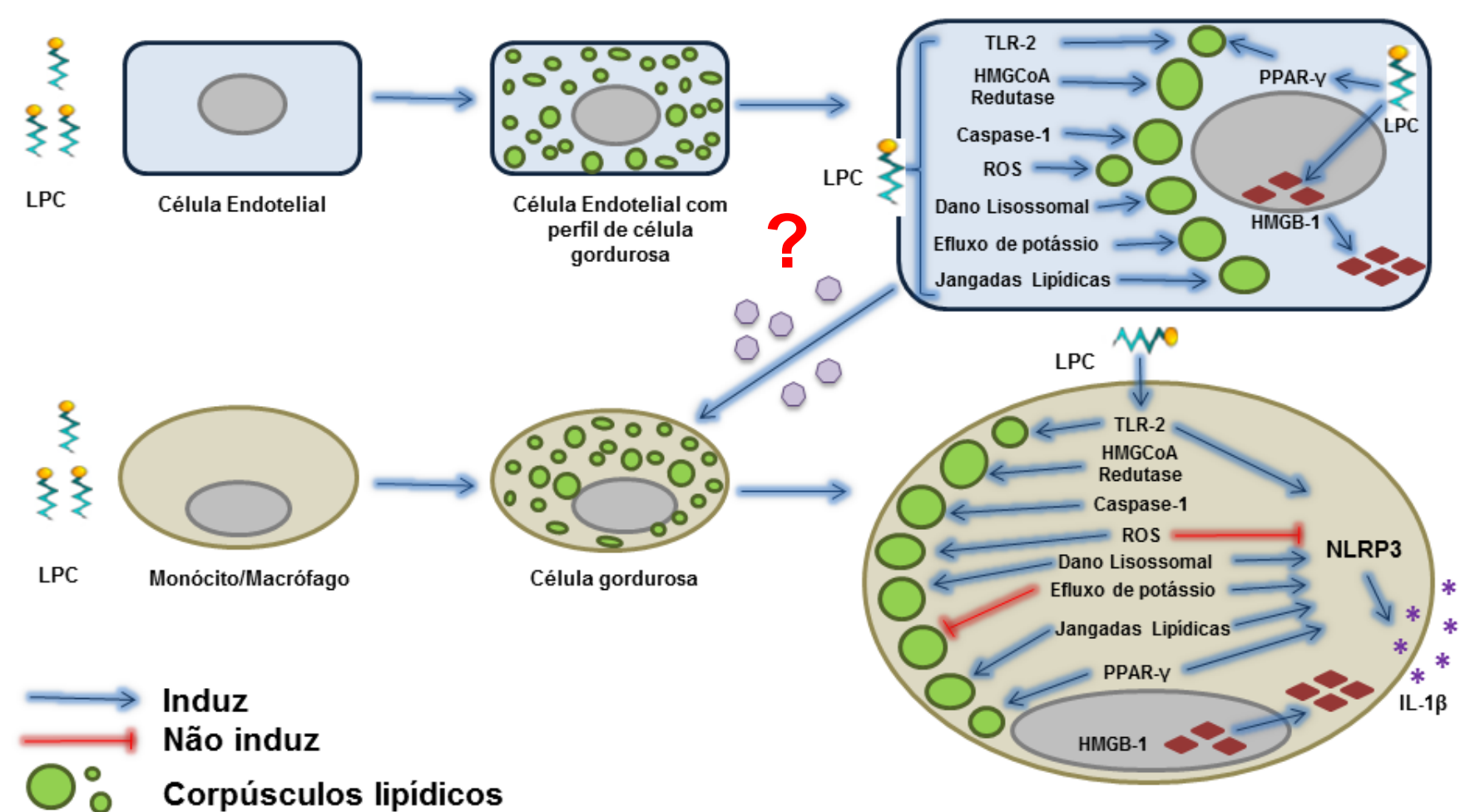

Fig. 15: Modelo proposto com base nas conclusões do trabalho. 


\section{Referências}

Allen, I.C. et al., 2009. The NLRP3 Inflammasome Mediates In Vivo Innate Immunity to Influenza A Virus through Recognition of Viral RNA. Immunity, 30(4), pp.556-565. Available at: http://linkinghub.elsevier.com/retrieve/pii/S1074761309001393.

Anand, P.K. \& Kanneganti, T.D., 2013. NLRP6 in infection and inflammation. Microbes and Infection, 15(10-11), pp.661-668. Available at: http://dx.doi.org/10.1016/j.micinf.2013.06.009.

Bandeira-Melo, C., Phoofolo, M. \& Weller, P.F., 2001. Extranuclear Lipid Bodies, Elicited by CCR3mediated Signaling Pathways, Are the Sites of Chemokine-enhanced Leukotriene C4 Production in Eosinophils and Basophils. Journal of Biological Chemistry, 276(25), pp.22779-22787.

Bauernfeind, F. et al., 2011. Inflammasomes: current understanding and open questions. Cellular and Molecular Life Sciences, 68(5), pp.765-783. Available at: http://link.springer.com/10.1007/s00018-010-0567-4.

Bauernfeind, F.G. et al., 2009. Cutting edge: NF-kappaB activating pattern recognition and cytokine receptors license NLRP3 inflammasome activation by regulating NLRP3 expression. Journal of Immunology, 183(2), pp.787-791. Available at: http://www.jimmunol.org/cgi/doi/10.4049/jimmunol.0901363\nhttp://www.jimmunol.org/conten t/183/2/787.full.pdf.

Beil, W.J. et al., 1995. Ultrastructural immunogold localization of subcellular sites of TNF-alpha in colonic Crohn's disease. Journal of leukocyte biology, 58(3), pp.284-98. Available at: http://www.ncbi.nlm.nih.gov/pubmed/7665984.

Berger, J. \& Moller, D.E., 2002. The mechanisms of action of PPARs. Annu. Rev. Med.

Bergsbaken, T., Fink, S.L. \& Cookson, B.T., 2009. Pyroptosis: host cell death and inflammation. Nature Reviews Microbiology, 7(2), pp.99-109. Available at: http://www.nature.com/doifinder/10.1038/nrmicro2070.

Bot, I., Shi, G.-P. \& Kovanen, P.T., 2014. Mast Cells as Effectors in Atherosclerosis. Arteriosclerosis, thrombosis, and vascular biology, pp.1-8. Available at: http://www.ncbi.nlm.nih.gov/pubmed/25104798.

Boyden, E.D. \& Dietrich, W.F., 2006. Nalp1b controls mouse macrophage susceptibility to anthrax lethal toxin. Nature genetics, 38(2), pp.240-244.

Bozza, P.T., Magalhães, K.G. \& Weller, P.F., 2009. Leukocyte lipid bodies -- Biogenesis and functions in inflammation. Biochimica et Biophysica Acta (BBA) - Molecular and Cell Biology of Lipids, 1791(6), pp.540-551. Available at: http://www.sciencedirect.com.passerelle.univrennes1.fr/science/article/B6VNN-4VDY86F-

3/2/eaded0776f1d147bd326d2869d576cf7\nhttp://www.sciencedirect.com.passerelle.univrennes1.fr/science?_ob=ArticleURL\&_udi=B6VNN-4VDY86F-

3\&_user $=509919 \& \_c o v e r D a t e=06 / 30 \%$.

Bozza, P.T. \& Viola, J.P.B., 2010. Lipid droplets in inflammation and cancer. Prostaglandins, Leukotrienes and Essential Fatty Acids (PLEFA), 82(4-6), pp.243-250. Available at: http://linkinghub.elsevier.com/retrieve/pii/S0952327810000499.

Carneiro, A.B. et al., 2013. Lysophosphatidylcholine Triggers TLR2- and TLR4- Mediated Signaling Pathways but Counteracts LPS- Induced NO Synthesis in Peritoneal Macrophages by Inhibiting NF-кB Translocation and MAPK / ERK Phosphorylation. , 8(9), pp.1-9.

Cassel, S.L., Joly, S. \& Sutterwala, F.S., 2009. The NLRP3 inflammasome: a sensor of immune danger signals. Seminars in immunology, 21(4), pp.194-8. Available at: http://www.sciencedirect.com/science/article/pii/S1044532309000451.

Cerqueira, D.M. et al., 2015. Caspase-1 but Not Caspase-11 Is Required for NLRC4-Mediated Pyroptosis and Restriction of Infection by Flagellated Legionella Species in Mouse Macrophages and In Vivo. The Journal of Immunology, 195(5), pp.2303-2311. Available at: 
http://www.jimmunol.org/cgi/doi/10.4049/jimmunol.1501223.

Chen, G.Y., 2014. Role of Nlrp6 and Nlrp12 in the maintenance of intestinal homeostasis. European Journal of Immunology, 44(2), pp.321-327.

Chen, Y. et al., 1995. Lysophosphatidylcholine causes Ca2+ influx, enhanced DNA synthesis and cytotoxicity in cultured vascular smooth muscle cells. Atherosclerosis, 112(1), pp.69-76. Available at: http://www.ncbi.nlm.nih.gov/pubmed/7772068.

Cookson, B.T. \& Brennan, M.A., 2001. Pro-inflammatory programmed cell death. Trends Microbiol, 9(3), pp.113-114. Available at: http://ac.els-cdn.com/S0966842X00019363/1-s2.0S0966842X00019363-main.pdf?_tid=6f19c706-15c1-11e5-9b92-

00000aacb35f\&acdnat=1434635804_6c42e6218e509c5a0803594ef49d08e8.

Creagh, E.M., 2014. Caspase crosstalk: Integration of apoptotic and innate immune signalling pathways. Trends in Immunology, 35(12), pp.631-640. Available at: http://dx.doi.org/10.1016/j.it.2014.10.004.

David, W. \& Bryan, S., 1996. Lysophosphatidylcholine Stimulates Interleukin-6 release from Rat anterior pituitary cells in vitro. Endocrinology, 137(November).

Drechsler, M. et al., 2010. Hyperlipidemia-Triggered Neutrophilia Promotes Early Atherosclerosis. Circulation, 122(18), pp.1837-1845. Available at: http://circ.ahajournals.org/cgi/doi/10.1161/CIRCULATIONAHA.110.961714.

Drzazga, A., Sowiñska, A. \& Kiewicz, M.K., 2014. Lysophosphatidylcholine and Lysophosphatidylinosiol $\tilde{\mathrm{N}}$ Novel Promissing Signaling Molecules and Their Possible Therapeutic Activity. , 71(6), pp.887-899.

Duewell, P. et al., 2010. NLRP3 inflammasomes are required for atherogenesis and activated by cholesterol crystals. Nature, 464(7293), pp.1357-1361. Available at: http://www.nature.com/doifinder/10.1038/nature08938.

Duncan, J.A. et al., 2009. Neisseria gonorrhoeae Activates the Proteinase Cathepsin B to Mediate the Signaling Activities of the NLRP3 and ASC-Containing Inflammasome. The Journal of Immunology, 182(10), pp.6460-6469. Available at: http://www.jimmunol.org/cgi/doi/10.4049/jimmunol.0802696.

Dvorak, a M., Morgan, E.S. \& Weller, P.F., 2001. Ultrastructural immunolocalization of basic fibroblast growth factor to lipid bodies and secretory granules in human mast cells. The Histochemical journal, 33(7), pp.397-402. Available at: http://www.ncbi.nlm.nih.gov/pubmed/11858459.

Edfeldt, K. et al., 2002. Expression of toll-like receptors in human atherosclerotic lesions: a possible pathway for plaque activation. Circulation, 105(10), pp.1158-1161.

Estruch, M. et al., 2015. Electronegative LDL induces priming and inflammasome activation leading to IL-1 $\beta$ release in human monocytes and macrophages. Biochimica et Biophysica Acta (BBA) Molecular and Cell Biology of Lipids, 1851(11), pp.1442-1449. Available at: http://linkinghub.elsevier.com/retrieve/pii/S1388198115001638.

Ewald, S.E., Chavarria-Smith, J. \& Boothroyd, J.C., 2014. NLRP1 is an inflammasome sensor for Toxoplasma gondii. Infection and Immunity, 82(1), pp.460-468.

Fernandes-Alnemri, T. et al., 2009. AIM2 activates the inflammasome and cell death in response to cytoplasmic DNA. Nature, 458(7237), pp.509-513. Available at: http://www.nature.com/doifinder/10.1038/nature07710.

Fernandes-Alnemri, T. et al., 2007. The pyroptosome: a supramolecular assembly of ASC dimers mediating inflammatory cell death via caspase-1 activation. Cell Death and Differentiation, 14(9), pp.1590-1604. Available at: http://www.nature.com/doifinder/10.1038/sj.cdd.4402194.

Fink, S.L. \& Cookson, B.T., 2006. Caspase-1-dependent pore formation during pyroptosis leads to osmotic lysis of infected host macrophages. Cellular Microbiology, 8(11), pp.1812-1825. Available at: http://doi.wiley.com/10.1111/j.1462-5822.2006.00751.x.

Franchi, L. et al., 2006. Cytosolic flagellin requires Ipaf for activation of caspase-1 and interleukin 
1beta in salmonella-infected macrophages. Nat Immunol, 7(6), pp.576-582. Available at: http://www.ncbi.nlm.nih.gov/entrez/query.fcgi?cmd=Retrieve \&db=PubMed\&dopt=Citation\&list _uids=16648852 ไnhttp://www.nature.com/ni/journal/v7/n6/pdf/ni1346.pdf.

Frishman, W.H., 1998. Biologic markers as predictors of cardiovascular disease. The American journal of medicine, 104(6A), p.18S-27S. Available at: http://www.ncbi.nlm.nih.gov/pubmed/9684848.

Gauster, M. et al., 2005. Endothelial lipase releases saturated and unsaturated fatty acids of high density lipoprotein phosphatidylcholine. Journal of lipid research, 46(7), pp.1517-25. Available at: http://www.ncbi.nlm.nih.gov/pubmed/15834125.

Gonçalves, V.M. et al., 2013. NLRP3 Controls Trypanosoma cruzi Infection through a Caspase-1Dependent IL-1R-Independent NO Production. PLoS Neglected Tropical Diseases, 7(10), pp.111.

Greenberg, A.S. et al., 2011. Review series The role of lipid droplets in metabolic disease in rodents and humans. The Journal of Clinical investigation, 121(6).

Gross, O. et al., 2009. Syk kinase signalling couples to the Nlrp3 inflammasome for anti-fungal host defence. $\quad$ Nature, $459(7245), \quad$ pp.433-436. Available at: http://www.nature.com/doifinder/10.1038/nature07965.

Guo, C. et al., 2014. Acapsular Cryptococcus neoformans activates the NLRP3 inflammasome. Microbes and Infection, 16(10), pp.845-854. Available at: http://linkinghub.elsevier.com/retrieve/pii/S1286457914001282.

Guo, H., Callaway, J.B. \& Ting, J.P.-Y., 2015. Inflammasomes: mechanism of action, role in disease, and therapeutics. Nature medicine, 21(7), pp.677-687. Available at: http://dx.doi.org/10.1038/nm.3893.

Hacman, D.G. \& Anand, S.S., 2003. Emerging risk factors for atherosclerotic vascular disease: a critical review. Clinical Cardiology, 290(7).

Haeggstr m, J.Z. \& Funk, C.D., 2011. Lipoxygenase and Leukotriene Pathways: Biochemistry, Biology, and Roles in Disease. Chemical Reviews, 111(10), pp.5866-5898. Available at: http://dx.doi.org/10.1021/cr200246d.

Hansson, G.K., 2005. Inflammation, Atherosclerosis, and Coronary Artery Disease. New England Journal, 352, pp.1685-1695.

Hansson, G.K. \& Hermansson, A., 2011. The immune system in atherosclerosis. Nature Immunology, 12(3), pp.204-212. Available at: http://www.nature.com/doifinder/10.1038/ni.2001.

Harder, J. et al., 2009. Activation of the Nlrp3 Inflammasome by Streptococcus pyogenes Requires Streptolysin O and NF- B Activation but Proceeds Independently of TLR Signaling and P2X7 Receptor. The Journal of Immunology, 183(9), pp.5823-5829. Available at: http://www.jimmunol.org/cgi/doi/10.4049/jimmunol.0900444.

Hasegawa, H. et al., 2011. Lysophosphatidylcholine enhances the suppressive function of human naturally occurring regulatory $\mathrm{T}$ cells through TGF- $\beta$ production. Biochemical and biophysical research communications, 415(3), pp.526-31. Available at: http://www.ncbi.nlm.nih.gov/pubmed/22074829.

$\mathrm{He}$, X. et al., 2010. Inflammation and fibrosis during Chlamydia pneumoniae infection is regulated by IL-1 and the NLRP3/ASC inflammasome. Journal of immunology (Baltimore, Md. : 1950), 184(10), pp.5743-5754.

Hise, A.G. et al., 2009. An Essential Role for the NLRP3 Inflammasome in Host Defense against the Human Fungal Pathogen Candida albicans. Cell Host \& Microbe, 5(5), pp.487-497. Available at: http://linkinghub.elsevier.com/retrieve/pii/S1931312809001437.

Hong, C. et al., 2014. Lysophosphatidylcholine Increases Neutrophil Bactericidal Activity by Enhancement of Azurophil Granule-Phagosome Fusion via Glycine GlyRa2/TRPM2/p38 MAPK Signaling. The Journal of Immunology, (184), pp.4401-4413.

Hopkins, P. \& Williams, R., 1981. A survey of 246 suggested coronary risk factors. Atherosclerosis, 
40, pp.1-52.

Hornung, V. \& Latz, E., 2010. Critical functions of priming and lysosomal damage for NLRP3 activation. European Journal of Immunology, 40(3), pp.620-623. Available at: http://doi.wiley.com/10.1002/eji.200940185.

Hou Mengjun, Min Xia, Huilian Zhu, Qing Wang, Yan Li, Yongmei Xiao, T.Z. \& Zhihong Tang, J.M. and W.L., 2007. Lysophosphatidylcholine promotes cholesterol efflux from mouse macrophage foam cells via PPARg-LXRa-ABCA1- dependent pathway associated with apoE. Cell biochemistry and function, 25(7), p.33:44.

Huang, Y.H. et al., 1999. Lysophosphatidylcholine (LPC) induces proinflammatory cytokines by a platelet-activating factor (PAF) receptor-dependent mechanism. Clinical and experimental immunology, 116(2), pp.326-31. Available at: http://www.pubmedcentral.nih.gov/articlerender.fcgi?artid=1905274\&tool=pmcentrez\&renderty $\mathrm{pe}=\mathrm{abstract}$.

Hurt-Camejo, E. et al., 2001. Phospholipase A(2) in vascular disease. Circulation research, 89(4), pp.298-304.

Jackson, R. et al., 2015. Nlrp6 regulates intestinal antiviral innate immunity. , (October), pp.1-8.

Jonasson, L. et al., 1986. Regional accumulations of T cells, macrophages, and smooth muscle cells in the human atherosclerotic plaque. Arteriosclerosis (Dallas, Tex.), 6(2), pp.131-138.

Jorgensen, I. \& Miao, E.A., 2015. Pyroptotic cell death defends against intracellular pathogens. Immunological Reviews, 265(1), pp.130-142.

Keller, M. et al., 2008. Active Caspase-1 Is a Regulator of Unconventional Protein Secretion. Cell, 132(5), pp.818-831. Available at: http://linkinghub.elsevier.com/retrieve/pii/S0092867408001116.

Keyel, P. a., 2014. How is inflammation initiated? Individual influences of IL-1, IL-18 and HMGB1. Cytokine, 69(1), pp.136-145. Available at: http://dx.doi.org/10.1016/j.cyto.2014.03.007.

Kim, E. a et al., 2009. Lysophosphatidylcholine induces endothelial cell injury by nitric oxide production through oxidative stress. The journal of maternal-fetal \& neonatal medicine: the official journal of the European Association of Perinatal Medicine, the Federation of Asia and Oceania Perinatal Societies, the International Society of Perinatal Obstetricians, 22(4), pp.32531. Available at: http://www.ncbi.nlm.nih.gov/pubmed/19089771.

Kohno, M. et al., 1998. Induction by lysophosphatidylcholine, a major phospholipid component of atherogenic lipoproteins, of human coronary artery smooth muscle cell migration. Circulation, 98(4), pp.353-9. Available at: http://www.ncbi.nlm.nih.gov/pubmed/9711941.

Kunjathoor, V. V., 2002. Scavenger Receptors Class A-I/II and CD36 Are the Principal Receptors Responsible for the Uptake of Modified Low Density Lipoprotein Leading to Lipid Loading in Macrophages. Journal of Biological Chemistry, 277(51), pp.49982-49988. Available at: http://www.jbc.org/cgi/doi/10.1074/jbc.M209649200.

Kureishi, Y. et al., 2000. The HMG-CoA reductase inhibitor simvastatin activates the protein kinase Akt and promotes angiogenesis in normocholesterolemic animals. Nature medicine, 6(9), pp.1004-10. Available

at: http://www.pubmedcentral.nih.gov/articlerender.fcgi?artid=2828689\&tool=pmcentrez\&renderty pe $=$ abstract.

Lamkanfi, M. et al., 2010. Inflammasome-dependent release of the alarmin HMGB1 in endotoxemia. Journal of immunology (Baltimore, Md. : 1950), 185, pp.4385-4392.

Li, X. et al., 2014. Activation of Nlrp3 inflammasomes enhances macrophage lipid-deposition and migration: Implication of a novel role of inflammasome in atherogenesis. PLOS ONE, 9(1), pp.111.

Liao, K.C. \& Mogridge, J., 2013. Activation of the Nlrp1b inflammasome by reduction of cytosolic ATP. Infection and Immunity, 81(2), pp.570-579.

Lin, P. et al., 2005. Lysophosphatidylcholine modulates neutrophil oxidant production through 
elevation of cyclic AMP. Journal of immunology (Baltimore, Md. : 1950), 174(5), pp.2981-9. Available at: http://www.ncbi.nlm.nih.gov/pubmed/15728511.

Liu, W. et al., 2014. OxLDL-induced IL-1beta secretion promoting foam cells formation was mainly via CD36 mediated ROS production leading to NLRP3 inflammasome activation. Inflammation Research, 63(1), pp.33-43. Available at: http://link.springer.com/10.1007/s00011-013-0667-3.

Liu-Wu, Y., Hurt-Camejo, E. \& Wiklund, O., 1998. Lysophosphatidylcholine induces the production of IL-1beta by human monocytes. Atherosclerosis, 137(2), pp.351-357.

Lopez-Pastrana, J. et al., 2015. Inhibition of Caspase-1 Activation in Endothelial Cells Improves Angiogenesis. Journal of Biological Chemistry, 290(28), pp.17485-17494. Available at: http://www.jbc.org/lookup/doi/10.1074/jbc.M115.641191.

Loppnow, H. \& Libby, P., 1990. Proliferating or interleukin 1-activated human vascular smooth muscle cells secrete copious interleukin 6. J Clin Invest, 85(3), pp.731-738. Available at: http://www.ncbi.nlm.nih.gov/pubmed/2312724.

Lozano, R. et al., 2012. Global and regional mortality from 235 causes of death for 20 age groups in 1990 and 2010: a systematic analysis for the Global Burden of Disease Study 2010. The Lancet, 380(9859),

pp.2095-2128.

Available

at: http://linkinghub.elsevier.com/retrieve/pii/S0140673612617280.

Lundberg, A.M. \& Hansson, G.K., 2010. Innate immune signals in atherosclerosis. Clinical Immunology, 134(1), pp.5-24. Available at: http://dx.doi.org/10.1016/j.clim.2009.07.016.

Magalhães, K.G. et al., 2010. Schistosomal-Derived Lysophosphatidylcholine Are Involved in Eosinophil Activation and Recruitment through Toll-Like Receptor - 2 - Dependent Mechanisms. , 900(9), pp.1369-1379.

Matsumoto, T., Kobayashi, T. \& Kamata, K., 2007. Role of Lysophosphatidylcholine (LPC) in Atherosclerosis. Current Medicinal Chemistry, 14(30), pp.3209-3220.

Melo, R.C.N. et al., 2011. Lipid Bodies in Inflammatory Cells. Journal of Histochemistry \& Cytochemistry, 59(5), pp.540-556. Available at: http://jhc.sagepub.com/content/59/5/540.abstract.

Melo, R.C.N., Sabban, A. \& Weller, P.F., 2006. Leukocyte lipid bodies: inflammation-related organelles are rapidly detected by wet scanning electron microscopy. Journal of lipid research, 47, pp.2589-2594.

Miao, E.A. et al., 2006. Cytoplasmic flagellin activates caspase-1 and secretion of interleukin 1beta via Ipaf. Nat Immunol, 7(6), pp.569-575. Available at: http://www.ncbi.nlm.nih.gov/entrez/query.fcgi?cmd=Retrieve \&db=PubMed\&dopt=Citation\&list _uids=16648853ไnhttp://www.nature.com/ni/journal/v7/n6/abs/ni1344.html/nhttp://www.nature.c om/ni/journal/v7/n6/pdf/ni1344.pdf.

Miao, E.A. et al., 2010. Innate immune detection of the type III secretion apparatus through the NLRC4 inflammasome. Proceedings of the National Academy of Sciences, 107(7), pp.30763080. Available at: http://www.pnas.org/cgi/doi/10.1073/pnas.0913087107.

Miao, E.A., Rajan, J. V \& Aderem, A., 2011. Caspase-1-induced pyroptotic cell death. Immunological reviews, 243(1), pp.206-14. Available at: http://www.pubmedcentral.nih.gov/articlerender.fcgi?artid=3609431\&tool=pmcentrez\&renderty pe $=$ abstract.

Miller, Y.I. et al., 2003. Minimally Modified LDL Binds to CD14, Induces Macrophage Spreading via TLR4/MD-2, and Inhibits Phagocytosis of Apoptotic Cells. Journal of Biological Chemistry, 278(3), pp.1561-1568. Available at: http://www.jbc.org/cgi/doi/10.1074/jbc.M209634200.

Monack, D.M., Detweiler, C.S. \& Falkow, S., 2001. Salmonella pathogenicity island 2-dependent macrophage death is mediated in part by the host cysteine protease caspase-1. Cellular microbiology, 3(12), pp.825-37. Available at: http://www.ncbi.nlm.nih.gov/pubmed/11736994.

Murakami, N. et al., 2004. G2A is a proton-sensing G-protein-coupled receptor antagonized by lysophosphatidylcholine. Journal of Biological Chemistry, 279(41), pp.42484-42491. 
Nakano, T. et al., 1994. Lysophosphatidylcholine upregulates the level of heparin-binding epidermal growth factor-like growth factor mRNA in human monocytes. Cell Biology, 91(February), pp.1069-1073.

Nakashima, Y. et al., 1998. Upregulation of VCAM-1 and ICAM-1 at atherosclerosis-prone sites on the endothelium in the ApoE-deficient mouse. Arteriosclerosis, thrombosis, and vascular biology, 18(5), pp.842-51. Available at: http://www.ncbi.nlm.nih.gov/pubmed/9598845.

Ozaki, E., Campbell, M. \& Doyle, S., 2015. Targeting the NLRP3 inflammasome in chronic inflammatory diseases: current perspectives. Journal of inflammation research, pp.15-27. Available at: http://www.ncbi.nlm.nih.gov/pmc/articles/PMC4303395/.

Pacheco, P. et al., 2002. Lipopolysaccharide-Induced Leukocyte Lipid Body Formation In Vivo: Innate Immunity Elicited Intracellular Loci Involved in Eicosanoid Metabolism. The Journal of Immunology, 169(11), pp.6498-6506. Available at: http://www.jimmunol.org/cgi/doi/10.4049/jimmunol.169.11.6498.

Park, Y.M., 2014. CD36, a scavenger receptor implicated in atherosclerosis. Experimental \& molecular medicine, 46(6), p.e99. Available at: http://www.nature.com/emm/journal/v46/n6/full/emm201438a.html\#bib81.

Parthasarathy, S. et al., 1985. Essential role of phospholipase A2 activity in endothelial cell-induced modification of low density lipoprotein. Proc. Natl. Acad. Sci. USA, 82(May), pp.3000-3004.

Peluso, I. et al., 2012. Oxidative stress in atherosclerosis development: the central role of LDL and oxidative burst. Endocrine, metabolic \& immune disorders drug targets, 12(4), pp.351-60. Available at: http://www.ncbi.nlm.nih.gov/pubmed/23061409.

Perrin-Cocon, L. et al., 2006. Lysophosphatidylcholine is a natural adjuvant that initiates cellular immune responses. Vaccine, 24(9), pp.1254-1263. Available at: http://www.sciencedirect.com/science/article/pii/S0264410X05010017.

Pétrilli, V. et al., 2007. Activation of the NALP3 inflammasome is triggered by low intracellular potassium concentration. Cell Death and Differentiation, 14(9), pp.1583-1589. Available at: http://www.nature.com/doifinder/10.1038/sj.cdd.4402195.

Pol, A., Gross, S.P. \& Parton, R.G., 2014. Biogenesis of the multifunctional lipid droplet: Lipids, proteins, and sites. The Journal of Cell Biology, 204(5), pp.635-646. Available at: http://www.jcb.org/cgi/doi/10.1083/jcb.201311051.

van Puijvelde, G.H.M. et al., 2009. Effect of natural killer T cell activation on the initiation of atherosclerosis. Thrombosis and haemostasis, 102(2), pp.223-30. Available at: http://www.ncbi.nlm.nih.gov/pubmed/19652872.

Quinn, M.T., Parthasarathy, S. \& Steinberg, D., 1988. Lysophosphatidylcholine: a chemotactic factor for human monocytes and its potential role in atherogenesis. Proceedings of the National Academy of Sciences of the United States of America, 85(8), pp.2805-2809.

Rajamäki, K. et al., 2010. Cholesterol Crystals Activate the NLRP3 Inflammasome in Human Macrophages: A Novel Link between Cholesterol Metabolism and Inflammation. PLoS ONE, 5(7), p.e11765. Available at: http://dx.plos.org/10.1371/journal.pone.0011765.

Rajavashisth, T.B. et al., 1990. Induction of endothelial cell expression of granulocyte and macrophage colony-stimulating factors by modified low-density lipoproteins. Nature, 344(6263), pp.254-7. Available at: http://www.ncbi.nlm.nih.gov/pubmed/1690354.

Raynor, A. et al., 2015. Saturated and mono-unsaturated lysophosphatidylcholine metabolism in tumour cells: a potential therapeutic target for preventing metastases. Lipids in Health and Disease, pp.1-15. Available at: http://dx.doi.org/10.1186/s12944-015-0070-x.

Ridker, P.M. et al., 2011. Interleukin-1 $\beta$ inhibition and the prevention of recurrent cardiovascular events: Rationale and Design of the Canakinumab Anti-inflammatory Thrombosis Outcomes Study (CANTOS). American Heart Journal, 162(4), pp.597-605. Available at: http://linkinghub.elsevier.com/retrieve/pii/S0002870311004820.

Riederer, M. et al., 2010. Acyl chain-dependent effect of lysophosphatidylcholine on endothelial 
prostacyclin production. Journal of lipid research, 51(10), pp.2957-66. Available at: http://www.pubmedcentral.nih.gov/articlerender.fcgi?artid=2936763\&tool=pmcentrez\&renderty pe $=$ abstract.

Ritter, M. et al., 2010. Schistosoma mansoni triggers Dectin-2, which activates the Nlrp3 inflammasome and alters adaptive immune responses. Proceedings of the National Academy of Sciences, 107(47), pp.20459-20464. Available at: http://www.pnas.org/cgi/doi/10.1073/pnas.1010337107.

Robbins, C.S. et al., 2013. Local proliferation dominates lesional macrophage accumulation in atherosclerosis. Nature Medicine, 19(9), pp.1166-1172. Available at: http://www.nature.com/doifinder/10.1038/nm.3258.

Rousset, X. et al., 2009. Lecithin: cholesterol acyltransferase--from biochemistry to role in cardiovascular disease. Current opinion in endocrinology, diabetes, and obesity, 16(2), pp.163171. Available at: papers2://publication/uuid/34018FE5-89D9-4D43-9774-D0FB991578E4.

Saïd-Sadier, N. et al., 2010. Aspergillus fumigatus Stimulates the NLRP3 Inflammasome through a Pathway Requiring ROS Production and the Syk Tyrosine Kinase. PLoS ONE, 5(4), p.e10008. Available at: http://dx.plos.org/10.1371/journal.pone.0010008.

Santamarina-Fojo, S., 2004. Hepatic Lipase, Lipoprotein Metabolism, and Atherogenesis. Arteriosclerosis, Thrombosis, and Vascular Biology, 24(10), pp.1750-1754. Available at: http://atvb.ahajournals.org/cgi/doi/10.1161/01.ATV.0000140818.00570.2d.

Sato, H. et al., 2008. Analyses of group III secreted phospholipase A2 transgenic mice reveal potential participation of this enzyme in plasma lipoprotein modification, macrophage foam cell formation, and atherosclerosis. Journal of Biological Chemistry, 283(48), pp.33483-33497.

Schilling, T. \& Eder, C., 2010. Importance of lipid rafts for lysophosphatidylcholine-induced caspase1 activation and reactive oxygen species generation. Cellular immunology, 265(2), pp.87-90. Available at: http://www.ncbi.nlm.nih.gov/pubmed/20832779.

Schilling, T. \& Eder, C., 2011. Sodium dependence of lysophosphatidylcholine-induced caspase-1 activity and reactive oxygen species generation. Immunobiology, 216(1-2), pp.118-125.

Schmitz, G. \& Ruebsaamen, K., 2010. Metabolism and atherogenic disease association of lysophosphatidylcholine. , 208, pp.10-18.

Schroder, K. \& Tschopp, J.J.J., 2010. The inflammasomes. Cell, 140(6), pp.821-32. Available at: http://www.ncbi.nlm.nih.gov/pubmed/20303873.

Sheikh, A.M., Ochi, H. \& Masuda, J., 2001. Lysophosphatidylcholine inhibits T cell-specific CXC chemokines IP-10, MIG, and I-TAC expression induced by IFN-gamma in human endothelial cells. Ann N Y Acad Sci, 947, pp.306-307. Available at: http://www.ncbi.nlm.nih.gov/entrez/query.fcgi?cmd=Retrieve \&db=PubMed\&dopt=Citation\&list uids $=11795279$.

Shi, J. et al., 2014. Inflammatory caspases are innate immune receptors for intracellular LPS. Nature, 514(7521), pp.187-192. Available at: http://www.nature.com/doifinder/10.1038/nature13683 \npapers3://publication/doi/10.1038/natur e13683.

Shimada, K. et al., 2011. Caspase-1 Dependent IL-1 $\beta$ Secretion Is Critical for Host Defense in a Mouse Model of Chlamydia pneumoniae Lung Infection. PLoS ONE, 6(6), p.e21477. Available at: http://dx.plos.org/10.1371/journal.pone.0021477.

Silva, A.R. et al., 2009. Lipid bodies in oxidized LDL-induced foam cells are leukotriene-synthesizing organelles: a MCP-1/CCL2 regulated phenomenon. Biochimica et Biophysica Acta - Molecular and Cell Biology of Lipids, 1791(11), pp.1066-1075. Available at: http://dx.doi.org/10.1016/j.bbalip.2009.06.004.

Silva-Neto, M. a C. et al., 2012. Lysophosphatidylcholine: A Novel Modulator of Trypanosoma cruzi Transmission. Journal of parasitology research, 2012, p.625838. Available at: http://www.pubmedcentral.nih.gov/articlerender.fcgi?artid=3206328\&tool=pmcentrez\&renderty 
pe $=$ abstract.

Silveira, T.N. \& Zamboni, D.S., 2010. Pore formation triggered by Legionella spp. is an Nlrc4 inflammasome-dependent host cell response that precedes pyroptosis. Infection and Immunity, 78(3), pp.1403-1413.

Stock, C. et al., 2006. Lysophosphatidylcholine stimulates IL-1beta release from microglia via a P2X7 receptor-independent mechanism. Journal of immunology (Baltimore, Md.: 1950), 177(12), pp.8560-8568.

Strowig, T. et al., 2012. Inflammasomes in health and disease. Nature, 481(7381), pp.278-286.

Sutterwala, F.S. et al., 2007. Immune recognition of Pseudomonas aeruginosa mediated by the IPAF/NLRC4 inflammasome. Journal of Experimental Medicine, 204(13), pp.3235-3245. Available at: http://www.jem.org/cgi/doi/10.1084/jem.20071239.

Tait, S.W.G., Ichim, G. \& Green, D.R., 2014. Die another way - non-apoptotic mechanisms of cell death. Journal of Cell Science, 127(10), pp.2135-2144. Available at: http://jcs.biologists.org/cgi/doi/10.1242/jcs.093575.

Takahara, N. et al., 1996. Lysophosphatidylcholine stimulates the expression and production of MCP1 by human vascular endothelial cells. Metabolism: clinical and experimental, 45(5), pp.559-64. Available at: http://www.ncbi.nlm.nih.gov/pubmed/8622597.

Takahashi, M. et al., 2002. Lysophosphatidylcholine induces apoptosis in human endothelial cells through a p38-mitogen-activated protein kinase-dependent mechanism. Atherosclerosis, 161(2), pp.387-394. Available at: http://www.sciencedirect.com/science/article/pii/S0021915001006748.

Tavares, A.H. et al., 2013. NLRP3 inflammasome activation by Paracoccidioides brasiliensis. PLoS neglected tropical diseases, 7(12), p.e2595. Available at: http://www.pubmedcentral.nih.gov/articlerender.fcgi?artid=3855149\&tool=pmcentrez\&renderty pe $=$ abstract.

Toma, C. et al., 2010. Pathogenic Vibrio Activate NLRP3 Inflammasome via Cytotoxins and TLR/Nucleotide-Binding Oligomerization Domain-Mediated NF- B Signaling. The Journal of Immunology, 184(9), pp.5287-5297. Available at: http://www.jimmunol.org/cgi/doi/10.4049/jimmunol.0903536.

Tontonoz, P. et al., 1998. PPAR?? promotes monocyte/macrophage differentiation and uptake of oxidized LDL. Cell, 93(2), pp.241-252.

Tschopp, J. \& Schroder, K., 2010. NLRP3 inflammasome activation: The convergence of multiple signalling pathways on ROS production? Nature reviews. Immunology, 10(3), pp.210-215. Available at: http://dx.doi.org/10.1038/nri2725.

Tupin, E., 2004. CD1d-dependent Activation of NKT Cells Aggravates Atherosclerosis. Journal of Experimental Medicine, 199(3), pp.417-422. Available at: http://www.jem.org/cgi/doi/10.1084/jem.20030997.

U, C.L. et al., 1999. Perilipins, ADRP, and other proteins that associate with intracellular neutral lipid droplets in animal cells. Seminars in cell \& developmental biology, 10(1), pp.51-8. Available at: http://www.ncbi.nlm.nih.gov/pubmed/10355028.

Walther, T.C. \& Farese, R. V., 2012. Lipid Droplets and Cellular Lipid Metabolism. Annual Review of Biochemistry, 81(1), pp.687-714. Available at: http://www.annualreviews.org/doi/abs/10.1146/annurev-biochem-061009-102430.

Warren, S.E. et al., 2010. Cutting edge: Cytosolic bacterial DNA activates the inflammasome via Aim2. $J$ Immunol, 185(2), pp.818-821. Available at: http://www.ncbi.nlm.nih.gov/entrez/query.fcgi?cmd=Retrieve\&db=PubMed\&dopt=Citation\&list _uids=20562263\nhttp://www.jimmunol.org/content/185/2/818.full.pdf.

West, X.Z. et al., 2010. Oxidative stress induces angiogenesis by activating TLR2 with novel endogenous ligands. Nature, 467(7318), pp.972-976. Available at: http://www.nature.com/doifinder/10.1038/nature09421.

Whitman, S.C., 2004. Depletion of Natural Killer Cell Function Decreases Atherosclerosis in Low- 
Density Lipoprotein Receptor Null Mice. Arteriosclerosis, Thrombosis, and Vascular Biology, 24(6), pp.1049-1054.

Available

at:

http://atvb.ahajournals.org/cgi/doi/10.1161/01.ATV.0000124923.95545.2c.

Wong, J.T. et al., 1998. Lysophosphatidylcholine Stimulates the Release of Arachidonic Acid in Human Endothelial Cells *. THE JOURNAL OF BIOLOGICAL CHEMISTRY, 273(12), pp.6830-6836.

Wree, A. et al., 2014. NLRP3 inflammasome activation results in hepatocyte pyroptosis, liver inflammation, and fibrosis in mice. Hepatology, 59(173), pp.898-910.

Yu, E.P.K. \& Bennett, M.R., 2014. Mitochondrial DNA damage and atherosclerosis. Trends in endocrinology and metabolism: TEM, 25(9), pp.1-7. Available at: http://www.ncbi.nlm.nih.gov/pubmed/25034130.

$\mathrm{Yu}, \mathrm{W}$. et al., 1998. Co-compartmentalization of MAP kinases and cytosolic phospholipase A2 at cytoplasmic arachidonate-rich lipid bodies. Am J Pathol, 152(3), pp.759-769. Available at: http://www.ncbi.nlm.nih.gov/pubmed/9502418.

Zembowicz, A., Jones, S.L. \& Wu, K.K., 1995. Induction of Cyclooxygenase-2 in Human Umbilical Vein Endothelial Cells by Lysophosphatidylcholine. J. Clin. Invest., 96, pp.1688-1692.

Zou, Y. et al., 2007. Upregulation of endothelial adhesion molecules by lysophosphatidylcholine. Involvement of G protein-coupled receptor GPR4. The FEBS journal, 274(10), pp.2573-84. Available at: http://www.ncbi.nlm.nih.gov/pubmed/17437524. 